\title{
Die Hieronymusgesellschaft Kurfürst Friedrichs II. von Sachsen \\ Antihussitisches Selbstverständnis und herrschaftliche Integration im Spiegel einer wettinischen Hofstiftung von 1450
}

\author{
von \\ PETER WIEGAND
}

Adelsgesellschaften zählen zu den typischen Formen ständischer Gruppenbildung im Spätmittelalter. Teilweise geprägt durch „religiös-bruderschaftliche Elemente“, dienten sie vor allem der „Behauptung traditioneller Herrschaftsansprüche“ und stärkten die „politisch-militärische Kampfbereitschaft“ ihrer Mitglieder. ${ }^{1}$ Neben egalitären Schwurgemeinschaften, die sich überwiegend in Regionen ohne starke Landesherrschaft finden, standen hierarchisch organisierte, oft missverständlich als ,Orden' bezeichnete Personenverbände. ${ }^{2}$ Errichtet durch ein fürstliches Oberhaupt, das die Mitglieder aus seiner eigenen Vasallenschaft oder aus landfremdem Adel berief, dienten diese „hofgebundenen Stiftungen“" ${ }^{3}$ als Mittel höfischer Repräsentation und herrschaftlicher Integration. ${ }^{4}$ Als Instrument der Bündnispolitik

1 Andreas Ranft, Adelsgesellschaften. Gruppenbildung und Genossenschaft im spätmittelalterlichen Reich (Kieler Historische Studien 38), Sigmaringen 1994, S. 17, 22 f., 28 f., 252, 254; vgl. zuletzt auch Tanja Storn-Jaschкоwitz, Gesellschaftsverträge adliger Schwureinungen im Spätmittelalter. Edition und Typologie, Berlin 2007, S. 5 ff., $201 \mathrm{ff} ., 211 \mathrm{ff} ., 215 \mathrm{ff}$.

2 Deren Zahl war in Deutschland, wo das „genossenschaftliche Prinzip“ dominierte, vergleichsweise gering; Werner Paravicini, Die ritterlich-höfische Kultur des Mittelalters (Enzyklopädie deutscher Geschichte 32), München ${ }^{3} 2011$, S. 37.

3 Der Begriff nach STORN-JaschKowitz, Gesellschaftsverträge (wie Anm. 1), S. 195 ff., 211 ff.; vgl. Dies., Orden und Ordensstiftungen, in: Werner Paravicini (Hg.), Höfe und Residenzen im spätmittelalterlichen Reich. Bilder und Begriffe, Teilband 1: Begriffe (Residenzenforschung 15.II/1), Ostfildern 2005, S. 53-57. Für bestimmte Adelsgesellschaften wird die Bezeichnung, Orden' als eingeführtes Appellativ hier weiter verwendet. Von „Curial Orders of Knighthood of the Confraternal Type“ spricht D'ARcY Jonathan Dacre Boulton, Introduction, in: Guy Stair Sainty/Rafal Heydel Mankoo (Hg.), World Orders of Knighthood and Merit, 2 Bde., Wilmington (Delaware) 2006, hier Bd. 1, S. 205-239; vgl. Ders., The Knights of the Crown. The Monarchical Orders of Knighthood in Later Medieval Europe 1325-1520, Woodbridge 2000, S. XVI.

4 Storn-Jaschkowitz, Gesellschaftsverträge (wie Anm. 1), S. 63 ff., 109 ff.; Malcolm Vale, War and Chivalry. Warfare and Aristocratic Culture in England, France and Burgundy at the End of the Middle Ages, London 1981, S. 33 ff.; Christian SteEb, Die Ritterbünde des Spätmittelalters. Ihre Entstehung und Bedeutung für die Entwicklung des europäischen Ordenwesens, in: Johann Stolzer/Christian Steeb (Hg.), Österreichs Orden vom Mittelalter bis zur Gegenwart, Graz 1996, S. 40-67; Andreas Ranft, Ritterorden und Rittergesellschaften im Spätmittelalter. Zu Formen der Regulierung und 
lebten sie in der Frühen Neuzeit fort, bis sie ihre Rolle als Ort „adlige[r] Vergesellschaftung" in einem "langanhaltenden Aussterben“ verloren, zu einer bloßen „Erinnerungsgemeinschaft [...] für die Idee des Rittertums“ wurden und sich früher oder später zu einem reinen Ehrenzeichen wandelten. ${ }^{5}$

Kennzeichnend für das im wettinischen Hoheitsgebiet früh ausgeprägte „Übergewicht der landesherrlichen Gewalt“6 gegenüber dem Niederadel ist, dass sich dort, im Vergleich mit dem Südwesten des Reichs, nur wenige genossenschaftlich strukturierte Adelsgesellschaften nachweisen lassen. Die Belege konzentrieren sich weitestgehend auf die Jahre vor 1400. So bezogen die Wettiner in ihre 1379, 1397 und 1398 mit dem Erzbischof von Magdeburg geschlossenen Bündnisse die in ihrem Herrschaftsbereich tätige Hosengesellschaft ein. 1386 einigte sich die Hosengesellschaft mit der nur hier belegten Widdergesellschaft, in Turnieren nicht gegeneinander anzutreten. Der Friedensschluss zwischen Landgraf Balthasar von Thüringen und Erzbischof Konrad III. von Mainz vom 13. Juli 1392 erwähnt die im Territorium des Hochstifts angesiedelten gesellen von den Bengel und die Fuchsgesellschaft. ${ }^{7}$ In Thüringen begegnen 1407 zwei anscheinend nur kurzlebige Gesellschaften, die Lewner (Löwen) und die von Markgraf Friedrich IV. initiierte geselleschaft [der] Flegiln. Hier handelt es sich um "geführte Gesellschaften [...] im Sinne einer selbständigen Genossenschaft, die sich [...] einseitig in die Interessensphäre eines Fürsten " begeben hatte. ${ }^{8}$

Später versuchte der wettinische Adel offenbar nicht mehr, sich durch Einungen von seinen Landesherren zu emanzipieren. ${ }^{9}$ Die im frühen 15. Jahrhundert auf

Internationalisierung ritterlich-höfischen Lebens in Europa, in: Kaspar Elm/Cosimo Damiano Fonseca (Hg.), Militia Sancti Sepulcri. Idea e istituzioni. Atti del Colloquio internazionale, Città del Vaticano 1998, S. 89-110.

5 Martin Wrede, Ohne Furcht und Tadel - Für König und Vaterland. Frühneuzeitlicher Hochadel zwischen Familienehre, Ritterideal und Fürstendienst (Beihefte der Francia 75), Ostfildern 2012, S. 234, 242 ff., 248 ff., 279 ff., 312 ff., die Zitate S. 229, 314; vgl. auch Lars Adler, Die Ordensstiftungen der Markgrafen von Baden 1584-1803. Adlige Korporationen im Spiegel fürstlicher Landespolitik, Offenbach 2008, S. 307 ff.

6 Herbert Helbig, Der wettinische Ständestaat. Untersuchungen zur Geschichte des Ständewesens und der landständischen Verfassung in Mitteldeutschland bis 1485 (Mitteldeutsche Forschungen 4), Köln/Wien 21980, S. 475, zu den „Adelsbünden“ ebd., S. 471.

7 Otto Posse/Hubert Ermisch (Hg.), Urkunden der Markgrafen von Meißen und Landgrafen von Thüringen 1381-1395, Bd. 1 (Codex diplomaticus Saxoniae regiae I/B/1), Leipzig 1899, Nr. 188, 442, Bd. 2: Urkunden der Markgrafen von Meißen und Landgrafen von Thüringen 1396-1406, Leipzig 1902, Nr. 168, 169; RanFT, Adelsgesellschaften (wie Anm. 1), S. 185, 194 f.; Holger Kruse/Werner Paravicini/Andreas RANFT (Hg.), Ritterorden und Adelsgesellschaften im spätmittelalterlichen Deutschland. Ein systematisches Verzeichnis (Kieler Werkstücke D/1), Frankfurt a. M. u. a. 1991, Nr. 27, 30, 33, 35, 58, 68 u. a.

8 Ranft, Adelsgesellschaften (wie Anm. 1), S. 206; vgl. auch Kruse/Paravicini/Ranft, Ritterorden (wie Anm. 7), Nr. 48, 49.

9 Ebenso wenig kam es zur „Übernahme einer Führungsrolle [der Wettiner] in Einungen mit dem Niederadel“; Joachim Schneider, Dynastengeschlechter zwischen Saale und Elbe vom 14. bis zum 16. Jahrhundert. Das Spannungsfeld zwischen adliger Selbst- 
der Grundlage von Gesamtbelehnungen und Familienverträgen einsetzende Ausbildung von Geschlechtsverbänden stellte wohl eine Art „Ersatz für föderative Tendenzen innerhalb des Ritteradels“ dar. ${ }^{10}$ Nun waren es die Wettiner selbst, die ihre Vasallen und benachbarte Grafen und Herren mit einer geführten Hofstiftung an sich zu binden suchten. So gründete Kurfürst Friedrich II. von Sachsen am 30. September 1450, dem Festtag des heiligen Kirchenvaters Hieronymus, die geselleschaft sent Ieronimi, die in der Literatur meist als Hieronymusorden bezeichnet wird. ${ }^{11}$ Nach den im 14. Jahrhundert an europäischen Königshöfen entstandenen Vorläufern wie dem Georgsorden (Ungarn, 1326), dem Schärpenorden (Kastilien, 1330), dem Hosenbandorden (England, 1348), dem Sternorden (Frankreich, 1351) ${ }^{12}$ und dem 1408 von Sigismund von Luxemburg in Ungarn errichteten Drachenorden (societas draconis, draconistarum) ${ }^{13}$ zählt sie zu den frühen Beispielen einer fürstlichen Hofstiftung. Ungeachtet vereinzelter Vorläufer wie der societas Templois Herzog Ottos IV. von Österreich (1337) ${ }^{14}$ und des weit ausstrahlenden Vorbilds des burgundischen Ordens vom Goldenen Vlies (errichtet 1430) ${ }^{15}$ ent-

behauptung, Landesherrschaft und Reichsunmittelbarkeit, in: NASG 78 (2007), S. 1-26, hier S. 25 f.

10 Ders., Die Bünaus in der wettinischen Adelslandschaft des Spätmittelalters, in: Martina Schattkowsky (Hg.), Die Familie von Bünau. Adelsherrschaften in Sachsen und Böhmen vom Mittelalter bis zur Neuzeit (Schriften zur sächsischen Geschichte und Volkskunde 27), Leipzig 2008, S. 167-190, hier S. 188.

11 Vgl. die Stiftungsurkunde in Anhang 1. - Ältere Hinweise bei Johann Joachim ScHWabe, Akademische Vorlesung von den bis hieher gestifteten Ritterorden des churfürstlichen und fürstlichen Hauses Sachsen, Leipzig 1756, S. 10 ff.; FerdinAND voN BIEDENFELD, Geschichte und Verfassung aller geistlichen und weltlichen, erloschenen und blühenden Ritterorden [...], Bd. 1, Weimar 1841, S. 74 f.; Gustav Adolph Ackermann, Ordensbuch sämmtlicher in Europa blühender und erloschener Orden und Ehrenzeichen, Annaberg 1855, S. 197; BERnHARD HEYdenreich, Ritterorden und Rittergesellschaften. Ihre Entwicklung vom späten Mittelalter bis zur Neuzeit. Ein Beitrag zur Phaleristik, Diss. phil., Würzburg 1960, S. 38, Nr. 25; BrigitTe Streich, Zwischen Reiseherrschaft und Residenzbildung. Der wettinische Hof im späten Mittelalter (Mitteldeutsche Forschungen 101), Köln/Wien 1989, S. 111 ff., 290; Kruse/Paravicini/Ranft, Ritterorden (wie Anm. 7), Nr. 73; Jörg Nimmergut, Deutsche Orden und Ehrenzeichen bis 1945, Teil 3, München 1999, S. 1155; Boulton, Knights of the Crown (wie Anm. 3), S. 622 ff.

12 Vgl. die Übersicht bei Rudolf Hiestand, Ritterorden, in: Lexikon des Mittelalters, Bd. 7, München 1995, Sp. 878 f.; zum Hosenbandorden und seiner Entwicklung bis in die Neuzeit jüngst Wrede, Frühneuzeitlicher Hochadel (wie Anm. 5), S. 244 ff.

13 Thomas von Bogyay, Drachenorden, in: Lexikon des Mittelalters, Bd. 3, München 1986, Sp. 1346; PÁL LöveI, Hoforden im Mittelalter unter besonderer Berücksichtigung des Drachenordens, in: Imre Takács (Hg.), Sigismundus rex et imperator. Kunst und Kultur zur Zeit Sigismunds von Luxemburg (1387-1437), Mainz 2006, S. 251-263.

14 Kruse/Paravicini/Ranft, Ritterorden (wie Anm. 7), Nr. 3; Christian Lackner, Österreich (ob und unter der Enns, Steiermark, Kärnten, Krain), in: Werner Paravicini (Hg.), Höfe und Residenzen im spätmittelalterlichen Reich. Ein dynastisch-topographisches Handbuch, Teilband 1: Dynastien und Höfe (Residenzenforschung 15.I/1), Ostfildern 2003, S. 846-854, hier S. 853.

15 Friedrich Merzbacher, Aus der Rechtsgeschichte des Ordens vom Goldenen Vlies, in: Nikolaus Grass/Werner Ogris (Hg.), Festschrift Hans Lentze. Zum 60. Geburtstag 
standen Einungen dieser Art in deutschen Territorien vermehrt seit dem zweiten Drittel des 15. Jahrhunderts. ${ }^{16}$ Der Hieronymusgesellschaft voraus gingen der von Herzog Albrecht V. von Österreich gestiftete Adlerorden (1433), ${ }^{17}$ der von Herzog Gerhard von Jülich errichtete Hubertusorden (1440),18 der von Kurfürst Friedrich II. von Brandenburg gegründete Schwanenorden (Gesellschaft Unser Lieben Frau, 1440) ${ }^{19}$ und die Gesellschaft St. Georg vom Pelikan, die Kurfürst Ludwig IV. von der Pfalz 1444 ins Leben rief. ${ }^{20}$ Die beiden letzteren spielten, wie noch zu zeigen ist, eine besondere Vorbildrolle für die kursächsische Stiftung. Wie die 1465 entstandene Christophorusbruderschaft der gefürsteten Grafen von

dargebracht (Forschungen zur Rechts- und Kulturgeschichte 4), Innsbruck/München 1969, S. 429-477; Sonja DünnebeIl, Die Entwicklung des Ordens unter den Burgunderherzögen (1430-1477), in: Leopold Auer (Hg.), Das Haus Österreich und der Orden vom Goldenen Vlies, Graz/Stuttgart 2007, S. 13-34; ferner Lothar HöвеLt, Der Orden vom Goldenen Vlies als Klammer eines Weltreiches, ebd., S. 37-52; MatThias F. MüLler, Der Orden vom Goldenen Vlies und das Haus Habsburg im Heiligen Römischen Reich. Ein (kultur-)geschichtlicher Rückblick, in: Mitteilungen der Gesellschaft für vergleichende Kunstforschung in Wien 61 (2009), Heft 3, S. 1-21; jüngst auch Wrede, Frühneuzeitlicher Hochadel (wie Anm. 5), S. 248 ff.

16 Übersichten bei Kruse/Paravicini/Ranft, Ritterorden (wie Anm. 7); Boulton, Knights of the Crown (wie Anm. 3), S. 575 ff.

17 Heinrich Gustav Thierl, Der österreichische Adlerorden (1433), in: Jahrbuch der k. k. heraldischen Gesellschaft Adler N. F. 15 (1905), S. 215-234; Kruse/Paravicini/ RANFT, Ritterorden (wie Anm. 7), Nr. 62. Die Mitglieder verpflichteten sich zu gegenseitiger Hilfe und sollten dem Stifter Heerfolge gegen die Hussiten leisten.

18 Helmut Lahrkamp, Beiträge zur Geschichte des Hubertusordens der Herzöge von Jülich-Berg und verwandter Gründungen, in: Düsseldorfer Jahrbuch 49 (1959), S. 3-49; Kruse/Paravicini/Ranft, Ritterorden (wie Anm. 7), Nr. 71; Leonie Gräfin von Nesselrode, Neue Erkenntnisse zum Heroldsbuch und Bruderschaftsbuch des jülichbergischen Hubertusordens, in: Jahrbuch für westdeutsche Landesgeschichte 36 (2010), S. 131-162; DiEs., Ikonographie und historische Erkenntnis. Loyalität und Loyalitätskonflikt in den Chorfenstern von Ehrenstein dargestellt am jülich-bergischen Hubertusorden, in: Rheinische Vierteljahrsblätter 75 (2011), S. 108-133, hier S. 114 f.

19 Rudolf von Stillfried, Der Schwanenorden. Sein Ursprung und Zweck, seine Geschichte und seine Alterthümer, Halle 21845; Ders./Siegrried Haenle, Das Buch vom Schwanenorden. Ein Beitrag zu den Hohenzollerischen Forschungen, Berlin 1881; Kruse/Paravicini/Ranft, Ritterorden (wie Anm. 7), Nr. 69; Storn-Jaschkowitz, Gesellschaftsverträge (wie Anm. 1), S. 109 ff.; Markus FrankL, Würzburger Vasallen und Diener im hohenzollerischen Schwanenorden. Adel zwischen Hochstift Würzburg und Markgraftum Ansbach, in: Mainfränkisches Jahrbuch für Geschichte und Kunst 61 (2009), S. 94-127; Ders., Der Schwanenorden unter Markgraf Albrecht Achilles, in: Mario Müller (Hg.), Kurfürst Albrecht Achilles (1414-1486), Kurfürst von Brandenburg, Burggraf von Nürnberg, in: Jahrbuch des Historischen Vereins für Mittelfranken 102 (2014), S. 249-264.

20 Kruse/Paravicini/Ranft, Ritterorden (wie Anm. 7), Nr. 70; Storn-Jaschkowitz, Gesellschaftsverträge (wie Anm. 1), S. 31 ff., 99 ff. Vermutlich bestand die Vereinigung nicht lange über den Tod ihres Gründers hinaus. Reminiszenzen finden sich noch unter Kurfürst Ludwig VI. († 1583); Maximilian Huffschmid, Zwei pfälzische Schaumünzen, in: Mannheimer Geschichtsblätter 2 (1901), Heft 5, Sp. 108-113, hier Sp. 110. 
Henneberg-Schleusingen belegt, leisteten sich vereinzelt auch kleinere Dynasten eine eigene Hofgesellschaft. ${ }^{21}$

Die Wettiner lassen sich schon früh als Mitglieder auswärtiger Gesellschaften nachweisen. Kurfürst Friedrich I. war Mitglied der societas draconis, 22 Friedrich II. gehörte dem Schwanen-, Herzog Wilhelm III. dem Schwanen- und Hubertusorden an. Auf ihren Palästinareisen ließen sich Wilhelm III. (1461), Albrecht der Beherzte (1476), Friedrich der Weise (1493) und Heinrich der Fromme (1498) zu Rittern des Heiliggrabordens schlagen. ${ }^{23}$ Das Goldene Vlies trug Herzog Albrecht seit 1491, sein Sohn Georg seit 1515. Beide ließen sich mit dem Ordenskleinod in zeitgenössischen Porträts, Georg auch im Münzbild, darstellen. ${ }^{24}$ Wet-

21 Die Vereinigung, der Verwandte und Vasallen des Stifters angehörten, umfasste rund 60 männliche und weibliche Mitglieder; Kruse/Paravicini/Ranft, Ritterorden (wie Anm. 7), Nr. 77; Johannes Möтsch, Die Christophorus-Bruderschaft in Kloster Veßra, in: Norbert Moczarski/Johannes Mötsch/Katharina Witter (Hg.), Archiv und Regionalgeschichte. 75 Jahre Thüringisches Staatsarchiv Meiningen (Schriften des Thüringischen Staatsarchivs Meiningen 3; Sonderveröffentlichung des HennebergischFränkischen Geschichtsvereins 12), Hildburghausen 1998, S. 21-60; Ders., Die gefürsteten Grafen von Henneberg und ihre fürstlichen Standessymbole, in: Jörg Rogge/Uwe Schirmer (Hg.), Hochadlige Herrschaft im mitteldeutschen Raum (1200 bis 1600). Formen - Legitimation - Repräsentation (Quellen und Forschungen zur sächsischen Geschichte 23), Leipzig/Stuttgart 2003, S. 227-242, hier S. 240 f.

22 In seinem Nachlass fand sich ein heute verschollenes Ordensemblem; Dirk Syndram, Kleinodien und Insignien, in: Jutta Charlotte von Bloh/Dirk Syndram/Brigitte Streich (Hg.), Mit Schwert und Kreuz zur Kurfürstenmacht. Friedrich der Streitbare, Markgraf von Meißen und Kurfürst von Sachsen (1370-1428), München/Berlin 2007, S. 48-53, hier S. $49 \mathrm{ff}$.

23 Christian Juncker, Discours Von denen Von dem Durchlauchtigsten Chur- und Fürstlichen Hause zu Sachsen gestiffteten Ritter- und andern Orden [...], Eisenach 1708, S. 5; Schwabe, Vorlesung (wie Anm. 11), S. 13 f.; Heydenreich, Ritterorden (wie Anm. 11), S. 61; Kruse/Paravicini/Ranft, Ritterorden (wie Anm. 7), Nr. 69, S. 341, Nr. 71, S. 367 f., 371 f.; dazu IngETRaut Ludolphy, Friedrich der Weise. Kurfürst von Sachsen 1463-1525, Göttingen 1984, Neudruck Leipzig 2006, S. 351 ff.; KASPAR Elm, Kanoniker und Ritter vom Heiligen Grab. Ein Beitrag zur Entstehung und Frühgeschichte der palästinensischen Ritterorden, in: Josef Fleckenstein/Manfred Hellmann (Hg.), Die geistlichen Ritterorden Europas (Vorträge und Forschungen. Konstanzer Arbeitskreis für mittelalterliche Geschichte 26), Sigmaringen 1980, S. 206-214; JEAN-PIERRE DE Gennes, Les Chevaliers du Saint-Sépulcre de Jérusalem. Essai critique, Bd. 1: Origines et histoire générale de l'ordre, Versailles 2004, S. 304, 310 f., 325, 329 f. Zur Mitgliedschaft von Wettinern im Schwanenorden vgl. unten Anm. 156.

24 Liste nominale des chevaliers de l'ordre de la Toison d'or depuis son institution jusqu'à nos jours, in: Auer, Haus Österreich (wie Anm. 15), S. 164, 169; Höвelt, Orden (wie Anm. 15), S. 40; RAphael de SMedt (Dir.), Les chevaliers de l'ordre de la Toison d'or au XVe siècle. Notices bio-bibliographiques (Kieler Werkstücke D/3), Frankfurt a. M. 22000, S. 229 ff. Herzog Georg erhielt das gülden tuch nicht erst auf dem Ordenskapitel von 1531, wie hier angegeben, sondern bereits 1515 für seine ritterlich wolltaten, sonderlich in Frießland; Sächsisches Staatsarchiv - Hauptstaatsarchiv Dresden (im Folgenden: HStA Dresden), 10024 Geheimer Rat (Geheimes Archiv), Loc. 9953/10, Bl. 2r, 4r. Offenbar hatte Karl V. eine Nomination extra capitulum, d. h. ohne den erforderlichen Konsens der Mitglieder, vorgenommen, zu der er offiziell erst seit 1556 berechtigt war; dazu DünnebeIL, Orden (wie Anm. 15), S. 19. Das um 1494 geschaffene Porträt Herzog 
tinerinnen begegnen als Ehefrauen hohenzollerischer Fürsten in den Matrikeln des Schwanenordens. ${ }^{25}$

Mit der Hieronymusgesellschaft Kurfürst Friedrichs II. hat sich in jüngerer Zeit vor allem Brigitte Streich in ihrer Arbeit über den wettinischen Hof befasst. Sie nahm an, dass diese „in erster Linie den Zweck hatte, im Bruderkrieg [zwischen Friedrich II. und Herzog Wilhelm III.] die [...] Vasallen [des Kurfürsten] bei der Stange zu halten“. Nachdem diese „unmittelbaren Erfordernisse“ mit dem Naumburger Frieden vom 27. Januar 1451 hinfällig geworden waren, sei ihr „keine lange Lebenszeit beschieden“ gewesen. ${ }^{26}$ Jörg Nimmergut vermutete, dass der Vertrag von Naumburg seinerseits den Anlass zur Errichtung dieses „Ordens“ gegeben habe - eine Deutung, die bereits chronologisch problematisch ist. Auch er ging davon aus, dass die Vereinigung schon bald, und zwar mit dem Tod seines Stifters im Jahr 1464, erloschen sei.27 Ältere phaleristische Arbeiten vertraten die Ansicht, „daß ein so wohl befestigter Orden [...] einige Zeitlang im Ansehen geblieben“28 und erst mit dem „Übertritt der Sachsen zu Luthers Lehre eines natürlichen Tods" gestorben sei. ${ }^{29}$ In den Kontext von Auseinandersetzungen zwischen Wettinern und Hohenzollern in der Niederlausitz wurde die Gesellschaft jüngst von Joachim Schneider gerückt. ${ }^{30}$

Albrechts und seine Grabplatte im Dom zu Meißen zeigen ihn mit dem Ordenskleinod. Gleiches gilt für die beiden Porträts seines Sohnes Georg aus der Hand Lukas Cranachs d. Ä. und dessen Werkstatt; Jean Louis Sponsel, Fürsten-Bildnisse aus dem Hause Wettin, Dresden 1906, S. 25, Nr. 49, 50, S. 26 f., Nr. 53-55. Zu den unter Georg geprägten Guldengroschen, die ihn mit dem Ordenskleinod darstellen vgl. Paul Arnold, Die sächsische Talerwährung von 1500 bis 1763, in: Schweizerische Numismatische Rundschau 59 (1980), S. 50-94, hier S. 58 ff.

25 Katharina, Gemahlin Kurfürst Friedrichs II., Anna, Ehefrau von Markgraf Albrecht Achilles, Magdalena, Gemahlin Kurfürst Joachims II.; Stillfried/Haenle, Buch vom Schwanenorden (wie Anm. 19), S. 125, 127, 130; Kruse/Paravicini/Ranft, Ritterorden (wie Anm. 7), Nr. 69, S. 337.

26 Streich, Hof (wie Anm. 11), S. 177, ähnlich S. 112; ferner Dies., Sepultus in Wymaria. Grablegen und Begräbnisrituale der Kurfürsten und Herzöge von Sachsen, in: Carola Fey/Steffen Krieb/Werner Rösener (Hg.), Mittelalterliche Fürstenhöfe und ihre Erinnerungskulturen (Formen der Erinnerung 27), Göttingen 2007, S. 249-275, hier S. 265 f.

27 Nimmergut, Orden 3 (wie Anm. 11), S. 1155. Zum Naumburger Frieden von 1451 vgl. Herbert Koch, Der sächsische Bruderkrieg 1446-1451, in: Jahrbücher der Königlichen Akademie gemeinnütziger Wissenschaften zu Erfurt N. F. 35 (1910), S. 179 ff.; JörG RogGe, Herrschaftsweitergabe, Konfliktregelung und Familienorganisation im fürstlichen Hochadel. Das Beispiel der Wettiner von der Mitte des 13. bis zum Beginn des 16. Jahrhunderts (Monographien zur Geschichte des Mittelalters 49), Stuttgart 2002, S. $168 \mathrm{ff}$.

28 Schwabe, Vorlesung (wie Anm. 11), S. 13.

29 Biedenfeld, Geschichte (wie Anm. 11), S. 75; ihm folgt Boulton, Knights of the Crown (wie Anm. 3), S. 622, der eine Lebenszeit zwischen 1450 und 1464/1520 annimmt. Auf diesem Stand fußt die Arbeit von STORN-JaschKowitz, Gesellschaftsverträge (wie Anm. 1), S. 317 ff.

30 JoAchim Schneider, Fränkischer Adel in den Nachbar-Territorien. Zur Mobilität der Ritterschaft im 15. und 16. Jahrhundert, in: Wolfgang Wüst (Hg.), Frankens Städte und Territorien als Kulturdrehscheibe. Kommunikation in der Mitte Deutschlands (Mittel- 
Auf der Basis neuer Quellen soll die Frage nach Lebensdauer, Funktion und Umfeld der einzigen bekannten spätmittelalterlichen Hofstiftung der Wettiner hier noch einmal aufgegriffen werden. Der Forschung stand bislang nur ein unvollständiger Auszug aus der Stiftungsurkunde vom 30. September 1450 zur Verfügung, den der kursächsische Hofhistoriograf Johann Gottlob Horn 1733 publiziert hatte. ${ }^{31}$ Dem Druck lag ein Transsumpt der wohl schon damals verlorenen Ausfertigung zugrunde, das anlässlich einer Bestätigung der Gesellschaft durch den Bischof von Meißen, Caspar von Schönberg, am 1. Januar 1460 entstand. Obwohl Horn die bischöfliche Konfirmation, die vom Bemühen zeugt, der Einung nach ihrem ersten Jahrzehnt des Bestehens neue Impulse zu verleihen, ausdrücklich erwähnt, blieb diese in der Literatur bisher unberücksichtigt. Überliefert ist dazu ein Mitgliederverzeichnis, das vermutlich im Zusammenhang mit der Bestätigung entstand. Die beiden Texte, die im Anhang zu diesem Beitrag erstmals kritisch ediert werden, ermöglichen es, fundiertere Aussagen über die Bedeutung der Hieronymusgesellschaft als Repräsentationsmedium und Herrschaftsinstrument zu treffen. Diese gilt es hier mit dem zu vergleichen, was über andere (reichs-) fürstliche Stiftungen des 15. Jahrhunderts bekannt ist. Mit dem Schwanenorden der brandenburgischen Hohenzollern und der kurpfälzisch-wittelsbachischen Pelikangesellschaft richtet sich der Blick dabei vor allem auf zwei kurfürstliche Gesellschaften, die beide in jüngerer Zeit mehrfach Gegenstand verfassungs-, kultur- und sozialhistorischer Untersuchungen waren. ${ }^{32}$

\section{Zur Verfassung der Hieronymusgesellschaft}

Wie der Schwanen- und der Pelikanorden ist auch die Hieronymusgesellschaft nach den oben dargestellten Kategorien als eine „hofgebundene Stiftung“ zu charakterisieren. Der kurfürstliche Gründer fungierte als Obmann, dem die Mitglieder zur Treue verpflichtet waren, wenngleich sie in den Angelegenheiten der Gesellschaft ein gewisses Mitspracherecht besessen zu haben scheinen. ${ }^{33} \mathrm{Im}$ Vergleich mit anderen fürstlichen Hofstiftungen des 15. Jahrhunderts zeichnet sich die Hieronymusgesellschaft jedoch durch eine recht einfache Organisation aus. So fehlte

fränkische Studien 19), Ansbach 2008, S. 32-55, hier S. 36 mit Anm. 20, wonach die Hieronymusgesellschaft als „Konkurrenzprodukt [...] zu der überregional angelegten Schwanengesellschaft der Hohenzollern, mit denen die Wettiner im Jahre 1450 um den Besitz der Niederlausitz stritten“, zu interpretieren sei. Zu den bereits seit 1440 schwelenden Auseinandersetzungen Rudolf Lehmann, Geschichte der Niederlausitz (Veröffentlichungen der Historischen Kommission beim Friedrich-Meinecke-Institut der Freien Universität Berlin 5), Berlin 1963, S. 80 ff.

31 Johann GotTlob Horn, Nützliche Sammlungen zu einer historischen Hand-Bibliothec von Sachsen und dessen incorporirten Landen, Teil 8, Leipzig 1733, S. 873 ff.; danach Biedenfeld, Geschichte 1 (wie Anm. 11), S. 74 f.; und zuletzt Storn-JaschkowITZ, Gesellschaftsverträge (wie Anm. 1), S. 317 ff.

Wie oben Anm. 19, 20.

33 Vgl. unten bei Anm. 53; zum Begriff der „hofgebundenen Stiftung“ oben Anm. 3. 
es ihr etwa an Ordensämtern, einer eigenen Schriftgutverwaltung oder Regeln zur gütlichen Beilegung von Konflikten unter den Mitgliedern, wie sie ihre Gegenstücke in Brandenburg und, noch ausgeprägter, in der Kurpfalz kennen. ${ }^{34}$

Die Statuten (Anhang 1) benennen den heiligen Kirchenvater Hieronymus als Patron, die Muttergottes und alle Heiligen als Konpatrone (Z. 28-30). Darauf folgt eine Beschreibung des Emblems (cleynot) der Gesellschaft, das von jedem Mitglied auf eigene Kosten erworben werden musste (Z. 71-82). Dabei handelt es sich, einem verbreiteten Typus entsprechend, um eine Imprese (Bilddevise) mit den Attributen des Titelheiligen, die an einer Halskette getragen wurde. ${ }^{35}$ Unter einem Kardinalshut als Zeichen der Hieronymus seit dem 12. Jahrhundert zugeschriebenen Amtswürde hing ein Löwe, wie ihn der Heilige nach der Legende einst gezähmt hatte. ${ }^{36}$ Die Halskette bestand aus ringförmig gebogenen Griffeln als Symbol der Gelehrsamkeit des Gesellschaftspatrons, die jeweils die Wortdevise $\mathrm{O}$ wie groß ist der gloube, den der heylige sent Ieronimus gelert hat unde geprediget trugen. Die Formulierung ist einer ursprünglich auf den Kirchenvater Augustin bezogenen Sequenz des 15. Jahrhunderts entlehnt. ${ }^{37}$ Eine Abbildung der Imprese zeigt das wohl um 1485/86 entstandene Wappenbuch des Konrad Grünenberg (Abb. 1-2), das sie als Beiwerk des kursächsischen Wappens darstellt. ${ }^{38} 1469$ ver-

34 Kruse/Paravicini/Ranft, Ritterorden (wie Anm. 7), Nr. 69, S. 326 ff. (Schwan); Storn-Jaschkowitz, Gesellschaftsverträge (wie Anm. 1), S. 68 ff., 80 f., 82 ff. (Pelikan), 127 ff., 153 f., 154 ff. (Schwan); exemplarisch auch Peter Vetter, Der französische Ritterorden vom heiligen Michael (1469-1830), Diss. phil. Bonn 1979, S. 14 ff., 26 ff.; zum Orden vom Goldenen Vlies DünnebeIL, Entwicklung (wie Anm. 15), S. 24; zu dessen Gesellschaftsämtern ebd., S. 18.

35 Vgl. Joachim Schneider, Devisen und Embleme, in: Werner Paravicini (Hg.), Höfe und Residenzen im spätmittelalterlichen Reich. Hof und Schrift (Residenzenforschung 15.III), Ostfildern 2007, S. 87-100; weiter Malte Prietzel, Hosenband und Halbmond, Schwan und Hermelin. Zur Ikonographie weltlicher Ritterorden im späten Mittelalter, in: Herold-Jahrbuch N. F. 4 (1999), S. 119-134. Zur Symbolik der Ordensimpresen und -devisen auch Heydenreich, Ritterorden (wie Anm. 11), S. 41 ff.; Boulton, Knights of the Crown (wie Anm. 3), S. $478 \mathrm{ff}$.

36 Zur Hieronymuslegende im 15. Jahrhundert Toвias Leuker, Eine kritische Hieronymus-Vita des Quattrocento. Giannozzo Manetti als Vorläufer des Erasmus von Rotterdam, in: Quellen und Forschungen aus italienischen Archiven und Bibliotheken 83 (2003), S. 102-140, hier S. $111 \mathrm{f}$.

37 Vgl. Anhang 1, Sachanm. 6. In der ersten Fassung des Entwurfs der Stiftungsurkunde war die Devise noch als Umrahmung der Imprese gedacht, Anhang 1, Textanm. m)-m).

38 Geheimes Staatsarchiv Preußischer Kulturbesitz, VIII. HA, II, Nr. 21, Bl. 47v (olim XLIIII b); vgl. das Faksimile von Rudolf von Stillfried/Adolph M. HildebrandT (Hg.), Des Conrad von Grünenberg Ritters und Burgers zu Costenz Wappenbuch volbracht am nünden Tag des Abrellen do man zalt tusendvierhundert frü und achtzig jar, Görlitz 1875. Eine später entstandene Kopie in der Bayerischen Staatsbibliothek München (cgm 145, hier Bl. 87r); vgl. Steen Clemmensen, Conrad Grünenberg's Wappenbuch. Introduction and edition, Farum 2009, S. 30, 109, Nr. 415, www.armorial. dk [Zugriff 18. August 2015]. Zur Datierung Klaus Graf, Adel als Leitbild - Zur Geschichte eines Grundwerts in Spätmittelalter und früher Neuzeit, in: Horst Carl/ Sönke Lorenz (Hg.), Gelungene Anpassung? Adelige Antworten auf gesellschaftliche Wandlungsvorgänge vom 14.-16. Jahrhundert (Schriften zur südwestdeutschen Lan- 
wahrte die wettinische Hofsilberkammer zwei Exemplare, die jedoch als verloren gelten. ${ }^{39}$

Das Emblem wurde in einer silbernen und einer goldenen Variante vergeben. Möglicherweise sollten damit verschiedene Rangstufen der Mitgliedschaft gekennzeichnet werden, wie es für den Schwanenorden, ${ }^{40}$ den Pelikan ${ }^{41}$ und den Drachenorden ${ }^{42}$ belegt ist. Dafür spricht, dass auch das Begräbniszeremoniell der Hieronymusgesellschaft zwischen Grafen, Herren, Rittern und Knechten differenzierte (Z. 71 f., 143-145). Im Fall des Hubertusordens in Jülich, für den man annahm, dass goldene Insignien für hochadlige, silberne für niederadlige Mitglieder vorgesehen waren, vergab der Stifter das goldene Emblem jedoch unabhängig von der sozialen Stellung des Trägers, was subtile Möglichkeiten der individuellen Bevorzugung bot. ${ }^{43}$ Auch diese Praxis erscheint in Kursachsen denkbar. Die von den Albertinern im späten 16. und frühen 17. Jahrhundert vergebenen Gesell-

deskunde 53), Ostfildern 2005, S. 67-81, hier S. 67, Anm. 1, www.freidok.uni-freiburg. de/volltexte/5632/pdf/Graf_adel_leitbild.pdf [Zugriff 18. September 2015]; ferner Christoph Rolker, Konrad Grünenbergs Wappenbuch I: Die Handschriften, http:// heraldica.hypotheses.org/464 [Zugriff 22. März 2015]; Ders., Heraldische Orgien und sozialer Aufstieg. Oder: Wo ist eigentlich „oben“ in der spätmittelalterlichen Stadt?, in: Zeitschrift für Historische Forschung 42 (2015), S. 191-224; Michel Pastoureau/ Michel Popoff (Hg.), Armorial Grünenberg. Édition critique de l'armorial de Conrad Grünenberg (1483), Milano [2011], S. 97, Nr. 417; Paul Ganz, Die Abzeichen der Ritterorden im Mittelalter, in: Schweizer Archiv für Heraldik 19 (1905), I, S. 28-37, II, S. 52-67, III, S. 134-140, 20 (1905), IV, S. 16-25, hier 19 (1905), II, S. 57; Nimmergut, Orden 3c (wie Anm. 11), S. 1155. - Neben dem Emblem der Hieronymusgesellschaft zeigt Grünenberg beim sächsischen Wappen auch das der von Herzog Adolf II. von Kleve (1394-1448) gegründeten Antoniusbruderschaft und das des von Kaiser Friedrich III. 1469 gegründeten Georgsordens; Ganz, a. a. O., S. 53; Clemmensen, a. a. O., S. 28, 30; unwahrscheinlich die Deutung als Gesellschaft vom St. Jörgenschild bei Boulton, Knights of the Crown (wie Anm. 3), S. 483; und Pastoureau/Popoff, a. a. O., S. 97. Zum Georgsorden Kruse/Paravicini/Ranft, Ritterorden (wie Anm. 7), Nr. 79; Heinrich Gustav Thierl, Zur Symbolik der Abzeichen alter Ritterorden, in: Jahrbuch der k. k. heraldischen Gesellschaft Adler N. F. 13 (1903), S. 83-103, hier S. 88 f.; zur Antoniusbruderschaft Adalbert Mischlewski, Soziale Aspekte der spätmittelalterlichen Antoniusverehrung, in: Klaus Schreiner (Hg.), Laienfrömmigkeit im späten Mittelalter. Formen, Funktionen, politisch-soziale Zusammenhänge (Schriften des Historischen Kollegs. Kolloquien 20), München 1992, S. 137-156, hier S. 146 f.; Kruse/Paravicini/Ranft, Ritterorden (wie Anm. 7), Nr. 56.

39 Friedrich August von O’Byrn, Die Hof-Silberkammer und die Hof-Kellerei zu Dresden, Dresden 1880, S. 6: Item zcwu gesellschafft sancti Ieronimi.

40 Stillfried/Haenle, Buch vom Schwanenorden (wie Anm. 19), S. 22; vgl. auch Thierl, Symbolik (wie Anm. 38), S. 87; GAnz, Abzeichen (wie Anm. 38), S. 30.

41 Der darüber hinaus sehr differenzierte Tragevorschriften kennt; STORN-JAschкowitz, Gesellschaftsverträge (wie Anm. 1), S. 65 f., 73 f.

42 Prietzel, Hosenband (wie Anm. 35), S. 127.

43 Nesselrode, Ikonographie (wie Anm. 18), S. 115. Zur Bewahrung hoch- und niederadliger Standesunterschiede in Adelseinungen und Turniergesellschaften auch KARLHeINz SpIEss, Ständische Abgrenzung und soziale Differenzierung zwischen Hochadel und Ritteradel im Spätmittelalter, in: Rheinische Vierteljahrsblätter 56 (1992), S. 181205, hier S. 194-196. 


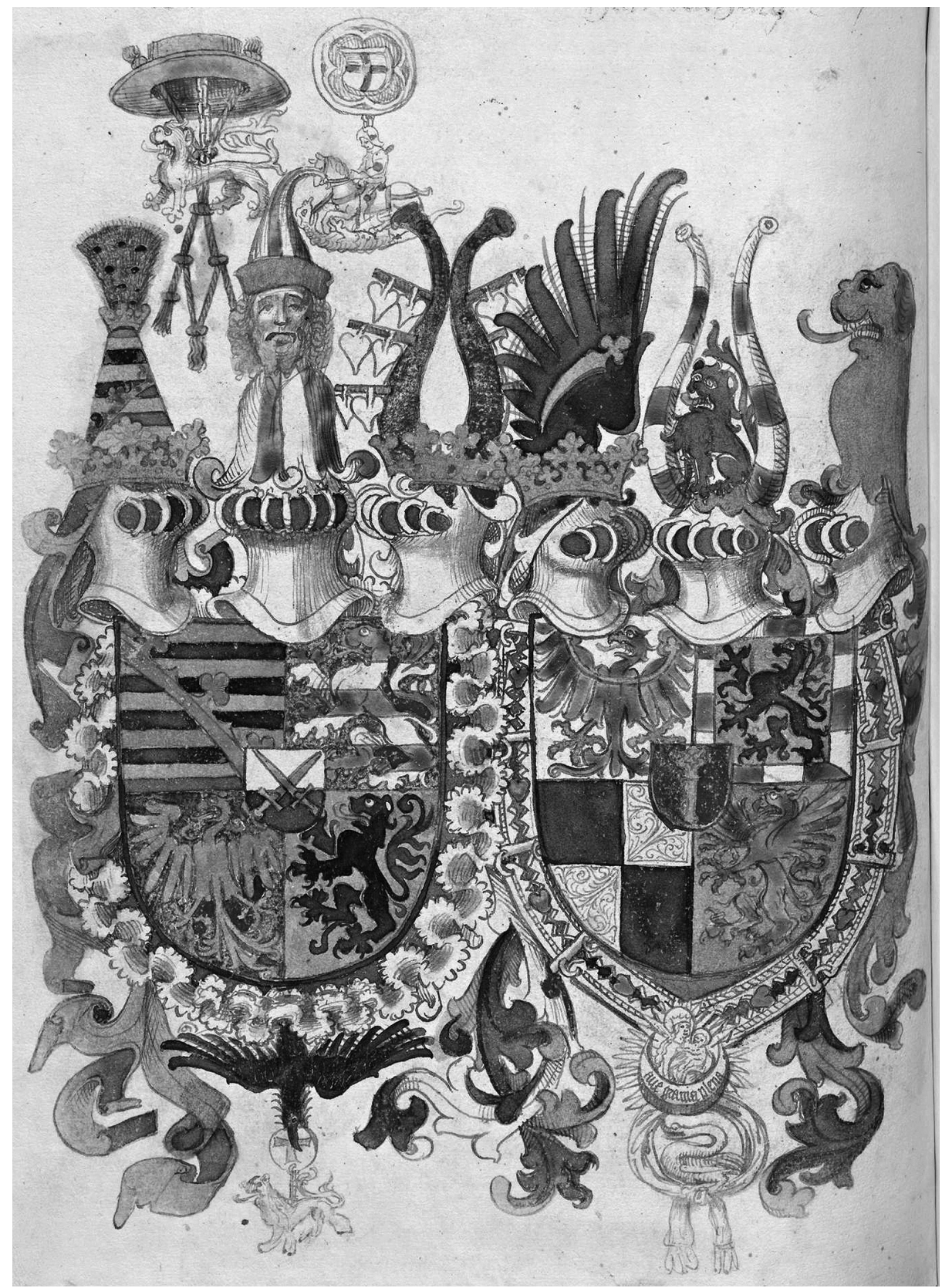

Abb. 1: Wappenbuch des Konrad Grünenberg, um 1485/86. Heraldisch rechts das Wappen des Kurfürstentums Sachsen. Dort über der Helmzier heraldisch rechts die Imprese der Hieronymusgesellschaft. Heraldisch links das Wappen des Kurfürsten von Brandenburg mit dem um den Schild gelegten Emblem des hohenzollerischen Schwanenordens (vgl. auch Anm. 38). 


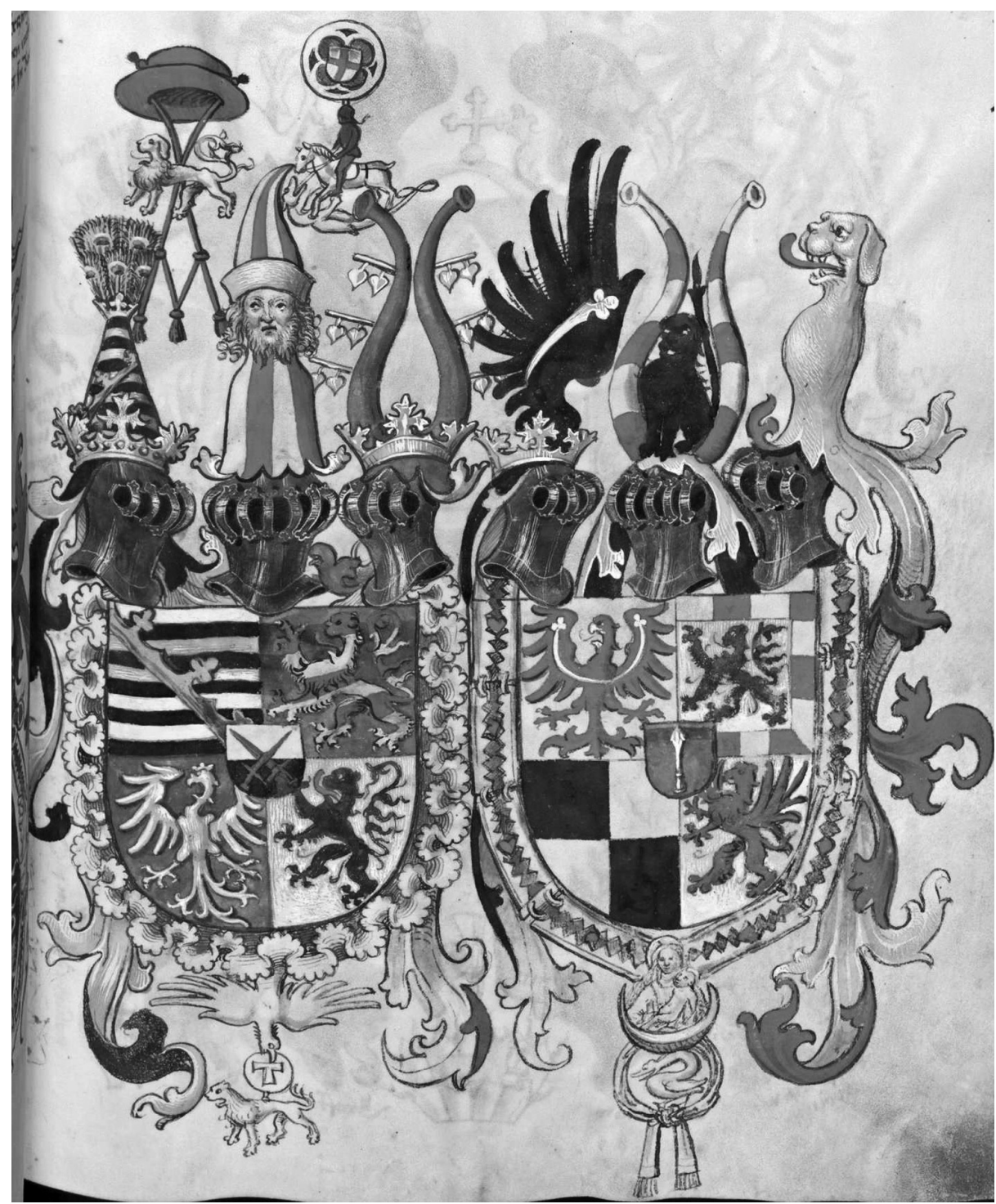

Abb. 2: Wappenbuch des Konrad Grünenberg, Kopie, um 1500? Beschreibung wie Abb. 1, zur Datierung vgl. ROLKER, Wappenbuch (wie Anm. 38). 
schaftsketten, hinter denen freilich keine förmliche Organisation mehr stand, wurden später ebenfalls ganz nach persönlicher Gunst des Stifters gestaltet. ${ }^{44}$

Ein Entwurf der Stiftungsurkunde bezeichnet die Hieronymusgesellschaft als „erblich“ . ${ }^{45} \mathrm{Da}$ sich die Statuten hierzu nicht weiter äußern, bleibt unklar, ob sich dies auf die Mitgliedschaft bezog, die etwa auch im Schwanenorden vererbbar war. ${ }^{46}$ Dem scheint die Verpflichtung zur Rückgabe des Gesellschaftsemblems nach dem Tod des Trägers (Z. 141-146) zu widersprechen. Vielleicht sollte der Begriff daher zum Ausdruck bringen, dass die Gesellschaft nach dem Willen ihres Stifters unter dessen Nachfolgern weiterbestehen sollte. Die Mitgliederzahl war nicht begrenzt und die Mitgliedschaft nicht exklusiv, sodass sich einzelne Hieronymusgesellen auch in anderen Hofstiftungen wie dem Schwanenorden nachweisen lassen. ${ }^{47}$ Weibliche Mitglieder, wie sie der Schwanenorden kannte, ${ }^{48}$ waren nicht vorgesehen, hätten aber auch dem dezidiert kämpferischen Auftrag der wettinischen Einung widersprochen. Über die Form der Aufnahme schweigen die Statuten. So heißt es zwar, dass die Stiftung nach zcitlichem rate der unsern, fursten, graven, herren, frÿen, rittern, knechten, auch unser rete, manne unde lieben getruwenn (Z. 69-71) gegründet worden sei, dass aber die Mitglieder bei der Auswahl neuer Gesellen ein Konsensrecht besaßen, wie dies in Pelikan und Goldenem Vlies üblich war, ${ }^{49}$ ist nicht belegt.

Erklärter Zweck der Hieronymusgesellschaft war die Verteidigung des christlichen Glaubens. Die Mitglieder sollten sich in striten ader andern ritterlichen geschefften bewähren und die geistlichkeit lieben, kirchen, witwen unde weisen schuczen unde schirmen nach aller mogelichkeit (Z. 125 f., 129-131). Voraussetzung einer Mitgliedschaft war die durch vier Ahnen zu belegende adlige Abkunft, eheliche Geburt und, wie auch in anderen Gesellschaften üblich, ${ }^{50}$ ein untadeliger Ruf. Darüber hinaus war die uneingeschränkte Loyalität gegenüber dem Stifter gefordert. Wer diesem die Fehde erklären wollte, musste ihm als Zeichen der Feindschaft vier Wochen zuvor sein Gesellschaftsemblem übersenden. Im Gegenzug versprach der Kurfürst, durch redeliche ursach verarmte Gesellen lebenslang zu unterstützen (Z. 172-175). Ähnliche, an lehnsrechtlichen Vorstellungen orien-

44 Christine Nagel, Die Gesellschaften der sächsischen Kurfürsten, in: Dresdner Geschichtsbuch 13 (2008), S. 53-75, hier S. 57, 65-68, 71.

$45 \mathrm{Vgl}$. Anhang 1, Formalbeschreibung zu Textzeuge $\mathrm{B}_{2}$ : dis sal sein eyn erblich geselschaft.

46 Storn-Jaschkowitz, Gesellschaftsverträge (wie Anm. 1), S. 138 ff.

47 In anderen Gesellschaften war sie limitiert, so etwa im Drachenorden (22 Barone, Zahl der Ritter unbestimmt), im Michaelsorden (35 Ritter, dies im 14. Jahrhundert aber nur zur Hälfte ausgeschöpft; VeTter, Ritterorden, wie Anm. 34, S. 1621 ff.) und im Schwanenorden; HeYdenreich, Ritterorden (wie Anm. 11), S. 51 f.; vgl. Ranft, Adelsgesellschaften (wie Anm. 1), S. 227.

48 Kruse/Paravicini/Ranft, Ritterorden (wie Anm. 7), Nr. 69, S. 335; Storn-JaschkowITZ, Gesellschaftsverträge (wie Anm. 1), S. 137 f.

49 Storn-Jaschkowitz, Gesellschaftsverträge (wie Anm. 1), S. 72 f. (Pelikan); zum Goldenen Vlies und der Mitsprache seiner Träger bei der Aufnahme neuer Mitglieder oben Anm. 24.

50 Heydenreich, Ritterorden (wie Anm. 11), S. 35 f., 48 f. 
tierte Regelungen kannten auch der Schwanenorden und die Pelikangesellschaft. Die Verpflichtung zur Leistung eines förmlichen Gelöbnisses wie bei Pelikan und Schwan sehen die Statuten nicht ausdrücklich vor. ${ }^{51}$

Den Alltag der Hieronymusgesellen prägte die Gebetsgemeinschaft. Hierzu verfügte man, wie auch im Fall anderer Stiftungen, 52 über ein geistliches Zentrum. In einem Zug mit der Ordensgründung hatte Kurfürst Friedrich II. einen neuen Altar in der Fürstenkapelle des Meißner Doms errichten lassen, dessen Priester in sinen messen und ampten vlissiglich bitten sal vor alle, die sulche gesellschafft tragen werden unde getragen babenn (Z. 137 f.). Darüber hinaus war jedes Mitglied verpflichtet, an Samstagen und Sonntagen auch zu Hause zum heiligen Hieronymus und zum Seelenheil seiner Genossen zu beten (Z. 152-157). In der Meißner Fürstenkapelle sollten an den Quatemberterminen regelmäßige Mitgliederversammlungen stattfinden. Die Teilnehmer hatten hier ihrer verstorbenen Genossen zu gedenken und über die Tätigkeit der Gesellschaft zu beraten (Z. 160-172). Letzteres belegt, dass auch die wettinische Stiftung durchaus egalitäre Züge besaß, wenngleich über den Inhalt der gemeinsamen Verhandlungen und die konkreten Formen möglicher Mitbestimmung nichts überliefert ist. Ansätze zu einer schriftlichen Überlieferungsbildung, wie es sie im Pelikan oder in anderen Gesellschaften gab, ${ }^{53}$ sind nicht erkennbar.

Starb ein Mitglied der Einung, sollte dessen Kleinod dem Hieronymusaltaristen in der Fürstenkapelle übergeben und zur Finanzierung des Messdiensts verwendet werden. Darüber hinaus musste ein Schild des Toten mit sinen wapenn gezciret in der Ordenskapelle aufgehängt werden. Deutlich unterscheiden die Statuten hier zwischen hoch- und ritteradligen Mitgliedern: Im Fall eines Grafen oder Herren hatten sich dieser Aufgabe zwei niederadlige Mannen (erbarn knechten) aus der Gesellschaft anzunehmen, war der Verstorbene ein ritter ader edelmann, genügte ein Begleiter. ${ }^{54}$ Die nächsten Nachbarn sollten an der Beisetzung teilnehmen (Z. 157-160). Damit erinnern die Vorschriften an Rituale, wie sie auch aus fürstlichen Beisetzungen geläufig sind. Die Gegenwart der Standesgenossen beim Begräbnis kann als „Loyalitätsbekundung“, die Stiftung von Wappenschilden als Ausdruck „adliger Standesgemeinschaft“ interpretiert werden. ${ }^{55}$ Mit der Übergabe eines heraldischen Totenschilds, wie sie sich noch heute in der Ordens-

51 Storn-Jaschkowitz, Gesellschaftsverträge (wie Anm. 1), S. 70 f., 73 ff. (Pelikan), $130 \mathrm{ff} ., 135 \mathrm{ff}$.

52 Vgl. etwa den Schwanenorden (Harlungerberg bei Brandenburg, Georgskapelle in St. Gumpert in Ansbach) unten Anm. 103; zum Pelikanorden (Heiliggeiststift in Heidelberg, später auch das Dominikanerkloster in Worms) STORN-JASCHKowitz, Gesellschaftsverträge (wie Anm. 1), S. 66 f., 78 f.; allgemein Heydenreich, Ritterorden (wie Anm. 11), S. $50 \mathrm{f}$.

53 Storn-Jaschkowitz, Gesellschaftsverträge (wie Anm. 1), S. 76 f., 80 ff.

54 Ähnliche Beispiele bei RanFt, Adelsgesellschaften (wie Anm. 1), S. 228; vgl. auch oben Anm. 43, unten Anm. 113, 150.

55 Vgl. Cornell Babendererde, Sterben, Tod, Begräbnis und liturgisches Gedächtnis bei weltlichen Reichsfürsten des Spätmittelalters (Residenzenforschung 19), Ostfildern 2006, S. 142 f., 145, 150 f., 152 f., 165 ff., die Zitate S. 143, 153 und 165. 
kapelle des hohenzollerischen Schwanenordens in St. Gumpert in Ansbach finden, symbolisierte der Verstorbene zudem postum die Erledigung seines kämpferischen Auftrags für Gott und Kirche. ${ }^{56}$

Die Verpflichtung zu Gebet und liturgischer Memoria steht für den religiösbruderschaftlichen Charakter der Hieronymusgesellschaft. ${ }^{57}$ Berücksichtigt man, dass sich ihr Titelheiliger seit Beginn des 15. Jahrhunderts als Musterbeispiel des Asketen zu etablieren begann und als „Prediger der Erfüllbarkeit des Gesetzes und eines sittlichen Vollkommenheitsideals" galt, ${ }^{58}$ treten hier die Züge einer Bußfrömmigkeit am wettinischen Hof hervor, wie sie sich unter dem Patronat des Hieronymus damals vor allem in Religiosengemeinschaften in Italien und Spanien ausbreitete. ${ }^{99}$ In dieser Hinsicht war der Heilige eine „Identifikationsfigur spätmittelalterlicher Devotion", 60 die sich in besonderem Maß der Werkfrömmigkeit verpflichtet sah. Als „Lebensmodell des sich durch tugendhaftes Wirken auf den Zielgewinn des himmlischen Lohnes hin verwirklichenden Menschen",61 bot er sich insbesondere als Patron einer ritterlichen Gesellschaft an. Festzuhalten ist aber auch hier, dass die Ausgestaltung der liturgischen Memoria, die in erster Linie der Stärkung des Zusammenhalts in der wettinischen Vasallenschaft diente, im Vergleich mit anderen Hofstiftungen wie Schwan und Pelikan ${ }^{62}$ eher bescheiden wirkt.

\section{Die Hieronymusgesellschaft als Träger antibussitischen Selbstverständnisses}

Als eigentliche Aufgabe der Hieronymusgesellschaft betrachten die Statuten den Kampf gegen Ungläubige und Häretiker. Auffällig ist dabei zum einen die konkrete Bestimmtheit, mit der die Mitglieder zum militärischen Einsatz für den Glauben angehalten wurden, zum anderen, dass der Rekurs auf das ritterliche Kreuzzugsideal hier ganz auf die inneren Feinde der Kirche zielt - anders als etwa

56 Ebd., S. 154. Zu den Schilden in St. Gumbert unten Anm. 150.

57 Diesen betont bereits Heydenreich, Ritterorden (wie Anm. 11), S. 50.

58 Berndt Hamm, Hieronymus-Begeisterung und Augustinismus vor der Reformation. Beobachtungen zur Beziehung zwischen Humanismus und Frömmigkeitstheologie (am Beispiel Nürnbergs), in: Kenneth Hagen (Hg.), Augustine, the Harvest, and Theology (1300-1650). Essays dedicated to Heiko Augustinus Oberman in honor of his sixtieth birthday, Leiden u. a. 1990, S. 127-235, hier zitiert nach dem Wiederabdruck in: Ders., Religiosität im späten Mittelalter. Spannungspole, Neuaufbrüche, Normierungen (Spätmittelalter, Humanismus, Reformation 54), Tübingen 2011, S. 154-243, hier S. 172, 174 f. (Zitat); vgl. auch Renate Jungblut, Hieronymus. Darstellung und Verehrung eines Kirchenvaters, Diss. phil. Tübingen 1967, S. 137 ff.

59 Vgl. Eugene F. Rice, Saint Jerome in the Renaissance, Baltimore/London 21988, S. 68 ff.; Bernhard Ridderbos, Saint and Symbol. Images of Saint Jerome in early Italian art, Groningen 1984, S. $73 \mathrm{ff}$.

60 Hамм, Hieronymus-Begeisterung (wie Anm. 58), S. 174.

61 Ebd., S. 178.

62 Storn-Jaschkowitz, Gesellschaftsverträge (wie Anm. 1), S. 77 f. (Pelikan), 142 ff. (Schwan). 
im Fall der Gemeinschaft vom Goldenen Vlies, die sich nach dem Vorbild der geistlichen Orden des Hochmittelalters der Idee des Türkenkampfs verpflichtet hatte. ${ }^{63}$ Hierzu betonen die Statuten ganz dezidiert die Rolle des Hieronymus als Ketzerverfolger: Als harter hammer und swerer vertriber der keczer habe sich dieser irer falschen leve und verkarten boßheit entgegengestellt, viele getötet oder zcu[r] rechten erkentnis unde zcu dem glouben geführt (Z. 56-64).

Mit den Begriff des, Ketzerhammers' greift die Urkunde ein Epitheton des Heiligen auf, das im 15. Jahrhundert weitverbreitet war. Es begegnet bereits im ,Hieronymianus‘ des Bologneser Juristen Johannes Andreae, einer hagiografischen Materialsammlung, die zwischen 1334 und 1346/47 entstand. ${ }^{64}$ Ähnliche Formulierungen verwendet auch Johannes Trithemius in seinem 1494 gedruckten ,Liber de scriptoribus ecclesiasticis' (haereticorum malleus et expugnator). ${ }^{65} \mathrm{Als}$ ,Ketzerhammer‘ erscheint Hieronymus ferner im Missale von Tours (15. Jahrhundert) ${ }^{66}$ sowie in Brevieren aus Madrid (1463) ${ }^{67}$ und dem Vallombrosanerkloster Trinità dell'Alpi bei Arezzo (1455), ${ }^{68}$ als expugnator perfidorum in einem Reimgebet des 15. Jahrhunderts aus dem südböhmischen Zisterzienserkloster Hohenfurth (Vyšší Brod). ${ }^{69}$ Als haereticorum iacula begegnet er schließlich in einer Sequenz, die in den um 1500 gedruckten Meißner Missalien überliefert ist, und der Stiftungsurkunde der Hieronymusgesellschaft mithin besonders nahesteht. ${ }^{70}$

Dass sich die wettinische Hofstiftung nicht gegen die Heiden, sondern die Abweichler vom katholischen Dogma richtete, klingt auch im Lob des Hieronymus als Bibelübersetzer an: Er sei, so die Gründungsurkunde, der hochste ußleger [...]

63 Vgl. Heribert Müller, Kreuzzugspläne und Kreuzzugspolitik des Herzogs Philipp des Guten von Burgund (Schriftenreihe der Historischen Kommission bei der Bayerischen Akademie der Wissenschaften 51), Göttingen 1993, S. 16 ff., 32 ff., 69 f. Zu den Adelsgesellschaften, die sich eng am Vorbild geistlicher Ritterorden orientierten, gehörten auch der von Amadeus VIII. von Savoyen errichtete Mauritiusorden (1434) und der Sankt-Georgs-Orden; Elisa Mongiano, Mauritius, Ritterorden vom hl., in: Lexikon des Mittelalters, Bd. 6, München 1993, Sp. 413 f.; Kruse/Paravicini/Ranft, Ritterorden (wie Anm. 7), Nr. 79.

64 Johannes Andreae, Hieronymianus, [Köln, Konrad Winters von Homberg], 9. August $1482,2^{\circ}, \mathrm{Bl} .9 \mathrm{v}$; Ders., Hieronymianus. Divi Hieronymi vitae, mortis, prodigiorum, dictorum ac scriptorum exflorationes [...], Wien 1514, Bl. 15v; vgl. auch GUIDO MARIA Dreves (Hg.), Analecta Hymnica medii aevi, Bd. 46: Pia dictamina. Reimgebete und Leselieder des Mittelalters, Leipzig 1905, S. 265 f. Zu Johannes Andreae vgl. JosEPH Klapper, Aus der Frühzeit des Humanismus. Dichtungen zu Ehren des heiligen Hieronymus, in: Ernst Boehlich/Hans Heckel (Hg.), Bausteine. Festschrift Max Koch zum 70. Geburtstage dargebracht, Breslau 1926, S. 255-281; Rice, Saint Jerome (wie Anm. 59), S. 64 f., 67 f.; ferner Erika Bauer, Hieronymus und Hieronymianus. Johannes Andreae und der Hieronymuskult, in: Daphnis 18 (1989), S. 199-221. Basel: Johann Amerbach, 1494 (GW M47578), Bl. 17r

66 Guido Maria Dreves (Hg.), Analecta Hymnica medii aevi, Bd. 10, Leipzig 1891, S. 191.

67 Ebd., Bd. 16, Leipzig 1894, S. 151.

68 Ebd., Bd. 22, Leipzig 1895, S. 129.

69 Ebd., Bd. 15, Leipzig 1893, S. 210.

70 Vgl. Anhang 1, Sachanm. 5. 
der heiligen schrifft, ein meister des cristengloubens, gebe allen eine rechte und unstreffliche regil, er kenne aller schriffte warbeit, dorczu auch aller heimlichkeit, dovon die aldenn in beydenn geseczen in krichscher, arabischer, hebreischer, kaldeiischer, latinischer, windescher und aller ander zcungen zcu iren schrifften gesagt und verkundigt haben (Z. 39 f., 41 f., 45-49). Hinter diesen Worten steht der Heilige als Typus des humanistischen Gelehrten. ${ }^{71}$ Entstanden ist dieses Bild im italienischen Frühhumanismus, der den Schöpfer der Vulgata als „Repräsentanten exakter theologischer Wissenschaften" sah. So galt der Kirchenvater als ein Garant „für die Festigung kirchlicher Lehre und Macht"72 und wandelte sich im Lauf des 15. Jahrhunderts zu einem beliebten „Patron bestimmter spiritueller und sozialer Eliten “. ${ }^{73}$ Dabei wurde er als vermeintlicher Repräsentant der Papstkirche interpretiert, ließ sich mit seinen asketischen Zügen aber auch als „Anwalt [...] für einen Weg der Reform an Haupt und Gliedern der Kirche" deuten. ${ }^{74}$

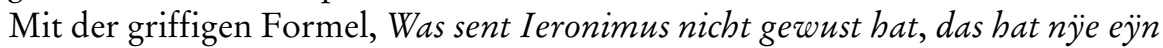
lebende mensche gerwust (Z. 44 f.), bringt die Stiftungsurkunde das Bild des orthodoxen Gelehrten auf den Punkt. Sie zitiert hier eine der einflussreichsten hagiografischen Quellen ihrer Zeit, die Hieronymusbriefe des Johann von Neumarkt $(\dagger 1380)$, des Hofkanzlers Karls IV. ${ }^{75}$ Mit diesem Werk gelangte die humanistische Interpretation des Heiligen über Böhmen in den nordalpinen Raum. Während einer Italienfahrt an der Seite seines Königs (1354/55) hatte Johann von Neumarkt den bereits erwähnten ,Hieronymianus' kennengelernt, der seine Bewunderung für den Heiligen begründete. Von einer zweiten Italienreise brachte er 1369 eine Handschrift dreier im 13. Jahrhundert entstandener Briefe mit, als deren fiktive Autoren der Hieronymusschüler Eusebius von Cremona, Augustinus von Hippo und Cyrillus von Jerusalem galten. Sie bilden die literarische Grundlage der spätmittelalterlichen Hieronymusverehrung. Zwischen 1371 und 1375 schuf Johann eine mittelhochdeutsche Fassung der Texte, ${ }^{76}$ die das Gründungsdokument der

71 Hamm, Hieronymus-Begeisterung (wie Anm. 58), S. 158; ferner Rice, Saint Jerome (wie Anm. 59), S. $84 \mathrm{ff}$.

72 Jungblut, Hieronymus (wie Anm. 58), S. 41 ff., 54 ff., 107, 113 ff., das Zitat S. 11, 113; vgl. auch Hamm, Hieronymus-Begeisterung (wie Anm. 58), S. 175, 178 f., 181 ff.; Rice, Saint Jerome (wie Anm. 59), S. 89 f.

73 Hamm, Hieronymus-Begeisterung (wie Anm. 58), S. 159, 175; zu Hieronymus als Heiligem sozialer Eliten auch ebd., S. 222 f.

74 Ebd., S. 175 f., Zitat S. 176.

75 Vgl. Anhang 1, Sachanm. 3.

76 Joseph Klapper (Hg.), Schriften Johanns von Neumarkt, Bd. 2: Hieronymus. Die unechten Briefe des Eusebius, Augustin, Cyrill zum Lobe des Heiligen (Vom Mittelalter zur Reformation 6/2), Berlin 1932. Einige Handschriften sind in mitteldeutscher Schreibsprache gehalten, doch finden sich darunter keine thüringisch-sächsischen Provenienzen; vgl. ebd., S. IX f.; sowie die Angaben unter http://www.handschriften census.de/werke/883 [Zugriff 18. August 2015]. Zu den Hieronymusbriefen auch Joseph Klapper, Johann von Neumarkt, Bischof und Hofkanzler. Frührenaissance in Böhmen zur Zeit Kaiser Karls IV. (Erfurter theologische Studien 17), Leipzig 1964, S. 29 ff.; Jungblut, Hieronymus (wie Anm. 58), S. 60 f., 107; Erika Bauer, Hieronymus-Briefe, in: Die Deutsche Literatur des Mittelalters. Verfasserlexikon, 14 Bde., 
Hieronymusgesellschaft auch an anderen Stellen paraphrasiert. ${ }^{77}$ Die Urkunde stellt damit ein bedeutendes Zeugnis für das Frömmigkeitsprofil, aber auch die Humanismusrezeption am wettinischen Hof dar. Die Tatsache, dass die Formel vom allwissenden Hieronymus in den Jahren um 1500 auch in Meißner Missalien nachweisbar ist, ${ }^{78}$ belegt nachdrücklich ihre Wirkmächtigkeit, wobei die Frage, ob die liturgische Rezeption der Hieronymusbriefe durch die wettinische Hofstiftung begünstigt wurde oder selbstständig erfolgte, an dieser Stelle offenbleiben muss.

Dabei greift die Stiftungsurkunde von 1450 bevorzugt jene Aspekte aus Johanns Werk auf, die für das ritterliche Ideal der Hieronymusgesellschaft vorbildhaft waren. Ohne Zweifel hat die Deutung des Kirchenvaters als vnsers herren Jhesus Christus ritter ond erwelter kempfer ${ }^{79}$ entscheidend dazu beigetragen, dass Kurfürst Friedrich ihn zum Patron seiner Gesellschaft bestimmte. Aber auch die von den Hieronymusbriefen geprägte Darstellung des Heiligen als philologisch gebildeter Gewährsmann des Katholizismus wurde durch die wettinische Kanzlei reflektiert. Hier nun hat der Diktator der Urkunde seine Vorlage an einer entscheidenden Stelle erweitert. Während Johann von Neumarkt die hebräischen, griechischen, arabischen, chaldäischen, persischen, medischen und lateinischen Sprachkenntnisse des Gelehrten preist, sieht ihn der meißnische Notar zusätzlich auch als Kenner der windeschen schrifften (Z. 48). ${ }^{80}$ Der ansonsten unübliche Bezug auf slawische (hier wohl gemeint: tschechische) Sprachkompetenz lässt ahnen, wo der kurfürstliche Stifter die eigentliche Stoßrichtung der Hieronymusgesellschaft sah: Es war die Bekämpfung der Hussiten, die auch in der Mitte des 15. Jahrhunderts ganz oben auf der Agenda der Wettiner stand und neben dem religiösen Aspekt

Berlin 21977-2008, hier Bd. 3, Berlin 1981, Sp. 1233-1238; Werner Höver, Johann von Neumarkt, in: ebd., Bd. 4, Berlin 1983, Sp. 686-695, hier Sp. 688 f.; Hamm, HieronymusBegeisterung (wie Anm. 58), S. 170 ff.; Erika Bauer, Zur Geschichte der „HieronymusBriefe", in: Johannes Janota u. a. (Hg.), Festschrift Walter Haug und Burghart Wachinger, Tübingen 1992, Bd. 1, S. 305-321, hier S. 310 (vor 1295 entstanden).

77 Vgl. Anhang 1, Sachanm. 2, 4, 5.

78 Vgl. ebd., Sachanm. 3.

79 Johann von Neumarkt, Eusebiusbrief, c. 11, ed. Klapper, Schriften 2 (wie Anm. 76), S. 33, Z. 12-14; vgl. ähnlich ebd., c. 16, S. 42, Z. 15-17: wann di wappen vnserr ritterschaft nicht fleichleich, sunder geistleich sint; ebd., Augustinusbrief, c. 1, ed. KlaPPER, Schriften 2 (wie Anm. 76), S. 246, Z. 12-14: des erwirdigen kempfen des beilgen cristenleichen gelawben sant Jeronimus. Hieronymus als Bekämpfer der Ketzer (beretici) begegnet in Johanns Briefbearbeitung immer wieder; vgl. z. B. Eusebiusbrief, c. 108, ed. KLAPPER, Schriften 2 (wie Anm. 76), S. 222 f.

80 Nachweise in Anhang 1, Sachanm. 4. Als Kenner von sieben Sprachen (Hebräisch, Griechisch, Arabisch, Chaldäisch, Lateinisch, Persisch und Medisch) erscheint Hieronymus im deutschsprachigen ,Prosapassional' (entstanden Ende des 14. Jahrhunderts), das hinzufügt: Und kunnt darzu allen Landes und Volkes Buchstaben also vollkommenlich, als ob er in einem jeglichen Land geboren wäre; SEVERIN RÜTTGERs (Hg.), Der Heiligen Leben und Leiden. Anders genannt das Passional, Bd. 1: Winterteil, Leipzig 1913, S. 8; vgl. Konrad Kunze, ,Der Heiligen Leben' (,Prosa'-, ,Wenzel-Passional'), in: Verfasserlexikon (wie Anm. 76), Bd. 3, S. 618-625. 
eine eminent politische Bedeutung in Hinblick auf die schon lange schwelenden sächsisch-böhmischen Konflikte besaß. ${ }^{81}$

Dass der Hieronymuskult für die Wettiner eine dezidiert antihussitische Konnotation besaß, zeigt sich etwa auch in der Wallfahrtskirche von Chemnitz-Ebersdorf. Dort befindet sich bis heute eine Statue des Heiligen, die für einen seit 1465/66 nachweisbaren Hieronymusaltar bestimmt war und bisher als Stiftung des Ebersdorfer Patronatsherrn Dietrich von Harras galt. Mit einiger Wahrscheinlichkeit ist das Stück, das sich auf die Zeit um 1450 datieren lässt und in Burgund entstand, jedoch eine Schenkung Kurfürst Friedrichs II. Sie dürfte während einer Wallfahrt erfolgt sein, die der Landesherr 1455 zum Dank für die Befreiung seiner Söhne aus der Gewalt des Kunz von Kaufungen nach Ebersdorf unternahm. ${ }^{82}$ Mit ihrer Förderung der Ebersdorfer Wallfahrt hatten die Wettiner schon früher eine antihussitische Aussage verbunden. Bereits 1421 ist ein erster Besuch durch die Ehefrau Markgraf Friedrichs IV., Katharina von Braunschweig, bezeugt. 1426 erwirkte ihr Mann einen päpstlichen Ablass für die Kirche. ${ }^{83}$ Kurfürst Friedrich II. erlangte 1437 in Rom eine weitere Indulgenz, die ausdrücklich mit dem Hinweis beantragt wurde, dass man das Gotteshaus in den zurückliegenden Jahren erfolg-

81 Dazu Christoph Volkmar, Reform statt Reformation. Die Kirchenpolitik Herzog Georgs von Sachsen 1488-1525 (Spätmittelalter, Humanismus, Reformation 41), Tübingen 2008, S. 460 ff.; Armin Kohnle, Martin Luther, Johannes Hus und die hussitische Tradition in Sachsen, in: Uwe Fiedler/Hendrik Thoß/Enno Bünz (Hg.), Des Himmels Fundgrube. Chemnitz und das sächsisch-böhmische Gebirge im 15. Jahrhundert, Chemnitz 2012, S. 175-187; Thomas Kaufmann, Der Anfang der Reformation. Studien zur Kontextualität der Theologie, Publizistik und Inszenierung Luthers und der reformatorischen Bewegung (Spätmittelalter, Humanismus, Reformation 67), Tübingen 2012, S. $30 \mathrm{ff}$.

82 Friedrich Staemmler, Die Skulptur des „Schönen Stils“ in der Region Chemnitz. Ihr Bezug zu Böhmen und Schlesien, in: Fiedler/Thoß/Bünz, Des Himmels Fundgrube (wie Anm. 81), S. 241-253, 273-281, hier S. 276. Der Autor zieht ebenfalls Parallelen zur Hieronymusgesellschaft, sieht deren Hintergrund jedoch weiterhin im wettinischen Bruderkrieg. Vgl. auch KATHRIN IsELT, „Feria sexta postquam Martini venit domina ad cenam, do sy geyn Ebersdorff czouch [...].“ Quellen und Legenden zur Wallfahrtsgeschichte der Ebersdorfer Stiftskirche, in: Jan Hrdina/Hartmut Kühne/Thomas T. Müller (Hg.), Wallfahrt und Reformation. Zur Veränderung religiöser Praxis in Deutschland und Böhmen in den Umbrüchen der Frühen Neuzeit (Europäische Wallfahrtsstudien 3), Frankfurt a. M. u. a. 2007, S. 184-199, hier S. 193.

83 Karl August Fink/Sabine Weiss (Bearb.), Repertorium Germanicum. Verzeichnis der in den Registern und Kameralakten vorkommenden Personen, Kirchen und Orte des Deutschen Reiches, seiner Diözesen und Territorien vom Beginn des Schismas bis zur Reformation, Bd. 4, Berlin/Tübingen 1943-1958/1979, hier zitiert nach der Online-Version www.romana-repertoria.net, IV, Nr. 2521 [Zugriff 18. August 2014]; zu Ebersdorf als Gnadenort vgl. zuletzt Barbara Bechter/Wiebre Fastenrath/Heinrich MagiRIUS (Bearb.), Sachsen II. Regierungsbezirke Leipzig und Chemnitz (Georg Dehio. Handbuch der Deutschen Kunstdenkmäler), München/Berlin 1998, S. 21; BIRGIT Franke, Mittelalterliche Wallfahrt in Sachsen. Ein Arbeitsbericht, in: Arbeits- und Forschungsberichte zur sächsischen Bodendenkmalpflege 44 (2002), S. 299-389, hier S. 346 ff.; Iselt, Wallfahrtsgeschichte (wie Anm. 82), S. 185. 
reich gegen die hussitischen Ketzer verteidigt habe. ${ }^{84}$ In dieses Bild passt auch, dass Friedrich II. der Ebersdorfer Kirche die Gewänder seiner beiden 1455 entführten Söhne überließ, war der legendäre ,Altenburger Prinzenraub‘ doch unmittelbar mit den sächsisch-böhmischen Konflikten dieser Tage verquickt. ${ }^{85}$

Die Abwehr des Hussitismus gehörte noch bis in die Reformationszeit hinein zum „kirchenpolitischen Alltag“ der Wettiner. ${ }^{86}$ So wird etwa vermutet, dass auch die Darstellung des heiligen Hieronymus auf der 1516 errichteten Kanzel der Stadtkirche von Annaberg als antihussitische Demonstration gedacht war. Schon bei der Gründung des Gotteshauses verfolgte man das erklärte Ziel, „viele der böhmischen Ketzer in den Gehorsam der Kirche zurückzuführen“, befand sich Annaberg doch in einem Gebiet, das wegen seiner Grenzlage „täglich vom Ansturm der böhmischen Ketzer bedroht war“, wie es Herzog Georg 1508 anlässlich der Beantragung eines Ablasses an der Kurie vortrug. ${ }^{87}$

Auf der 1505 errichteten Tulpenkanzel im Freiberger Marienstift findet sich eine weitere Darstellung des Hieronymus, die als Sinnbild der reinen Lehre interpretiert werden darf. Dieses Gotteshaus, 1489 nach einem Brand wiedererrichtet, galt ebenfalls als Bollwerk des Antihussitismus. ${ }^{88}$ Auch Kardinal Albrecht von

84 So die Supplik Friedrichs II. vom 23. März 1435: que a principibus et nobilibus et habitatoribus partium illarum manu forti ab hereticis regni Bobemie vicini defenditur; ad quam [...] ingens multitudo etiam Bohemorum noviter ad fidem reductorum confluit. Der Ablass wurde am 21. Februar 1437 bewilligt; Hermann Diener/Brigide Schwarz (Bearb.), Repertorium Germanicum (wie Anm. 83), Bd. 5, Tübingen 2004, Nr. 1601. Vgl. dazu Peter Wiegand, Der päpstliche Kollektor Marinus de Fregeno (1457-1482) und die Ablasspolitik der Wettiner. Quellen und Untersuchungen (Quellen und Materialien zur sächsischen Geschichte und Volkskunde 5), Leipzig 2015, S. 47, 95 f.; ferner HeInRICH Magirius, Die Stiftskirche zu Ebersdorf und ihr romanischer Vorgängerbau, in: Wissenschaftliche Zeitschrift der Karl-Marx-Universität Leipzig. Gesellschafts- und Sprachwissenschaftliche Reihe 12 (1963), S. 407-427, hier S. 418.

85 Uwe Tresp, Die Spur führt nach Böhmen. Der Prinzenraub im Kontext der sächsischböhmischen Beziehungen um die Mitte des 15. Jahrhunderts, in: Joachim Emig (Hg.), Der Altenburger Prinzenraub 1455. Strukturen und Mentalitäten eines spätmittelalterlichen Konflikts (Saxonia. Schriften des Vereins für sächsische Landesgeschichte 9; Mitteilungen der Geschichts- und Altertumsforschenden Gesellschaft des Osterlandes, Sonderband), Beucha 2007, S. 195-217.

86 Volkmar, Reform (wie Anm. 81), S. 461, vgl. auch S. 567 f.

87 Felician Gess (Hg.), Akten und Briefe zur Kirchenpolitik Herzog Georgs von Sachsen, Bd. 1: 1517-1524 (Schriften der Königlich Sächsischen Kommission für Geschichte 10), Leipzig/Berlin 1905, S. LXXX, Anm. 1: multos Boemos scismaticos ad obedientiam sanctae Romanae ecclesiae inde reversuros; oppidum istud in confinibus Boemie collocatum sit adeo quod incursiones Boemeorum et scismaticorum dietim pertimescere habet; vgl. Volkmar, Reform (wie Anm. 81), S. 143, 370 mit Anm. 128.

88 So Papst Innocenz VIII. in seinem Fastendispens für das Freiberger Marienstift; HuberT ERmisch (Hg.), Urkundenbuch der Stadt Freiberg in Sachsen, Bd. 1 (Codex diplomaticus Saxoniae regiae II/12), Leipzig 1883, Nr. 789: quod ipse Albertus dux predecessorum suorum laudabilia vestigia imitatus perfidam rabiem et impios conatus beretoricum Bohemorum [...] omni studio omnique conatu [...] reprimere non cessavit, [...] verum etiam ecclesiam tunc parrochialem beate Marie virginis [...] in collegiatam ecclesiam cum uno decano et duodecim canonicis [...] eligi [recte erigi] procuravit, ut [...] 
Brandenburg berief sich auf Hieronymus, als er sich zwischen 1525 und 1527 viermal von Lukas Cranach d. Ä. und seiner Werkstatt in Gestalt des Heiligen darstellen ließ. Die Identifikationsporträts sollten den Erzbischof als Wahrer der Autorität der Kirche zeigen, der sich als Vertreter erasmianischer Gelehrsamkeit damals gegen die übersetzerische Interpretation des Neuen Testaments durch Luther wendete. ${ }^{89}$ Hier klingen insofern antihussitische Tendenzen an, als die Lehre des Reformators in den Kreisen um Herzog Georg von Sachsen als Ausdruck utraquistischen Gedankenguts galt. ${ }^{90}$ Welche Bedeutung der heilige Kirchenvater für die persönliche Frömmigkeit der Wettiner besaß, spiegelt sich ferner darin, dass einem Zeugnis Luthers zufolge einer der nicht ehelichen Söhne Friedrichs des Weisen den Namen Hieronymus trug. ${ }^{91}$

Die antihussitische Zielrichtung der Hieronymusgesellschaft wird schließlich auch in einer Bemerkung der Gründungsurkunde deutlich, der zufolge Kurfürst Friedrich II. mit seiner Stiftung einen Kampf fortsetzen wolle, den bereits seine Vorfahren begonnen hatten (Z. 92-94). Hier wird auf die seit 1420 unter maßgeblicher Beteiligung des späteren Kurfürsten Friedrich I. geführten Hussitenkriege angespielt, die Grundlage für die Übertragung der sächsischen Kurwürde an die Wettiner (1423) waren und deren politisches Selbstverständnis auf Jahrzehnte hin prägten. Letztlich zielte auch die Wortdevise der Gesellschaft $O$ wie groß ist der gloube, den der heylige sent Ieronimus gelert hat unde gepredigt (Z. 81 f.), die erneut einen stilistischen Anklang an die Schriften des Johann von Neumarkt bietet, ${ }^{92}$ darauf, den Einsatz für die Orthodoxie als Leitmotiv herauszustellen. Bemerkenswert ist in diesem Zusammenhang, dass die Hieronymusverehrung in den Jahren um 1500 auch im Umkreis der Familie von Bünau verbreitet war, aus der zwei Mitglieder der wettinischen Hofstiftung kamen. ${ }^{93}$

fideles in ecclesie unitate ac orthodoxe fidei firmitate [...] roborent et stabiliant ac subdolis fraudibus et erroribus dictorum hereticorum resistant. Der Dispens galt für jeden, der mit Spenden zum Wiederaufbau der Kirche beitrug. Die Indienstnahme der Spenden für den Hussitenkampf wurde zum Gegenstand zeitgenössischer Kritik; vgl. dazu Helmut Petzold, Der Streit um die Freiberger ,Butterbriefe‘. Vorreformatorische Widerstände gegen das Ablaßwesen im Bistum Meißen, in: Franz Lau (Hg.), Das Hochstift Meißen. Aufsätze zur sächsischen Kirchengeschichte (Herbergen der Christenheit, Sonderband 1), Berlin 1973, S. 147-164, hier S. 150.

ANDREAS TACKE, Albrecht als heiliger Hieronymus. Damit ,der Barbar überall dem Gelehrten weiche!', in: Ders. (Hg.), Der Kardinal. Albrecht von Brandenburg, Renaissancefürst und Mäzen. Eine Ausstellung anlässlich des 1200jährigen Jubiläums der Stadt Halle an der Saale [...], Bd. 2, Regensburg 2006, S. 116-129; zum Hintergrund auch Jungblut, Hieronymus (wie Anm. 58), S. 90 ff.; Rice, Saint Jerome (wie Anm. 59), S. $137 \mathrm{ff}$.

90 Vgl. dazu Volkmar, Reform (wie Anm. 81), S. 577 ff.

91 Ludolphy, Friedrich der Weise (wie Anm. 23), S. 50.

92 Ähnlich exklamatorische Formulierungen finden sich auch dort; vgl. Anhang 1, Sachanm. 6.

93 Freundlicher Hinweis von Herrn Prof. Dr. Joachim Schneider (Dresden): Darstellungen des Heiligen finden sich in verschiedenen Besitzungen der Bünaus, so auf dem im ersten Drittel des 16. Jahrhunderts gestalteten Mönchsboden auf Schloss Weesenstein (1406 
So dürfte ein Vorbild der Hieronymusgesellschaft die societas draconis gewesen sein, die Sigismund von Luxemburg als ungarischer König 1408 gestiftet hatte. Seit 1409 auch für andere Fürsten offen, diente sie besonders dazu, die militärischen Kräfte in den Hussitenkriegen zu bündeln. In ihrer exklamatorischen Stilistik erinnert ihre Devise (O quam misericors est Deus iustus et pius) ${ }^{94}$ stark an die der Hieronymusgesellschaft. Als Gefolgsmann Sigismunds und einer der Köpfe des Hussitenkampfs gehörte Kurfürst Friedrich I. von Sachsen diesem Orden an, ${ }^{95}$ der noch von den Königen Albrecht II. und Friedrich III. sowie zuletzt von Matthias Corvinus verliehen wurde. Auch der österreichische Adlerorden (1433) war ursprünglich gegen die Hussiten gerichtet und kann in diesem Sinn als Vorläufer der wettinischen Hofstiftung gelten. ${ }^{96}$

Brigitte Streich hat als Zweck der Stiftung Friedrichs II. die Bildung einer loyalen Gefolgschaft im wettinischen Bruderkrieg vermutet und ihren Rekurs auf die Idee des Hussitenkampfs angesichts der bereits lange zurückliegenden Reichskriege als vorgeschoben bezeichnet. Nach dem Vertrag von Naumburg habe die Gesellschaft daher ihre Daseinsberechtigung verloren. ${ }^{97}$ Die Deutung ist insofern nachvollziehbar, als sich der wettinische Kurfürst im Bruderkrieg auch mit den böhmischen Verbündeten Herzog Wilhelms III. auseinanderzusetzen hatte. ${ }^{98}$ So spricht die Tatsache, dass sich unter den Mitgliedern der Hieronymusgesellschaft einige enge Verbündete Friedrichs aus der Zeit des Bruderkriegs finden, ${ }^{99}$ durchaus dafür, dass er seine Hofstiftung zunächst als Kampfgemeinschaft für diesen Konflikt errichtete und deren militärisch-politische Aufgabe geschickt mit der Verfolgung der böhmischen Ketzer verbrämte. Nachdem die Quellen jedoch eine längere Fortexistenz der Einung belegen und ihre Bestätigung durch den Bischof von Meißen am 1. Januar 1460 als der Versuch einer Neubelebung interpretiert werden muss, kommt ihrer antihussitischen Stoßrichtung offenbar eine größere und länger wirkende Bedeutung zu als bisher angenommen.

bis 1772 im Besitz der Bünaus), dem Altar der Bartholomäuskirche in Droyßig (1414 bis 1578 im Besitz der Bünaus) und dem um 1520 entstandenen Flügelaltar der Pfarrkirche in Geising (1945 zerstört); Andrea Dietrich/Birgit Finger/Lutz Hennig, Adel ohne Grenzen. Die Herren von Bünau in Sachsen und Böhmen, Dößel 2006, S. 60, 62; Ingo SAndner, Spätgotische Tafelmalerei in Sachsen, Dresden/Basel 1993, S. 344; Ute Bednarz/Folkhard Cremer/Hans-Joachim Krause (Bearb.), Sachsen-Anhalt II. Regierungsbezirke Dessau und Halle (Georg Dehio. Handbuch der deutschen Kunstdenkmäler), München 1999, S. 166.

Vgl. oben Anm. 13 und 22.

95 Wie Anm. 22.

96 Vgl. oben Anm. 17.

97 Streich, Hof (wie Anm. 11), S. 177; vgl. auch oben Anm. 26.

98 Tresp, Spur (wie Anm. 85), S. 207 ff.; Rogge, Herrschaftsweitergabe (wie Anm. 27), S. 201.

99 Das im Anhang edierte Verzeichnis nennt sie an vorderer Stelle; Anhang 2, Nr. 4 (Georg von Anhalt), 6 (Heinrich IX., Herr zu Greiz), 7 (Friedrich II. von Dohna zu Auerbach), 8 (Heinrich XIX. von Weida), 10 (Heinrich von Bünau zu Weesenstein), 11 (Dietrich von Miltitz ?), 12 (Jan von Schleinitz), 13 (Georg von Bebenburg), 17 (Hans Metzsch). 
Als Symbol für die stetigen Konflikte Sachsens mit der böhmischen Krone war die hussitische Bedrohung in den wettinischen Landen auch in den Jahren nach 1450 präsent. Die in erster Linie lehnsrechtlich begründeten Zwistigkeiten, die man 1454 und 1455 auf diplomatischem Weg zu schlichten versuchte, eskalierten 1457 und 1458, als sich Wilhelm III. mit der Unterstützung seines kurfürstlichen Bruders um die Nachfolge des verstorbenen Böhmenkönigs Ladislaus Postumus bemühte. ${ }^{100}$ Dabei verbanden die Wettiner politische Eigeninteressen geschickt mit der gegenüber Papst, Kaiser und Reichsfürsten vorgegebenen Absicht, die utraquistische Bewegung bekämpfen zu wollen. Über die Konstellation des 1451 beigelegten Bruderkriegs hinaus bestanden also auch längerfristig gute Gründe, die Hieronymusgesellschaft als antihussitische Kampfgemeinschaft zu deklarieren, die im Bedarfsfall als militärisches Instrument zur Verfügung stand. Dass eine höfische Adelseinung gezielt als Machtfaktor in politischen Konflikten eingesetzt werden konnte, zeigt das Beispiel des kurpfälzischen Ordens vom Pelikan, den Ludwig IV. von der Pfalz unmittelbar nach seiner Gründung 1444101 in ein Bündnis mit der französischen Krone einbezog. An diesem waren auch die Wettiner beteiligt, konnten also die pragmatische Funktion einer Hofstiftung bei dieser Gelegenheit aus direkter Anschauung beobachten. ${ }^{102}$ So dürfte insbesondere auch dem Pelikan eine Vorbildrolle für die Hieronymusgesellschaft zugekommen sein.

\section{Die Hieronymusgesellschaft als Instrument zur Formierung und Integration adliger Funktionseliten}

Die enge Bindung der Hieronymusgesellschaft an den Hof des sächsischen Kurfürsten kommt nicht zuletzt darin zum Ausdruck, dass als Ort der Mitgliederversammlungen und des liturgischen Gedenkens die Fürstenkapelle des Meißner Doms bestimmt war. Diese spielte damit eine ähnliche Rolle wie das Heidelberger Heiliggeiststift für den kurpfälzischen Pelikan oder das Marienstift auf dem Harlungerberg bei Brandenburg und die Georgskapelle des Gumpertstifts in Ansbach

100 Vgl. hierzu Wiegand, Marinus de Fregeno (wie Anm. 84), S. 45 ff.

101 STORN-JaschKowitz, Gesellschaftsverträge (wie Anm. 1), S. 97.

102 Ratifiziert im Bündnisvertrag zwischen Karl VII., Kurfürst Friedrich II. und Herzog Wilhelm III. von Sachsen (Nancy, 23. Februar 1445); gedruckt bei WALTER KäMMERER (Hg.), Deutsche Reichstagsakten unter Kaiser Friedrich III., 3. Abteilung: 1442-1445 (Deutsche Reichstagsakten 17), Göttingen 1963, S. 693-699 (Nr. 325); vgl. dazu HeINZDieter Heimann, Zwischen Böhmen und Burgund. Zum Ost-Westverhältnis innerhalb des Territorialsystems des Deutschen Reiches im 15. Jahrhundert, Köln/Wien 1982, S. 94 ff., 111 ff., hier besonders S. 130 f.; Ders., Die „auswärtige“ Politik der Wettiner und ihre Herrschaftsbeziehungen zum Haus Habsburg, zu Burgund und in die Niederlande im späteren Mittelalter, in: Dieter Berg/Martin Kintzinger/Pierre Monnet (Hg.), Auswärtige Politik und internationale Beziehungen im Mittelalter (13.-16. Jahrhundert) (Europa in der Geschichte 6), Bochum 2002, S. 197-221, hier S. 202 ff. 
für den brandenburgischen und fränkischen Zweig des Schwanenordens. ${ }^{103}$ Nachdem der Meißner Dom bereits im 13. Jahrhundert als wichtige Kultstätte des wettinischen Hofs fungierte, ${ }^{104}$ diente insbesondere die von Markgraf Friedrich IV. vielleicht schon um 1415, möglicherweise aber auch erst nach 1423 gestiftete, am Westende des Langhauses errichtete Fürstenkapelle als Grablege der Herrscherdynastie und als „religiöses Zentrum auch für die Mitglieder des Hofstaates“. ${ }^{105} \mathrm{Um}$ 1445 waren die Bauarbeiten vollendet. Damals vollzogen Kurfürst Friedrich II. und sein Bruder Wilhelm die vom Vater geplanten Stiftungen, gründeten neben dem Hauptaltar, geweiht Maria und den Heiligen Drei Königen, einen Altar der heiligen Anna, Viktor und Mauritius und erhöhten die Zahl der Priester auf sieben. ${ }^{106}$ Dem entspricht die Stiftungsurkunde der Hieronymusgesellschaft, der zufolge die Fürstenkapelle durch Friedrich II. gebuwet, gestifft und uffgebracht worden sei (Z. 134 f.).

Der Bau war also bereits seit geraumer Zeit fertiggestellt, als der Kurfürst den Entschluss zur Errichtung seiner Hofstiftung und zur Dotierung eines weiteren Altars für deren Titelheiligen fasste. ${ }^{107}$ Als geistiges Zentrum der Hieronymus-

103 Zur Rolle des Marienstifts als Zentrum des brandenburgischen Zweigs des Schwanenordens vgl. Stillfried/Haenle, Buch vom Schwanenorden (wie Anm. 19), S. 1 f.; ferner Gregor Seebacher/Christian Gahlbeck, Brandenburg/Havel. Prämonstratenserstift St. Marien auf dem Harlungerberg, in: Heinz-Dieter Heimann u. a. (Hg.), Brandenburgisches Klosterbuch. Handbuch der Klöster, Stifte und Kommenden bis zur Mitte des 16. Jahrhunderts (Brandenburgische Historische Studien 14), Bd. 1, Berlin 2007, S. 307-328, hier S. 309; dazu auch Heydenreich, Ritterorden (wie Anm. 11), S. 50 f.; zum Pelikan oben Anm. 52.

104 BrigitTe Streich, Öffentlich inszenierte und private Frömmigkeit. Die Sakralkultur am wettinischen Hof, in: Werner Rösener/Carola Fey (Hg.), Fürstenhof und Sakralkultur im Spätmittelalter (Formen der Erinnerung 35), Göttingen 2008, S. 159-194, hier S. 163 f.; Dies., Sepultus in Wymaria (wie Anm. 26), S. 258 ff.

105 Streich, Hof (wie Anm. 11), S. 290; vgl. auch Dies., Sepultus in Wymaria (wie Anm. 26), S. 260 ff., 265 f.; ferner Susanne Baudisch/Reinhard Butz/Brigitte Streich, Meißen, in: Paravicini, Höfe (wie Anm. 14), Teilband 2: Residenzen, S. 371-376, hier S. 374. Zur Bedeutung der Fürstenkapelle als wettinisches Kultzentrum auch HeINRICH Magirius, Zur kultur- und kunstgeschichtlichen Bedeutung der Fürstenkapelle, in: Elisabeth Hütter u. a., Das Portal an der Westturmfront und die Fürstenkapelle (Forschungen zur Bau- und Kunstgeschichte des Meißner Domes 1), Halle 1999, S. 227-260, hier S. 228, 232; Ders., Zur Entstehung und Bedeutung der Fürstenkapelle am Meißner Dom, in: Ecclesia Misnensis. Jahrbuch des Dombau-Vereins Meißen 2001, S. 23-31, hier S. 23, $29 \mathrm{f}$.

106 Ernst Gotthelf Gersdorf (Hg.), Urkundenbuch des Hochstifts Meißen, Bd. 3 (Codex diplomaticus Saxoniae regiae II/3), Leipzig 1867, Nr. 993, 998, 1026; HeInRICH Magirius, Die schriftlichen Quellen zur Baugeschichte und zur liturgischen Nutzung der Westtürme und der Fürstenkapelle, in: Hütter, Portal (wie Anm. 105), S. 205-214, hier S. 207 f.; Ders., Bedeutung (wie Anm. 105), S. 249 mit Abb. 348.

107 Dessen ursprüngliche Ausstattung ist nicht bekannt. Er befand sich vermutlich links oder rechts vom Domportal; Maginius, Quellen (wie Anm. 106), S. 207 f.; MatTHias Donath, Die Altäre im Meißner Dom im Zeitraum von 1250 bis 1550 (Nachtrag), in: Monumenta Misnensia. Jahrbuch für Dom und Albrechtsburg zu Meißen 2003/04, S. 13-23, hier S. 19; ein Augustinus-Hieronymus-Altar bestand im Dom bereits seit dem Pontifikat Bischof Johanns von Eisenberg (1342-1370), ein Hieronymus-Katharinen- 
gesellen wurde dieser später mehrfach von Persönlichkeiten bestiftet, die dem Hof nahestanden. So bestätigte Friedrich II. am 14. August 1456 eine zweite Hieronymusvikarie, die der Bautzner Dompropst und Meißner Domkanoniker Lamprecht von Seehausen ausgestattet hatte, und legte fest, dass beide Altaristen die täglichen Messen künftig gemeinsam lesen sollten. Das Verleihrecht für die beiden Altarpfründen lag, wie ein aus der Mitte des 16. Jahrhunderts stammendes Verzeichnis der Kapellen und Vikarien im Meißner Dom bezeugt, beim Kurfürsten. ${ }^{108}$ Der besondere Charakter der Stiftung von 1456 ergibt sich aus der Person des Dotators, handelte es sich bei diesem doch, wie die Konfirmationsurkunde ausdrücklich hervorhebt, um einen langährigen Mitarbeiter der wettinischen Kanzlei. Für ihn dürfte das Privileg, neben der kurfürstlichen Vikarie eine weitere zu begründen, eine besondere Auszeichnung dargestellt haben. ${ }^{109}$

Auch dass die Stiftung Lamprechts durch den Kanzler, den Obermarschall und den landesherrlichen Rat Heinrich X. Reuß von Plauen bezeugt wurde, 110 belegt den höfischen Kontext des Altars, für den bei dieser Gelegenheit auch Georg, Christophorus, Bartholomäus, alle Heiligen und das gancze bymmelische her als Konpatrozinien genannt werden. Für Lamprecht, der als Kleriker kein Mitglied der Hieronymusgesellschaft werden konnte, bot die Dotierung ihres Altars eine Möglichkeit, seine Verbundenheit in anderer Form zum Ausdruck zu bringen. Auch bei weiteren Stiftern ist anzunehmen, dass sie mit der Förderung des Hieronymusaltars ihre besondere Hofnähe unterstreichen wollten. Dies gilt etwa für den kurfürstlichen Vasallen Kurt von Köckritz zu Elsterwerda, der dem Altaristen Dionysius Knorre am 25. Mai 1457 mit ausdrücklicher Zustimmung des Kurfürsten eine Rente von sieben rheinischen Gulden in Merzdorf verkaufte. ${ }^{111}$ Zwei Angehörige der Familie von Köckritz sind später als Mitglieder der Hieronymusgesellschaft nachweisbar. ${ }^{112}$

altar seit Februar 1419 (Stiftung des Dekans Johann Poczte und des Theologieprofessors Nicolaus Czoboth de Gubin), hierzu Gersdorf, Urkundenbuch Hochstift Meißen 3 (wie Anm. 106), Nr. 900; vgl. Donath, Meißner Dom, a. a. O., S. 15, 17 f. Die Vikarie des letzteren war mit dem Amt des Dompredigers verbunden; der Altar lag nahe am Grab des heiligen Benno; wie folgende Anm.

108 Friedrich Konrad Grundmann, Collectaneen zur Geschichte des Bistums Meißen, Bd. 2, Ms., um 1770, Bl. 70v-71r, 72v (HStA Dresden, Bibliothek, AA 982b).

109 Gersdorf, Urkundenbuch Hochstift Meißen 3 (wie Anm. 106), Nr. 1035: Vff vnserm altar sent Jeronimi in vnser capellen zcu Missen an der thumkirchen doselbs gelegen [...], das er sulche ewige vicaria bey vnde nebin vnser vicarian [...] $v$ ßgeseczen vnde gestifften muge; vgl. dazu Magirius, Quellen (wie Anm. 106), S. 208. Die im Zusammenhang mit der Gesellschaftserrichtung 1450 vollzogene Stiftung ist dort zu ergänzen. Vgl. auch Streich, Sepultus in Wymaria (wie Anm. 26), S. 265 f.

110 Heinrich der Jüngere, Herr zu Greiz, 1449 als kurfürstlicher Rat belegt; vgl. BERTHOLD Sснміdт, Die Reußen. Genealogie des Gesamthauses Reuß älterer und jüngerer Linie, Schleiz 1903, Tafel 6, Nr. 26.

111 Gersdorf, Urkundenbuch Hochstift Meißen 3 (wie Anm. 106), Nr. 1038: Dionysius Knorren, vicarien des altars sancti Jeronimi in der nuwen cappellen gelegen an der tumkirchen zcu Missen. Gemeint ist Merzdorf südlich von Elsterwerda (Kreis ElbeElster).

112 Anhang 2, Nr. 19, 20. 
Realzeugnisse der Frömmigkeitspraxis wie etwa die Wappenschilde der verstorbenen Mitglieder, die in der Fürstenkapelle aufgehängt werden sollten, haben sich anscheinend nicht erhalten. Die noch im 17. Jahrhundert sichtbare Ausmalung des Kapellengewölbes mit dem wettinischen Haus- und anderen Wappen zeigt, dass hierfür ein passender ikonografischer Rahmen bereitgestanden hätte. ${ }^{113}$ Die Konsolen der an der Kapellenwand aufgestellten Skulpturen waren wohl ebenfalls zur Anbringung von Wappen gedacht. Bereits 1489 soll die Kapelle so voll gewesen sein, dass für eine Vikariestiftung Kurfürst Ernsts kein neuer Altar mehr errichtet werden konnte, was auf eine insgesamt reiche Ausstattung hindeutet. ${ }^{114}$ Für eines der führenden Mitglieder der Hieronymusgesellschaft, Herzog Albrecht von Sachsen, veranstaltete man während seiner Beisetzung im Meißner Dom am 25. Januar 1501 zwar einen Wappenaufzug, doch ist eine Verbindung zur Gesellschaft hierbei nicht zu erkennen, da der zeitgenössische Bericht die Vorgänge in der Fürstenkapelle nicht näher kommentiert. ${ }^{115}$

Außer den erwähnten Nachrichten über die Dotierung des Hieronymusaltars gab es bisher keine Hinweise auf die weitere Entwicklung der Gesellschaft. Aus den im Anhang publizierten Archivalien ist zu ersehen, dass die Hofstiftung in der ersten Dekade ihres Bestehens zwar einige Mitglieder gewonnen, offenbar aber nicht den von ihrem Gründer erhofften Aufschwung genommen hatte. Darauf deutet hin, dass man Ende 1459 am kurfürstlichen Hof einige Maßnahmen zu ihrer Aufwertung traf. So bestätigte Bischof Caspar von Meißen am 1. Januar 1460 die Stiftung von Gesellschaft und Altar und gewährte jedem Mitglied, das seine Gebetspflichten erfüllte, einen Ablass von 40 Tagen. Dieser wurde auf all jene ausgedehnt, die an den Mess- und Begräbnisfeiern der Einung teilnahmen. Frauen wurden hier ausdrücklich einbezogen (Z. 205-212). Eine päpstliche Konfirmation der Gesellschaft, wie sie 1450 geplant war, ${ }^{116}$ scheint freilich auch jetzt nicht erfolgt zu sein.

Hier wird die Absicht erkennbar, das personelle Netzwerk der wettinischen Hofgesellschaft über den engeren Kreis der Mitglieder hinaus zu erweitern. Wäre ihr ein längeres Leben beschieden gewesen, hätte sie eine ähnliche Entwicklung

113 Magirius, Bedeutung (wie Anm. 105), S. 250. Sollten tatsächlich Schilde verstorbener Hieronymusgesellen in die Fürstenkapelle gelangt sein, dürfte es sich um heraldische Totenschilde gehandelt haben, wie sie im Fall der Ordenskapelle des fränkischen Zweigs des Schwanenordens in St. Gumpert in Ansbach aus der zweiten Hälfte des 15. Jahrhunderts erhalten sind; vgl. dazu unten Anm. 150.

114 Michael Kirsten, Die Bildwerke, in: Hütter, Portal (wie Anm. 105), S. 261-285, hier S. 282. Kirsten geht von Wappen wettinischer Herrschaften aus.

115 Wilhelm Loose, Das Begängnis des Herzogs Albrecht im Dom zu Meißen, in: Mitteilungen des Vereins für Geschichte der Stadt Meissen 4 (1897), S. 38-45; STREICH, Hof (wie Anm. 11), S. 113 f.; zuletzt Babendererde, Sterben (wie Anm. 55), S. 152 f.

116 Vgl. Anhang 1, Textanm. z; zu Caspar von Schönberg vgl. Matthias Donath, Domherren und Bischöfe aus dem Adelsgeschlecht von Schönberg, in: Monumenta Misnensia. Jahrbuch für Dom und Albrechtsburg zu Meißen 9 (2009/10), S. 6-19, hier S. 9 f.; Ders., Rotgrüne Löwen. Die Familie von Schönberg in Sachsen (Adel in Sachsen 4), Meißen 2014, S. 96 f., 285 ff. 
nehmen können wie der Schwanenorden und andere Schwureinungen, die zunächst eine begrenzte Mitgliederzahl besaßen, aus politischem Kalkül aber bald stark ausgeweitet wurden. ${ }^{117}$ Tatsächlich ist es dazu nicht gekommen. Eine so beachtliche Mitgliederzahl, wie sie etwa die hohenzollerische Hofstiftung aufwies, hat die Hieronymusgesellschaft nie erreicht. Ihre Dimension lässt sich eher mit limitierten Einungen wie dem kurpfälzischen Pelikan (30 Mitglieder) ${ }^{118}$ vergleichen, wenngleich ihre Mitgliederzahl formell nicht beschränkt war. Ungeachtet dessen belegen die Quellen, dass auch die wettinische Hofstiftung neben ihrer bruderschaftlichen Funktion vor allem auf die herrschaftliche Integration des landsässigen und landfremden Adels zielte. Ersichtlich wird dies aus einem bislang unbekannten Mitgliederverzeichnis (Anhang 2) mit insgesamt 41 Namen, das wohl im Kontext der bischöflichen Bestätigung von 1460 entstand. ${ }^{119}$

Dieses zeigt, dass Friedrich II. damals bereits einige benachbarte hochadlige Dynasten und Herren, überwiegend jedoch Angehörige der wettinischen Ehrbarmannschaft, darunter wichtige Funktionsträger aus der Hof-, Zentral- und Ämterverwaltung, in die Gesellschaft aufgenommen hatte. Nach dem Kurfürsten und seinen Söhnen Ernst und Albrecht nennt die nach Rang gegliederte Liste an erster Stelle Georg I. von Anhalt-Zerbst, gefolgt von Bernhard von Barby und Heinrich IX., Vogt von Plauen, Herren zu Greiz, danach Burggraf Friedrich II. von Dohna zu Auerbach, Heinrich XVIII., Vogt von Weida, sowie Matthias Schlick von Lazan, Burggraf von Cheb (Eger) und Loket (Elbogen), der sich als Aufsteiger am Ende dieser Gruppe findet. ${ }^{120}$ Diese Herrschaftsträger - die drei letztgenannten werden ausdrücklich als „Herren“ bezeichnet - standen sämtlich im Fokus des wettinischen Hegemoniestrebens, nahmen als Inhaber von Reichslehen wie die Grafen von Barby-Mühlingen ${ }^{121}$ oder böhmisch-meißnische Doppelvasallen wie die von Dohna aber eine besondere Stellung ein. ${ }^{122}$

Damit erfüllte die Einung eine dezidiert herrschaftssichernde Funktion, waren ihre Mitglieder doch zu besonderer Loyalität gegenüber dem sächsischen Kurfürs-

117 RANFT, Ritterorden und Rittergesellschaften (wie Anm. 4), S. 102.

118 STORn-Jaschkowitz, Gesellschaftsverträge (wie Anm. 1), S. 63 f.

119 Als Terminus ante quem seiner Niederschrift ist 1464, das Todesjahr des Stifters, anzunehmen, da dieser als lebend aufgeführt ist.

$120 \mathrm{Zu}$ Matthias Schlick, Bürgersohn aus Cheb und Bruder des Reichskanzlers Kaspar Schlick, der 1447 von den Wettinern mit der Herrschaft Stollberg belehnt und ab 1454 zu den Grafen und Herren gerechnet wurde, vgl. SchneIder, Dynastengeschlechter (wie Anm. 9), S. 7 f. Nach dem Verlust Stollbergs (1473) verschwand Schlick wieder aus der wettinischen Vasallität.

$121 \mathrm{Zu}$ ihnen Eberhard Holtz, Politische Kräfte und politische Entwicklungen in Mitteldeutschland während des 14./15. Jahrhunderts, in: Peter Moraw (Hg.), Akkulturation und Selbstbehauptung. Studien zur Entwicklungsgeschichte der Lande zwischen Elbe/ Saale und Oder im späten Mittelalter (Berichte und Abhandlungen der Berlin-Brandenburgischen Akademie der Wissenschaften, Sonderband 6), Berlin 2001, S. 287-309, hier S. 299 f., $302 \mathrm{f}$.

122 Schneider, Dynastengeschlechter (wie Anm. 9), S. 15 ff., 20 ff.; Lothar Graf zu Dohna, Die Dohnas und ihre Häuser. Profil einer europäischen Adelsfamilie, 2 Bde., Göttingen 2013, hier Bd. 1, S. 51 ff., 67 ff., 113 ff. 
ten verpflichtet. ${ }^{123}$ Die Tatsache, dass Friedrich II. bevorzugt solche Dynasten aufgenommen hatte, die wie die Vögte von Plauen und Weida in der Konfliktzone zwischen Sachsen und Böhmen zu verorten sind, unterstreicht die spezifische Bedeutung der Stiftung für die Politik der Wettiner gegenüber dem benachbarten Königreich. So ist bezeichnend, dass als Mitglied der Hieronymusgesellschaft Friedrich II. von Dohna zu Auerbach begegnet, der im Bruderkrieg auf Seiten des Kurfürsten stand, nicht aber Friedrich I. von Dohna zu Wildstein (Vlčtejn, südlich Pilsen/Plzeń, † 1457), seinerzeit einer der wichtigsten Anhänger Herzog Wilhelms III. ${ }^{124}$ Mit Matthias Schlick fand sich in der Einung ein weiterer „Sachwalter wettinischer Interessen in Böhmen“.125

Im Anschluss an die Grafen und Herren führt die Mitgliederliste 32 niederadlige Vasallen des Kurfürsten auf, unter ihnen einige Räte und Inhaber von Hofämtern wie Heinrich von Bünau zu Weesenstein, Obermarschall Jan von Schleinitz, Untermarschall Hans Löser, die späteren Untermarschalle Hans Metzsch und Bernhard von Schönberg sowie den Hofmeister der Herzöge Albrecht und Ernst, Hug von Taubenheim. Ein Name - Engelhart Thoß - wurde später gestrichen. Die Aufstellung weist eine große Übereinstimmung mit verschiedenen Aufgebots- und Steuerverzeichnissen der kurfürstlichen Kanzlei auf, darunter vor allem mit zwei Aufgebotslisten von 1454 und 1460 sowie einem Steueranschlag von 1460, was die Vermutung stützt, dass sie etwa gleichzeitig mit der Bestätigung der Hieronymusgesellschaft durch Caspar von Meißen entstand. ${ }^{126}$ Einige der

123 Vgl. oben bei Anm. 51; dazu allgemein Heydenreich, Ritterorden (wie Anm. 11), S. 48; VETTER, Ritterorden (wie Anm. 34), S. 17 ff.

124 Heinz-Dieter Heimann/Uwe Tresp (Hg.), Thüringische und böhmische Söldner in der Soester Fehde. Quellen zum landesherrlichen Militärwesen im 15. Jahrhundert aus thüringischen und sächsischen Archiven (Quellen und Studien zur Geschichte und Kultur Brandenburg-Preußens und des Alten Reiches 8), Potsdam 2002, S. 7; UwE Tresp, Ein Beispiel für Anwerbung, Kosten und Rechtspraxis böhmischer Söldner in der Mitte des 15. Jahrhunderts. Die böhmischen Söldner Herzog Wilhelms III. von Sachsen, in: Mediaevalia Historica Bohemica 8 (2001), S. 168-201, hier S. 180 ff.; Ders., Spur (wie Anm. 85), S. 213; zuletzt Dohna, Die Dohnas (wie Anm. 122), Bd. 1, S. 79, 115. Zu Friedrich von Auerbach Anhang 2, Nr. 7.

125 Uwe Tresp, Zwischen Böhmen und Reich, Ständen und Königtum. Integration und Selbstverständnis der Grafen Schlick in Böhmen um 1500, in: Eva Schlotheuber/ Hubertus Seibert (Hg.), Böhmen und das Deutsche Reich. Ideen- und Kulturtransfer im Vergleich (13.-16. Jahrhundert) (Veröffentlichungen des Collegium Carolinum 116), München 2009, S. 177-202, hier S. 195.

126 Thüringisches Hauptstaatsarchiv Weimar, Ernestinisches Gesamtarchiv, Reg. R, Bl. 55b XIV Nr. 9, Bl. 10v-12r (Aufgebotsverzeichnis, 1454); ebd., Nr. 11, Bl. 2r-5b (Aufgebotsverzeichnis, 1460); HStA Dresden, 10005 Hof- und Zentralverwaltung der Wettiner (Wittenberger Archiv), Loc. 4374/1, Bl. 6r-16r, hier Bl. 12v-16r (vom Landrentmeister Hans von Mergenthal eigenhändig verfasster Steueranschlag, 1460); vgl. dazu JoAchim Schneider, Spätmittelalterlicher deutscher Niederadel. Ein landschaftlicher Vergleich (Monographien zur Geschichte des Mittelalters 52), Stuttgart 2003, S. 86, $397 \mathrm{ff}$. Eine größere Zahl von Hieronymusgesellen findet sich auch in Aufgebotsverzeichnissen der Jahre zwischen 1473 und 1482; HStA Dresden, 10024 Geheimer Rat (Geheimes Archiv), Loc. 7997/3; vgl. ferner das Tranksteuerausschreiben von 1470; 
Ehrbarmannen - Heinrich von Bünau, Dietrich von Miltitz, Jan von Schleinitz, Obermarschall Georg von Bebenburg und Nickel von Wolffersdorff - sind durch das Prädikat „Herr“ von den übrigen Mannen abgehoben. In anderen zeitgenössischen Verzeichnissen erscheinen sie als Ritter (milites). ${ }^{127}$ Eine größere Zahl der Hieronymusgesellen begegnet auch im Aufgebot, das Herzog Albrecht im November 1459, wenige Wochen vor der bischöflichen Bestätigung der Hofstiftung, zu seiner Hochzeit mit Sidonia von Podiebrad nach Eger begleitete. ${ }^{128}$

Bemerkenswert ist, dass es sich bei den niederadligen Mitgliedern bis auf zwei Fälle durchweg um Schriftsassen handelte. ${ }^{129}$ Die Hieronymusgesellen wurden also bevorzugt aus jener herausgehobenen Gruppe wettinischer Ehrbarmannen rekrutiert, mit denen der Landesherr unmittelbar über die Kanzlei, nicht, wie im Fall der Amtsassen, über die Vermittlung seiner Vögte korrespondierte. In einigen Aufgebotsverzeichnissen aus dem Vorfeld des wettinischen Bruderkriegs, also in engem zeitlichen Zusammenhang mit der Gründung der Hieronymusgesellschaft, wird die Zusammensetzung der beiden Gruppen erstmals genauer greifbar. ${ }^{130}$ Der „traditionelle[n], aber grundsätzlich offene[n] adlige[n] Elite“ der Schriftsassen gehörten im Kern jene Ehrbarmannen an, die als Inhaber befestigter Burgen sowie aufgrund ihrer Lehnsbindung an verschiedene Landesherren für die Wettiner besonders „interessant“ waren. ${ }^{131}$ Tatsächlich führt die Mitgliederliste von 1460 Angehörige fast aller wichtigen Schriftsassenfamilien der zweiten Hälfte des 15. Jahr-

HStA Dresden, 10005 Hof- und Zentralverwaltung der Wettiner (Wittenberger Archiv), Loc. 4376/18; zu diesem Uwe SchIRMER, Kursächsische Staatsfinanzen (14561656). Strukturen - Verfassung - Funktionseliten (Quellen und Forschungen zur sächsischen Geschichte 28), Leipzig/Stuttgart 2006, S. 94 f.

127 Vgl. Anhang 2, Nr. 10-14; zum Herrentitel auch Spiess, Abgrenzung (wie Anm. 43), S. $203 \mathrm{f}$.

128 HStA Dresden, 10024 Geheimer Rat (Geheimes Archiv), Loc. 9603/3, Bl. 2r-7v; einzelne Namen daraus auch bei Friedrich Albert von Langenn, Herzog Albrecht der Beherzte, Stammvater des königlichen Hauses Sachsen. Eine Darstellung aus der sächsischen Regenten- Staats- und Cultur-Geschichte des XV. Jahrhunderts, großentheils aus archivalischen Quellen, Leipzig 1838, S. 40.

129 Vgl. hierzu die Belege in den Sachanmerkungen zu Anhang 2. Lediglich für Konrad Mönch (Nr. 37) und Dietrich von Freiberg (Nr. 41) ist die Schriftsässigkeit bislang nicht belegt.

130 ManfRed Wilde, Die Ritter- und Freigüter in Nordsachsen. Ihre verfassungsrechtliche Stellung, ihre Siedlungsgeschichte und ihre Inhaber (Aus dem Deutschen Adelsarchiv 12), Limburg 1997, S. 98 ff.; JoAchim Schneider, Kleine Ehrbarmannen in Kursachsen. Adel zwischen Bauern, Bürgertum und landsässiger Ritterschaft, in: Kurt Andermann/ Peter Johanek (Hg.), Zwischen Nicht-Adel und Adel (Vorträge und Forschungen 53), Stuttgart 2001, S. 179-212, hier S. 190 f.; Ders., Niederadel (wie Anm. 126), S. 85 ff.; Ders., Schriftsassen und Amtssassen, in: Martina Schattkowsky (Hg.), Adlige Lebenswelten in Sachsen. Kommentierte Bild- und Schriftquellen, Köln/Weimar/Wien 2013, S. 27-35.

131 Schneider, Schriftsassen und Amtssassen (wie Anm. 130), S. 31 f. Zur Entstehung der Schriftsässigkeit, für die ursprünglich der Besitz einer befestigten Burg und die Mehrfachvasallität des Adligen ausschlaggebend gewesen zu sein scheint, vgl. SCHNEIDER, Niederadel (wie Anm. 126), S. 181 ff., besonders S. 187 ff., 197 ff. 
hunderts auf. ${ }^{132}$ In vier Fällen wurden Brüder in die Gesellschaft aufgenommen. ${ }^{133}$ Obwohl die Schriftsässigkeit kein förmliches Aufnahmekriterium bildete, scheint sie doch Voraussetzung oder wenigstens Begleiterscheinung der Mitgliedschaft gewesen zu sein. Die Hofstiftung lässt sich damit als Spiegel einer zunehmend ausgeprägten sozialen Differenzierung des wettinischen Niederadels interpretieren. Für einzelne Gesellen dürfte sie sogar als Katalysator eines persönlichen Aufstiegs vom Amt- zum Schriftsassen gedient haben. ${ }^{134}$

Und noch ein weiteres Spezifikum lässt das Mitgliederverzeichnis erkennen: Neben den bereits genannten Mitarbeitern des Hofs ${ }^{135}$ gehörte mehr als ein Drittel der niederadligen Hieronymusgesellen, soweit eine Identifizierung sicher möglich ist, in den Kreis der kurfürstlichen Amtleute. ${ }^{136}$ Angesichts der großen Zahl wettinischer Vogteien war damit zwar nur ein kleiner Teil der örtlichen Funktionäre erfasst - in der zweiten Hälfte des 15. Jahrhunderts ist von einem Bestand von rund 60 Beamten auszugehen, von denen der überwiegende Teil aus amtsässigem Adel stammte ${ }^{137}$-, doch eröffnete die Hofstiftung dem Landesherrn so die Chance, in einer geschützten Atmosphäre persönlichen Einfluss auf wichtige Amtsträger der lokalen Ebene zu nehmen. Die Mitglieder der Gesellschaft verfügten ihrerseits über einen unmittelbaren Zugang zum Fürsten und konnten ihn im bruderschaftlichen Umgang wohl auch leichter für ihre eigenen Interessen gewinnen. Vor diesem Hintergrund lassen sich die vierteljährlichen Versammlungen der Hieronymusgesellen in Meißen zugleich als Medium herrschaftlicher Kontrolle und Ort politischer Partizipation interpretieren. ${ }^{138}$

132 Vgl. dazu den Überblick bei SchneIder, Niederadel (wie Anm. 126), S. 378 ff.

133 Anhang 2, Nr. 15/23, 19/20, 26/29, 30/38.

134 Neben Konrad Mönch und Dietrich von Freiberg (Anhang 2, Nr. 37, 41; vgl. oben Anm. 129), die als Schriftsassen nicht belegt sind, sei hier auf Titz von Honsberg zu Schönfeld, Leuben und Schweta (Anhang 2, Nr. 21) verwiesen, der 1445 als Amtsasse, ab 1454 als Schriftsasse begegnet. Die Familie von Nickel Rabil zu Tiefensee (Anhang 2, Nr. 33) war 1447 noch amtsässig, doch wird Nickel ab 1454 als Schriftsasse geführt.

135 Anhang 2, Nr. 12 (Jan von Schleinitz, Obermarschall), 13 (Georg von Bebenburg, Obermarschall), 15 (Hans Löser, Erb- und Untermarschall), 16 (Hug von Taubenheim, Hofmeister).

136 Anhang 2, Nr. 9, 11 (27?, 28?), 13, 14, 16, 17, 23 (?), 26, 29 (?), 30 (?), 31, 32, 35 (?), 36, 40. Zur Sozialstruktur der wettinischen Amtleute vgl. Christian Hesse, Amtsträger der Fürsten im spätmittelalterlichen Reich. Die Funktionseliten der lokalen Verwaltung in Bayern-Landshut, Hessen, Sachsen und Württemberg 1350-1515 (Schriftenreihe der Historischen Kommission bei der Bayerischen Akademie der Wissenschaften 70), Göttingen 2005, hier S. 297 ff.

137 Ebd., S. 213.

138 Im Fall des Hubertusordens deckte sich die Bruderschaft weitgehend mit dem Kreis des pfandbesitzenden jülich-bergischen Adels und diente damit nicht nur als Kontrollinstrument des Landesherrn, sondern bot auch dem Adel selbst „zusätzlichen Einfluss“; Nesselrode, Ikonographie (wie Anm. 18), S. 114. Auch der Orden vom Goldenen Vlies gilt aufgrund des „weitgehend hierarchiefreien Kontakt[s]“ zwischen Mitgliedern und Stifter als ,erstaunlich egalitäre Einrichtung“, in der offen politische Kritik geäußert werden konnte; die Zitate nach Klaus Oschema, Freundschaft und Nähe im spätmittelalterlichen Burgund. Studien zum Spannungsfeld von Emotion und Institution 
So dürfte der Hieronymusgesellschaft auch eine gewisse Rolle bei der Ausbildung der landesherrlichen Funktionseliten zugekommen sein, die im letzten Drittel des 15. Jahrhunderts festere Konturen annahmen. Auch sie wurden vom schriftsässigen Adel dominiert. Er vertrat die wettinische Vasallenschaft auf den Landtagen, nahm einflussreiche Positionen im ernestinischen und albertinischen Hofrat ein, besetzte die führenden Funktionen in den landesherrlichen Zentralbehörden und spielte auch in der Lokalverwaltung eine herausragende Rolle. ${ }^{139}$ Eine direkte Verbindung zwischen den Hieronymusgesellen und jener Personengruppe, die Uwe Schirmer zur Führungsschicht der wettinischen Lande in den Jahren um 1500 zählt, lässt sich aufgrund der großen zeitlichen Distanz zwar nur in Einzelfällen herstellen, ${ }^{140}$ doch nimmt die Zusammensetzung der kurfürstlichen Hofstiftung von 1450 im Kern bereits die Sozialstruktur der niederadligen Aristokratie späterer Jahre vorweg.

Dies belegt zugleich die These Schirmers, wonach Entwicklung und Konsistenz der wettinischen Führungseliten auch durch die Einbindung ihrer Angehörigen in die höfische Fest- und Repräsentationskultur gefördert wurde, die den Raum zur „strategischen Kommunikation“ mit dem Landesherrn bot. ${ }^{141}$ Während der Kurfürst mit der Hieronymusgesellschaft über ein Instrument verfügte, mit dem er eine exklusive Gruppe ihm besonders verbundener Persönlichkeiten aus dem bei Hof präsenten Niederadel rekrutieren konnte, eröffnete diese ihren Mitgliedern neben den herkömmlichen Formen ständischer Repräsentation eine privilegierte Chance zur Herrschaftsteilhabe. ${ }^{142}$ In diesem Sinn ist die wettinische Hofstiftung auch im Kontext des Ständebildungsprozesses zu sehen. Bemerkens-

(Norm und Struktur 26), Köln/Weimar/Wien 2006, S. 341; bei DünNEBEIL, Entwicklung (wie Anm. 15), S. 26; vgl. ebd., S. 32.

139 Bürgerliche Funktionsträger konnten hier nur geringen Einfluss geltend machen und blieben vor allem auf das Finanzressort beschränkt. Vgl. Uwe Schirmer, Untersuchungen zur Herrschaftspraxis der Kurfürsten und Herzöge von Sachsen. Institutionen und Funktionseliten (1485-1513), in: Rogge/Schirmer, Hochadlige Herrschaft (wie Anm. 21), S. 305-378, hier besonders S. $311 \mathrm{ff} ., 336 \mathrm{ff}$.

140 Vgl. die Übersicht bei Schirmer, Untersuchungen (wie Anm. 139), S. 349 ff. In den Kreis der auch gegen Ende des 15. Jahrhunderts als kurfürstliche Räte einflussreichen Hieronymusgesellen zählen Hermann von Weißenbach (Anhang 2, Nr. 40), ein Dietrich von Miltitz (Nr. 11, 27, 28) und Hans Metzsch (Nr. 17); dazu Schirmer, Untersuchungen (wie Anm. 139), S. 315 mit Anm. 34. Zu nennen sind ferner Jörg von Schleinitz (Nr. 18), Heinrich Löser zu Pretzsch (Nr. 23), Siegmund von Miltitz (Nr. 26), Bernhard von Schönberg (Nr. 36) und Heinz vom Ende (Nr. 38); dazu Schirmer, Untersuchungen, (wie Anm. 139), S. 316 mit Anm. 37, 328, 337.

141 Ebd., S. 338 f.

142 Dass neben der auf den Landtagen ausgeübten ständischen Repräsentation informelle Formen politischer Teilhabe an der landesherrlichen Gewalt bestanden, betont auch Christoph Volkmar, Territoriale Funktionseliten, Ständebildung und politische Partizipation im Machtbereich der Wettiner, in: Oliver Auge/Burkhard Büsing (Hg.), Der Vertrag von Ripen 1460 und die Anfänge der politischen Partizipation in SchleswigHolstein, im Reich und in Nordeuropa (Kieler Historische Studien 43), Ostfildern 2012, S. 373-385. 
wert ist hier, dass sich einige Hieronymusgesellen in der Ständeeinung vom 29. November 1445, die in Vorbereitung des sogenannten Halleschen Machtspruchs erfolgte, nachweisen lassen. ${ }^{143}$ Einzelne Mitglieder sind auch als Teilnehmer späterer Landtage belegt. ${ }^{144}$

Mit ihrer Funktion, Lehnhof, Verwaltungsbeamte und sonstige Funktionseliten persönlich zu solidarisieren, steht die Hieronymusgesellschaft nicht allein. Das Bemühen der Reichsfürsten, „nach dem Absterben vasallitischer Bindungen“ den „im wesentlichen nur noch auf Soldzahlungen beruhende[n] Konnex zwischen Herrscher und ritterschaftlichem Adel“ durch die Gründung von Hofstiftungen in „seiner emotionalen Komponente“ zu stärken, ${ }^{145}$ war verbreitet. Auf die Bindung der Vasallenschaft des Stifters zielten auch Hubertus-, Pelikan- und Schwanenorden, dies aber in ganz unterschiedlicher Ausprägung. Während Hieronymusgesellschaft und Schwanenorden Doppelmitgliedschaften - und damit Doppelvasallitäten - ohne Weiteres zuließen, hatte der Gründer des Pelikans die Mitgliederzahl limitiert und dafür gesorgt, dass seine Gesellen ausschließlich dem kurpfälzischen Lehnhof entstammten. Landfremde Adlige waren nur als ,Ehrenmitglieder' mit minderen Rechten zugelassen. ${ }^{146}$ Die Hofstiftung der Hohenzollern verfolgte hingegen eine offenere Linie, für die bereits wenige Jahre nach der Gründung die ursprünglich vorgesehene Begrenzung der Mitgliederzahl aufgehoben wurde, um ihre wichtigste Aufgabe, die herrschaftliche Integration des brandenburgischen und fränkischen Adels gezielter erfüllen zu können. ${ }^{147}$

Insbesondere am Schwanenorden hat sich die wettinische Gründung in mehrfacher Hinsicht orientiert. Dessen 1440 und 1443 erlassenen Statuten waren denen der Hieronymusgesellschaft in einer Reihe von Punkten derart ähnlich, dass die

143 Heinrich IX. Reuß von Plauen, Herr zu Greiz (Anhang 2, Nr. 6), Friedrich II. von Dohna zu Auerbach (Nr. 7), Heinrich von Bünau zu Weesenstein (Nr. 10), Georg von Bebenburg (Nr. 13) sowie ein Dietrich von Miltitz (Nr. 11?). Nickel von Wolffersdorff (Nr. 14), Konrad Mönch (Nr. 37) und Ulrich vom Ende zu Ronneburg (Nr. 30) standen mutmaßlich in engen verwandtschaftlichen Beziehungen zu gleichnamigen Mitgliedern der Einung. Diese liegt nur vor in einem älteren Druck bei Johann CHRISTIan LüNIG (Hg.), Deutsches Reichs-Archiv, Bd. 8 = Pars Specialis. Continuatio 2, Leipzig 1712, Abteilung 4, S. 227 ff.; zu ihr und ihrer Rolle bei der Landesteilung von 1445 (Vorbereitung des Halleschen Machtspruchs) Helbig, Ständestaat (wie Anm. 6), S. 437 ff.; Martin Naumann, Die wettinische Landesteilung von 1445, in: NASG 60 (1939), S. 171-213, hier S. $209 \mathrm{ff}$.

144 Vgl. die Belege in Anhang 2, Nr. 21 (Dietrich von Honsberg), 26 (Siegmund von Miltitz), 29 (Hans von Miltitz).

145 Heinz Thomas, Deutsche Geschichte des Spätmittelalters 1250-1500, Stuttgart 1983, S. 272.

146 Zum Pelikan Storn-Jaschкowitz, Gesellschaftsverträge (wie Anm. 1), S. 60 f., 70 ff., 84 ff., 141; zum Schwan ebd., S. 130 ff., 135 ff., 138 ff., 176 f.; zum Hubertusorden oben Anm. 138.

147 Storn-Jaschkowitz, Gesellschaftsverträge (wie Anm. 1), S. 109 ff., 171 ff.; FrankL, Würzburger Vasallen (wie Anm. 19), S. 99; Ders., Schwanenorden (wie Anm. 19), S. $250 \mathrm{f}$. 
beiden Gemeinschaften geradezu als „Konkurrenzprodukt“ erscheinen. ${ }^{148}$ Hier wie dort finden sich die Vierahnenprobe und die Forderung einwandfreier Lebensführung, die Vorschrift gemeinsamen Betens, die Kapitelsitzungen sowie ähnliche Regelungen des Totenbegängnisses verstorbener Mitglieder, darunter die Verpflichtung, Wappenschilde der Toten im Kultzentrum aufzuhängen. ${ }^{149}$ In der Stiftskirche St. Gumpert in Ansbach sind bis heute Schilde von Mitgliedern des Schwanenordens erhalten. ${ }^{150}$ Auch die Gestaltung des Kleinods in einer silbernen und einer goldenen Variante findet sich in beiden Gesellschaften, ${ }^{151}$ ebenso die Verpflichtung des Stifters, schuldlos verarmte Genossen zu unterstützen, die im Schwanenorden erstmals in den Statuten von 1443 begegnet. ${ }^{152}$

Bislang ungeklärt sind Anlass und Hintergrund der kirchlichen Bestätigung der Hieronymusgesellschaft zu Beginn des Jahres 1460, die mit dem Versuch einer Neubelebung einherging. ${ }^{153}$ Nachdem sich die wettinische Hofstiftung schon bei ihrer Gründung am Schwanenorden orientiert hatte, liegt die Vermutung nahe, dass die zeitgleiche Errichtung von dessen fränkischen Ordenszweig den Anstoß hierfür gab. ${ }^{154}$ Dafür spricht, dass Schwanenorden und Hieronymusgesellschaft inzwischen durch einige Doppelmitgliedschaften personell verflochten waren und auch der sächsische Kurfürst selbst der hohenzollerischen Stiftung angehörte. Deren Vorbild war in den wettinischen Landen somit unmittelbar präsent. Ein Mitgliederverzeichnis des Schwanenordens aus dem Jahr 1455 nennt neben Friedrich II. den Hieronymusgesellen Georg von Bebenburg, ${ }^{155}$ ferner Heinrich von Bünau, Dietrich von Miltitz und Heinrich Spiegel, die vielleicht mit den gleichnamigen Angehörigen der Hieronymusgesellschaft zu identifizieren sind. Auch Georg I. von Anhalt begegnet sowohl als Mitglied des Schwanenordens wie der Hieronymusgesellschaft. Ein Verzeichnis von 1464/65 führt darüber hinaus Her-

148 Wie oben Anm. 30. Ähnliches gilt für die um 1473 durch Herzog Ernst II. von Pommern gegründete Hofstiftung, die als „Instrument zur Solidarisierung des heimischen Adels mit der Greifendynastie gegen die märkischen Ansprüche auf das Herzogtum Stettin" dienen sollte und sich gerade deshalb an den Regularien des Schwanenordens orientierte; Jürgen Petersohn, Eine übersehene fürstliche Adelsbruderschaft des späten Mittelalters. Die pommersche Fraternitas illustrium et nobilium ad honorem Annunciationis beate Marie in Buckow (1473) bzw. Stettin (1491), in: Peter Aufgebauer (Hg.), Herrschaftspraxis und soziale Ordnungen im Mittelalter und in der frühen Neuzeit. Ernst Schubert zum Gedenken (Veröffentlichungen der Historischen Kommission für Niedersachsen und Bremen 232), Hannover 2006, S. 391-403, hier S. 398 (Zitat).

149 Stillfried/Haenle, Buch vom Schwanenorden (wie Anm. 19), S. 35 ff., 39 ff.; vgl. ebd., S. 7 ff.

150 Theodor Dëschlein, Der Schwanenorden und die sogenannte SchwanenordensRitter-Kapelle in Ansbach, Ansbach 1926, S. 88 ff., 92 ff.; Rosemarie Asche, Die Inschriften des Stadtkreises Ansbach bis 1650, Diss. phil. Erlangen 1984, S. 22 u. ö.

151 Stillfried/Haenle, Buch vom Schwanenorden (wie Anm. 19), S. 22.

152 Ebd., S. 5 f.; vgl. oben bei Anm. 51.

153 Vgl. oben Anm. 116.

154 Vgl. oben Anm. 19.

$155 \mathrm{Zu}$ ihm Anhang 2, Nr. 13. 
zog Wilhelm III. von Sachsen, zwei weitere Heinriche und einen Rudolf von Bünau als Angehörige der hohenzollerischen Hofstiftung auf. ${ }^{156}$

Der Befund weist Parallelen zu den Erkenntnissen auf, die Markus Frankl für den fränkischen Zweig des Schwanenordens gewonnen hat. Dessen Mitglieder gehörten zu einem großen Teil auch dem Lehnhof des Bischofs von Würzburg an, einem der wichtigsten Gegner der fränkischen Hohenzollern. Danach muss das Ziel des Markgrafen Albrecht, seinen Adel durch die Einbindung in den Schwanenorden insbesondere im Kampf mit dem Würzburger Hochstift „politisch wirksam zu instrumentalisieren, letzten Endes als gescheitert bewertet werden“. 157 Aus der Sicht des Adels bot die lehnrechtliche Bindung an mehrere Herren die Möglichkeit, sich in Konflikten weitgehend neutral zu verhalten, und so eröffnete die Mitgliedschaft in verschiedenen Hofgesellschaften einen ähnlichen Spielraum. Insofern bestand auch zwischen der Schwanen- und der Hieronymusgesellschaft eine potenzielle Konkurrenz. Die Mitglieder scheinen damit auf unterschiedliche Weise umgegangen zu sein. So gehörte Graf Günther von Barby seit 1455 dem Schwanenorden, ${ }^{158}$ sein Sohn Bernhard hingegen der Hieronymusgesellschaft an. Damit konnten diese ihre Bindung gegenüber Wettinern und Hohenzollern zum Ausdruck bringen und zugleich Loyalitätskonflikte, die sich aus einer Doppelmitgliedschaft ergaben, vermeiden. Einen anderen Hintergrund dürfte das Beispiel der Burggrafen von Dohna haben: Während Friedrich II. zu Auerbach zu den Hieronymusgesellen zählte, gehörte Friedrich I. zu Wildstein dem Schwanenorden an, was nach der unterschiedlichen Stellung der beiden zu den Wettinern als politische Manifestation interpretiert werden kann. 159

$\mathrm{Ob}$ sich in der konkreten Situation der Jahre 1459 und 1460 jedoch von einem ausgeprägt machtpolitischen Gegensatz zwischen Schwanen- und Hieronymusgesellschaft sprechen lässt, erscheint angesichts des damals recht guten Verhältnisses zwischen Wettinern und Hohenzollern fraglich. ${ }^{160}$ Wenn die bischöfliche Bestätigung der Hieronymusgesellschaft dem Vorbild des Schwanenordens folgte, dürfte dies in erster Linie als ein repräsentativer Wettbewerb zu interpretieren sein. Tatsächlich befand sich der Schwanenorden in den Wochen unmittelbar vor der Erneuerung der Hieronymusgesellschaft im Ausbau. Ende 1459 hatte Markgraf Albrecht Achilles dessen fränkischen Zweig begründet und sich während eines Aufenthalts auf dem Kongress von Mantua, den Pius II. zur Vorbereitung eines

156 Stillfried/Haenle, Buch vom Schwanenorden (wie Anm. 19), S. 62 f., 67; Kruse/ Paravicini/Ranft, Ritterorden (wie Anm. 7), Nr. 69. Zu den genannten Personen auch Anhang 2. Ein Heinrich von Bünau - der 1455 genannte? - wird 1464/1465 als tot bezeichnet; STILlfried/Haenle, Buch vom Schwanenorden (wie Anm. 19), S. 65.

157 FrankL, Würzburger Vasallen (wie Anm. 19), S. 127.

158 Stillfried/Haenle, Buch vom Schwanenorden (wie Anm. 19), S. 62, 66, $116 \mathrm{f}$.

159 Ebd., S. 140, und oben Anm. 122, 124.

160 Vgl. dazu Hellmut Kretzschmar, Die Beziehungen zwischen Brandenburg und den wettinischen Landen unter den Kurfürsten Albrecht Achilles und Ernst 1464-1486 [Teil 1], in: Forschungen zur Brandenburgischen und Preußischen Geschichte 35 (1923), S. 21-44, hier S. $24 \mathrm{ff}$. 
neuen Türkenkreuzzugs einberufen hatte, um dessen päpstliche Bestätigung bemüht. Nachdem Nikolaus V. bereits 1448 das brandenburgische Kultzentrum des Ordens privilegiert hatte, erklärte der Piccolominipapst am 16. Januar 1460 die Georgskapelle im Ansbacher Gumpertstift zum Sitz der fränkischen Abteilung und verlieh ihr einen Ablass. 161

Auf den Tag von Mantua dürfte auch die Entscheidung des sächsischen Kurfürsten zurückgehen, die Hieronymusgesellschaft neu zu beleben. Friedrich II. war an den Kreuzzugsverhandlungen seit Oktober 1459 durch Gesandte beteiligt, denen neben Gesprächen über den Türkenkrieg die Beantragung von Ablässen und anderen kurialen Privilegien aufgetragen war. Dabei wurden die Kreuzzugspolitik der Wettiner und ihre antihussitische Haltung zum Thema. Friedrich II. hatte nämlich im Lauf des Jahres 1458 einen schwerwiegenden Konflikt mit der römischen Kurie heraufbeschworen, als sich der päpstliche Kollektor Marinus de Fregeno in Mitteldeutschland aufhielt. ${ }^{162}$ Dieser war damit betraut, einen von Calixt III. ausgeschriebenen Türkenablass zu verkünden. Um in den kursächsischen Landen tätig zu werden, musste er dem Wettiner die Hälfte seiner Einnahmen abtreten und sich damit einverstanden erklären, dass dieser seinen Anteil für die Bekämpfung der Hussiten einsetzte. Die Kurie empfand dies als Zweckentfremdung, zumal die Verfolgung der böhmischen Ketzer für Friedrich nur ein Vorwand war, die Ambitionen seines Bruders Wilhelm auf die böhmische Krone zu unterstützen. Calixt III., der im Frühjahr 1458 ein geheimes Abkommen mit dem utraquistischen Elekten Georg von Podiebrad getroffen hatte, untersagte Marinus de Fregeno daher, den Kurfürst weiterhin an den Ablasseinnahmen zu beteiligen, worauf dieser den päpstlichen Kollektor gefangen setzte.

Pius II., der im Herbst 1458 zum Papst gewählt worden war, bemühte sich, die Auseinandersetzungen beizulegen. Unter Vermittlung des päpstlichen Kubikulars Dr. Johann Lochner, der schon früher als Rat für die Wettiner tätig gewesen war, erklärte sich Friedrich II., der im April 1459 in Eger ein Bündnis mit Georg Podiebrad geschlossen hatte, bereit, die kurialen Planungen für den Türkenkrieg zu unterstützen. Am 17. Dezember $1459 \mathrm{kam}$ es am Rande der Verhandlungen in Mantua zu einem Kompromiss, in dessen Folge die kurfürstlichen Kongressgesandten auf den Anteil ihres Herrn an den von Marinus de Fregeno gesammelten Ablassgeldern verzichteten, diesen von Pius II. aber umgehend wieder zugesprochen erhielten - nun in ausdrücklicher Anerkennung des langjährigen Einsatzes der Wettiner gegen die Hussiten, aber verbunden mit der Mahnung, sich fortan im Kampf gegen die Osmanen zu engagieren. ${ }^{163}$

Zwei Wochen später, am 1. Januar 1460, vollzog Bischof Caspar von Meißen, der zu diesem Zeitpunkt wohl bereits Kenntnis vom Ergebnis der Einigung

161 Stillfried/Haenle, Buch vom Schwanenorden (wie Anm. 19), S. 10 ff., 52 f. (Nr. 5-7); dazu Kruse/Paravicini/Ranft, Ritterorden (wie Anm. 7), Nr. 69, S. 334.

$162 \mathrm{Vgl}$. nachfolgend Wiegand, Marinus de Fregeno (wie Anm. 84), S. 31 ff., 45 ff., $65 \mathrm{ff}$.

$163 \mathrm{Zu}$ den Verhandlungen vor und während des Tags von Mantua ebd., S. 70 ff.; die Edition der Einigung ebd., S. 289 f., Nr. 124; zur Person Lochners ebd., S. 74 f. mit Anm. 444. 
hatte, ${ }^{164}$ die Bestätigung der Hieronymusgesellschaft. Die Koinzidenz der Ereignisse lässt vermuten, dass die Erneuerung der wettinischen Hofstiftung als demonstrativer Ausdruck der in Mantua bezeugten Kreuzzugsbereitschaft Friedrichs II. gedacht war. ${ }^{165}$ Zugleich bekräftigte sie aber auch noch einmal die ursprüngliche, antihussitische Zielrichtung der kurfürstlichen Politik, die man in Mantua offiziell aufgegeben hatte. Der Konfirmationsakt richtete sich damit zum einen an die Kurie und ihre Bemühungen, den Türkenkrieg zu befördern, zum anderen aber auch an den wettinischen Adel, in dessen Kreisen trotz des Friedens von Eger nach wie vor eine hussitenfeindlich geprägte Haltung verbreitet war. Ihr kam der Kurfürst, der sich seinerseits an Georg von Podiebrad angenähert hatte, mit der Erneuerung der Hieronymusgesellschaft gezielt entgegen.

Als Symbol der Kreuzzugsbereitschaft Friedrichs II. steht die Erneuerung der Hieronymusgesellschaft in engem Zusammenhang mit der Jerusalemfahrt, die Herzog Wilhelm III. im Jahr 1461 unternahm. Die Reise, die am Beginn einer Folge von Besuchen des Heiligen Landes durch verschiedene Wettiner steht - 1476 durch Herzog Albrecht, 1493 durch Friedrich den Weisen, 1498 durch Heinrich den Frommen -, bot neben der „Möglichkeit, geistlichen Lohn zu erwerben, [...] auch eine Chance, sich weltlich zu bewähren, Ruhm und Ehre zu erlangen und schließlich mit dem Erwerb der Ritterschaft vom Heiligen Grab ihre Bereitschaft zum Heidenkampf zu dokumentieren“..166 Unter dem Eindruck der päpstlichen Kreuzzugsinitiativen war sie zweifellos mehr als nur eine säkulare Bewährungsprobe. ${ }^{167}$ Die Beweggründe, die Wilhelm in seinem vor Antritt der Fahrt verfass-

164 Noch am Tag der Einigung hatte Papst Pius II. den Bischof über den erzielten Kompromiss informiert; ebd., S. 292 f., Nr. 126.

165 Im Januar 1459 hatte Pius II. selbst einen neuen Ritterorden auf der Insel Lemnos zu gründen versucht; BenJAmin Weber, Lutter contre les Turcs. Les formes nouvelles de la croisade pontificale au XVe siècle (Collection de l'École française de Rome 472), Rom 2013, S. 143 f., 185 f.

166 Folker Reichert, Von Dresden nach Jerusalem. Albrecht der Beherzte im Heiligen Land, in: André Thieme (Hg.), Herzog Albrecht der Beherzte (1443-1500). Ein sächsischer Fürst im Reich und in Europa (Quellen und Materialien zur Geschichte der Wettiner 2), Köln/Wien 2002, S. 53-71, hier S. 54 f. Zur Reise Wilhelms III. WerneR Paravicini (Hg.), Europäische Reiseberichte des späten Mittelalters. Eine analytische Bibliographie, Teil 1 (Kieler Werkstücke D/5), Frankfurt a. M. u. a. 22001, S. 136 ff.; ferner Johannes Falke, Herzog Wilhelms III. Reise in das heilige Land, in: Archiv für die sächsische Geschichte 4 (1866), S. 283-320; und die Edition des Reiseberichts bei Johann Georg Kohl (Hg.), Pilgerfahrt des Landgrafen Wilhelm des Tapferen von Thüringen zum heiligen Lande im Jahre 1461, Bremen 1868.

167 André Thieme, Pilgerreisen wettinischer Fürsten im späten Mittelalter, in: Klaus Herbers/Enno Bünz (Hg.), Jakobuskult in Sachsen (Jakobus-Studien 17), Tübingen 2007, S. 175-217, hier S. 214, misst dem Reisemotiv demonstrativer Frömmigkeit nur nachgeordnete Bedeutung zu. Den religiösen Charakter der Reise betont hingegen Cordula Nolte, Erlebnis und Erinnerung. Fürstliche Pilgerfahrten nach Jerusalem im 15. Jahrhundert, in: Irene Erfen/Karl-Heinz Spieß (Hg.), Fremdheit und Reisen im Mittelalter, Stuttgart 1997, S. 65-92, hier S. 73. 
ten Testament anführte, ${ }^{168}$ sind mehrdeutig formuliert, könnten sich aber durchaus auf die Kreuzzugserwartungen beziehen, die Pius II. auch an ihn gerichtet hatte. Immerhin war Wilhelm ebenfalls durch Gesandte auf dem Kongress von Mantua vertreten, hatte sich freilich nach dessen Ende ebenso wenig wie sein Bruder ernsthaft für den Türkenkrieg stark gemacht. So wie sich Friedrich II. mit der Wiederbelebung seiner Hofstiftung wenigstens formal als Kreuzfahrer präsentierte, mag Wilhelm geglaubt haben, seine Verpflichtungen durch eine Palästinareise erfüllen zu können.

Zum Schluss seien die Ergebnisse dieser Studie in drei Punkten zusammengefasst:

1. Wie die Bestätigung durch Bischof Caspar von Meißen am 1. Januar 1460 zeigt, hat die kursächsische Hieronymusgesellschaft merklich länger bestanden, als in der Forschung zuletzt vermutet, freilich wohl auch nicht so lange, wie es ältere Arbeiten annahmen. ${ }^{169} \mathrm{Da}$ es sich bei einem Großteil der damals belegten Mitglieder um Altersgenossen der Prinzen Ernst und Albrecht handelt, wird die Stiftung nach dem Tod ihres Gründers (1464) zunächst wohl auch unter dessen Nachfolger weitergeführt worden sein. Darauf deutet die Tatsache hin, dass die kurfürstliche Silberkammer 1469 zwei Kleinode der Gesellschaft verwahrte und ihr Emblem noch im 1485/86 vollendeten Wappenbuch Konrad Grünenbergs begegnet. Nachdem die Einung aber ganz auf die Person des Kurfürsten ausgerichtet war, änderten sich ihre Existenzbedingungen mit der Leipziger Teilung von 1485 grundlegend. Damals fanden sich diejenigen Gesellschaftsmitglieder, die im Kernland der Mark Meißen und im Gebiet um Leipzig saßen, im albertinischen Landesteil wieder. Die überkommenden Loyalitätsbeziehungen zwischen einem Teil der Hieronymusgesellen und dem Kurfürsten waren damit gestört, sodass die Einung nicht mehr lange existiert haben dürfte. Nach 1485/86 fehlen jegliche Belege für ihr Fortleben. Vergleichbare Disintegrationsphänomene lassen sich in diesen Jahren auch in anderen Bereichen der wettinischen Herrschaft wie etwa beim 1485 zeitweilig eingetretenen Kompetenzverlust des von Kurfürst Ernst und Herzog Albrecht gemeinsam eingerichteten Oberhofgerichts in Leipzig beobachten. ${ }^{170}$

Die Chance, die Gesellschaft auf beide Landesteile auszudehnen und damit ein einigendes Band zu schaffen, das ihr Vorbild, der Schwanenorden, zeitweise für die hohenzollerischen Fürstentümer bildete, konnten oder wollten die Wettiner offenbar nicht nutzen. Vergleichbares lässt sich später auch beim Schwanenorden beobachten. Auch er hatte seinen Zenit überschritten, als Kurfürst Albrecht Achilles, der die Mark Brandenburg und die fränkischen Fürs-

168 Er wolle die Fahrt mit sonderlicher Inbrunst und Andacht, auch durch redliche Ursachen, die uns dazu bewogen, unternehmen; Christian Schoettgen/Georg Christoph KreYsig, Diplomataria et scriptores historiae Germaniae medii aevi, Bd. 1, Altenburg 1753, S. $539 \mathrm{ff}$.

169 Wie oben Anm. 26-29.

170 Schirmer, Untersuchungen (wie Anm. 139), S. 321 ff. 
tentümer seit 1470 wieder in einer Hand vereinte, starb und sein Besitz erneut geteilt wurde. ${ }^{171}$ Nach dem Tod Kurfürst Ernsts (1486) begann die Fürstenkapelle im Meißner Dom, die Versammlungsstätte der Hieronymusgesellschaft, zudem ihre Bedeutung als Ort ernestinisch-kurfürstlicher Memoria zu verlieren, ${ }^{172}$ was der kurfürstlichen Hofstiftung ebenfalls kaum zuträglich gewesen sein dürfte. Bis zur Reformation, wie es ältere Autoren vermuteten, hat sie wohl nicht überlebt. Die Tatsache, dass Herzog Georg eine ihrer wesentlichen Funktionen - die Förderung des Totengedenkens innerhalb der wettinischen Vasallenschaft - für die albertinischen Lande im Jahr 1516 noch einmal aufgriff, indem er eine Seelgerätstiftung für all diejenigen tätigte, die in militärischen Diensten seines Vaters Albrecht verstorben waren oder ihr Leben künftig für ihn und seine Nachfahren lassen würden, dürfte ein weiteres Indiz dafür sein, dass die Hieronymusgesellschaft damals nicht mehr bestand. ${ }^{173}$

2. Die Hieronymusgesellschaft entsprach hinsichtlich ihres bruderschaftlichen Charakters, ihres ritterlichen Kampfauftrags und ihrer herrschaftssichernden, die Vasallen des Stifters solidarisierenden Funktion dem Aufgabenspektrum anderer Hofstiftungen ihrer Zeit. Mit seiner Gründung hat Kurfürst Friedrich II. daher auch ein Rangdefizit zu beseitigen versucht. Um 1450 besaßen bereits mehrere Reichsfürsten vergleichbare Institutionen, mit Brandenburg und der Kurpfalz darunter zwei Kurfürsten, mit denen die Wettiner hinsichtlich ihres repräsentativen Anspruchs unmittelbar konkurrierten. Der hohenzollerische Schwan und der kurpfälzische Pelikan dürften so als direktes Vorbild für die wettinische Stiftung gedient haben. Dies gilt insbesondere für den Schwanenorden, dessen Statuten in ihrer konkreten Ausformung an einigen Punkten eng mit denen der Hieronymusgesellschaft übereinstimmen. Mit der Größe, inneren Struktur und räumlichen Ausstrahlung des Schwans konnte die kursächsische Einung nicht konkurrieren. Der Pelikan erfüllte zwar ähnliche Funktionen und hatte eine vergleichbare Größe, vertrat aber, was Organisationsgrad, pragmatische Schriftlichkeit und Gesellschaftsämter betrifft, einen repräsen-tativeren Anspruch als sein kursächsisches Pendant. Im Vergleich mit Pelikan und Schwan eher schlicht gestaltet war auch die liturgischen Memoria der Hieronymusgesellschaft. Gemeinsam ist allen drei kurfürstlichen Hofstiftungen, dass ihnen keine lange Lebensdauer - über den Tod des Gründers oder spätere Landesteilungen hinaus - beschieden war. Hinsichtlich ihrer antihussitischen Intention orientierte sich die Hieronymusgesellschaft offenbar vor allem am Drachenorden Sigismunds von Luxemburg.

171 Stillfried/Haenle, Buch vom Schwanenorden (wie Anm. 19), S. 14; Storn-Jaschkowitz, Gesellschaftsverträge (wie Anm. 1), S. 181 ff.

172 Streich, Sepultus in Wymaria (wie Anm. 26), S. $260 \mathrm{ff}$.

173 HStA Dresden, 12856 Domkapitel Meißen (D), Nr. 882; Teildruck: Gersdorf, Urkundenbuch Hochstift Meißen 3 (wie Anm. 106), Nr. 1354 (17. März 1516); vgl. dazu auch Streich, Hof (wie Anm. 11), S. 113; Dies., Sepultus in Wymaria (wie Anm. 26), S. 266, jeweils mit fehlerhaften Quellen- und Zeitangaben. 
3. Beim Vergleich mit anderen reichsfürstlichen Hofstiftungen des 15. Jahrhunderts weist die kursächsische Gründung zwei besondere Merkmale auf. Zum einen ist dies die pragmatische Instrumentalisierung der Kreuzzugsidee, hier in ihrer besonderen Ausprägung als Kampf gegen die Hussiten. Unübersehbar ist dabei, dass die Hieronymusgesellschaft als Machtinstrument für die böhmische Politik ihres Stifters konzipiert war. Dies weist Parallelen zur kurpfälzischen Gesellschaft vom Pelikan auf, der zwar dem Kreuzzugsgedanken fern stand, von Kurfürst Ludwig IV. aber ebenso wie die Hieronymusgesellschaft als außenpolitisches Werkzeug - hier sogar als Partner in Bündnisverträgen - eingesetzt worden ist. Zum anderen weist die wettinische Hofstiftung in Hinblick auf ihre soziale Zusammensetzung ein spezifisches Charakteristikum auf. $\mathrm{Zu}$ den Hieronymusgesellen zählten neben einigen Dynasten nahezu ausschließlich Angehörige der kanzleischriftsässigen Ehrbarmannschaft des Kurfürsten. Die Schwureinung spiegelt so die seit der Mitte des 15. Jahrhunderts greifbare Differenzierung des Niederadels in Schrift- und Amtsassen wieder, die für die wettinische Vasallenschaft typisch ist. Auffallend ist dabei die hohe Zahl kurfürstlicher Räte und Amtsträger der landesherrlichen Zentral- und Lokalverwaltung unter den Mitgliedern. Dies bildet zwar kein Alleinstellungsmerkmal der Gesellschaft, da sich ähnliche Befunde auch für Pelikan- und Schwanenorden konstatieren lassen, ${ }^{174}$ verweist aber auf die damals bereits weit fortgeschrittene „Verämterung“175 der wettinischen Lande und deutet auf eine gewisse Rolle der Hofstiftung bei der Ausformung und herrschaftlichen Integration einer adligen Funktionselite und damit indirekt auch bei der Ausbildung der wettinischen Stände hin.

$$
* * *
$$

Erst im späten 16. Jahrhundert kam es in den wettinischen Landen erneut zur Gründung von höfischen Gesellschaften. ${ }^{176}$ Sie besaßen keinen dezidiert religiö-

174 Storn-Jaschkowitz, Gesellschaftsverträge (wie Anm. 11), S. 175 (Schwan), 84 ff. (Pelikan).

175 Karlheinz Blaschke, Die Ausbreitung des Staates in Sachsen und der Ausbau seiner räumlichen Verwaltungsbezirke, in: Blätter für deutsche Landesgeschichte 91 (1954), S. 74-109, zitiert nach dem Wiederabdruck in: Uwe Schirmer/André Thieme (Hg.), Beiträge zur Verfassungs- und Verwaltungsgeschichte Sachsens. Ausgewählte Aufsätze von Karlheinz Blaschke (Schriften zur sächsischen Geschichte und Volkskunde 5), Leipzig 2002, S. 29-62, hier S. 32 ff.; Ludolphy, Friedrich der Weise (wie Anm. 23), S. $296 \mathrm{ff}$.

176 Die Nachricht, dass Kurfürst August 1577 versucht habe, einen Ritterorden für den Türkenkrieg zu stiften - wie Juncker, Discours (wie Anm. 23), S. 3; Ackermann, Ordensbuch (wie Anm. 11), S. 200 f.; Nimmergut, Orden 3 (wie Anm. 11), S. 1155 angeben, bezieht sich auf den Plan der Kaiser Maximilian II. und Rudolf II., den Deutschen Orden für den Türkenkampf an die ungarische Grenze zu verlegen; vgl. dazu HStA Dresden, 10024 Geheimer Rat (Geheimes Archiv), Loc. 9953/1. Der Kurfürst hat ihn im März 1577 auf einer Versammlung des obersächsischen Reichskreises vertreten; 
sen oder kämpferischen Auftrag mehr, sondern dienten in erster Linie repräsentativen Zwecken. Der mehr oder weniger stark ausgeprägte institutionelle Charakter der spätmittelalterlichen Hofstiftungen wurde nun durch ein System persönlicher Gunst- und Freundschaftbeziehungen überlagert. So errichteten Herzog Friedrich Wilhelm I. von Sachsen-Altenburg und sein Bruder Johann III. von Sachsen-Weimar 1590 eine Gesellschaft wider das Fluchen. ${ }^{177}$ Um die Solidarisierung ihres höfischen Umfelds bemühten sich die albertinischen Landesherren zur gleichen Zeit mittels der Vergabe von Gesellschaftsketten. ${ }^{178}$ Hierbei handelt es sich um Kleinode, die als Auszeichnung persönlicher Treue auf Lebzeiten des Stifters vergeben wurden, nicht aber um dauerhafte, durch Statuten regulierte Einungen. ${ }^{179}$

Die 1589 gegründete ,Goldene Gesellschaft' Kurfürst Christians I. diente beispielsweise als „persönliches Schutzbündnis“ des Fürsten, das seine Mitglieder auf einen tugendhaften Lebenswandel verpflichtete. ${ }^{180}$ Christian II. und Johann Georg I. stifteten Kleinode, die mit ihrem Devisen- und Bildschmuck vor allem politische Wertvorstellungen wie die Kaiser- und Reichstreue propagierten und die Ausgezeichneten - befreundete Kurfürsten, Fürsten, auswärtige und landsässige Adlige - auf diese orientieren sollten. ${ }^{181}$ Die ,Jägergesellschaft' Christians II., die seit 1605 bei höfischen Jagden vor allem an auswärtige Fürsten vergeben wurde ${ }^{182}$ und als Symbol für das kaiserliche Hofamt des ,Reichsjägermeisters' interpretiert werden könnte, ${ }^{183}$ ist ein deutlicher Beleg dafür, dass sich die vom christlichen

Schwabe, Vorlesung (wie Anm. 11), S. 6 ff. Um ein eigenes Projekt Augusts handelt es sich hier nicht.

177 Juncker, Discours (wie Anm. 23), S. 3 ff.; Schwabe, Vorlesung (wie Anm. 11), S. 17 ff.; Ackermann, Ordensbuch (wie Anm. 11), S. 200 f.

178 NagEL, Gesellschaften (wie Anm. 44), S. 53.

179 So mussten die Embleme nach dem Tod des Trägers auch nicht zurückgegeben werden; ebd., S. 55, $57 \mathrm{f}$.

180 Ebd., S. 56, 58 f.; vgl. auch Schwabe, Vorlesung (wie Anm. 11), S. 14 ff.; Nimmergut, Orden 3 (wie Anm. 11), S. 1155 f.

181 Nagel, Gesellschaften (wie Anm. 44), S. 57, 62 ff., 69 ff.; vgl. Schwabe, Vorlesung (wie Anm. 11), S. 14 ff.; Nimmergut, Orden 3 (wie Anm. 11), S. 1156 ff. Auch der kursächsische Administrator Friedrich Wilhelm von Sachsen-Altenburg schuf - wohl 1594 - eine eigene Gesellschaft; Nagel, Gesellschaften (wie Anm. 44), S. 60 f.

182 NAGEL, Gesellschaften (wie Anm. 44), S. 66 ff.

183 Dieses übten die Wettiner erstmals 1356 aus. Die Erinnerung an diese Rangauszeichnung dürfte auch während des 15. und 16. Jahrhunderts lebendig gewesen sein. Seit 1661 haben sich die sächsischen Kurfürsten den Titel mehrfach bestätigen lassen; vgl. dazu WINFRIED LEIST, Zwei Reichsämter der Markgrafen von Meißen, in: Blätter für deutsche Landesgeschichte 114 (1978), S. 433-440, hier S. 437 f.; EcKHART LeISERING, Die Rechte der Wettiner als Reichsfürsten. Eine Aufzeichnung von 1350, in: NASG 69 (1998), S. 233-243; Heiko Lass, Jagd- und Lustschlösser. Kunst und Kultur zweier landesherrlicher Bauaufgaben. Dargestellt an thüringischen Bauten des 17. und 18. Jahrhunderts, Petersberg 2006, S. 446 mit Literatur; zu ergänzen ist JoHanN GotTLOB Horn, Unvorgreiffliche Anzeige, was von dem Obrist-Reichs-Jägermeister-Amt, so denen [...] Churfürsten zu Sachsen als Marggrafen zu Meißen zuständig, in Wahrheit zu halten, Leipzig 1736. 
Ritterideal beeinflussten Hofgesellschaften des Spätmittelalters im Fall der Wettiner während des 16. Jahrhunderts zu einem säkular geprägten höfischen Ehrenzeichen gewandelt hatten. Hier vollzog sich ein Umbruch, der ähnlich auch in anderen Territorien zu beobachten ist: Der korporative Charakter der Hofstiftungen verblasste und ihre politische Funktion trat in den Hintergrund, was sich auch in einem sinkenden Anteil des landsässigen Niederadels unter den Mitgliedern niederschlug. ${ }^{184}$ Abgesehen vom polnischen Orden des Weißen Adlers, den Friedrich August I. (August II.) als König von Polen 1705 erneuerte, und dem eine gewisse Rolle bei seiner Herrschaftssicherung zukam, ${ }^{185}$ zählen die sächsischen ,Orden' aus der Zeit nach 1700 bereits durchweg in die bis heute lebendige Kultur der Auszeichnungen für militärische und zivile Leistungen, ${ }^{186}$ dienten als ständisch-korporatives Attribut ${ }^{187}$ oder trugen schlicht den Charakter von Freundschaftszeichen. ${ }^{188}$

halten, Leipzig 1736.

184 So exemplarisch Adler, Ordensstiftungen (wie Anm. 5), S. 307 ff.

185 Schwabe, Vorlesung (wie Anm. 11); Ackermann, Ordensbuch (wie Anm. 11), S. 92 f.; Paul Arnold, Die Medaillen und Münzen auf den Weißen Adlerorden in der Zeit der Sächsisch-Polnischen Union (1697-1763), in: Dresdner Kunstblätter 50 (2006), H. 1, S. 32-41.

186 Übersichten zu königlich und herzoglich sächsischen Orden der Neuzeit bei NimmeRGUT, Orden 3 (wie Anm. 11), S. 1160 ff., 1301 ff., 1360 ff.; Ders., Bibliographie zur deutschen Phaleristik. Übersicht über das gesamte Schrifttum zu deutschen Orden und Ehrenzeichen bis 31.12.2007, Regenstauf 2010, S. 417 ff.; vgl. dazu LuTz FrITSChE (Hg.), Die Orden und Ehrenzeichen des Großherzogtums Sachsen-Weimar-Eisenach. 1815-1918, Ilmenau 2012; Dietrich Herfurth/Jochen Klauss/Jürgen Klee, Im Zeichen des Weißen Falken. Sachsen-Weimar-Eisenach im Lichte seiner Orden und Ehrenzeichen, Berlin 2012; Henning Kästner, Der Weimarer Falkenorden und die Inszenierung des frühkonstitutionellen Staates, in: Zeitschrift für Thüringische Geschichte 63 (2009), S. 213-233. Zum sachsen-weißenfelsischen „Orden der edlen Neigung“ („Société de la Noble Passion“) vgl. Schwabe, Vorlesung (wie Anm. 11), S. 25 ff.

187 Wie etwa die 1763/64 von Kurfürst Friedrich Christian und Administrator Xaver für die Domkapitulare von Meißen und Merseburg gestifteten Orden; vgl. Karin HeIse/ Holger Kunde/Helge Wittmann (Hg.), Zwischen Kathedrale und Welt. 1000 Jahre Domkapitel Merseburg. Katalog (Schriftenreihe der Vereinigten Domstifter zu Merseburg und Naumburg und des Kollegiatstifts Zeitz 1), Petersberg 2004, S. 302 ff. (Berit Wagner).

188 Wie etwa der von Johann Georg IV. für das Treffen mit Kurfürst Friedrich III. von Brandenburg in Torgau geschaffene „Orden der guten Freundschaft" („Orden vom Goldenen Brasselet") oder der von Kurfürstin Christiane Eberhardine 1719 gestiftete „Orden der Treue“; Schwabe, Vorlesung (wie Anm. 11), S. 22 f., 36; Nimmergut, Orden 3 (wie Anm. 11), S. 1159. 


\section{Anhang}

1.

Caspar (von Schönberg), Bischof von Meißen, bestätigt die von Kurfürst Friedrich (II.) am 30. September 1450 gegründete Hieronymusgesellschaft und den für sie gestifteten Altar in der Fürstenkapelle des Meißner Doms. Jedem Mitglied, das seine Gebetspflichten erfüllt, sowie allen Männern und Frauen, die an Gottesdiensten und Begräbnisfeiern der Gesellschaft teilnehmen, erteilt er einen Ablass von 40 Tagen.

Stolpen, 1. Januar 1460

A Sächsisches Staatsarchiv - Hauptstaatsarchiv Dresden (im Folgenden: HStA Dresden), 10001 Ältere Urkunden, Nr. 7651 (Transsumpt; Ausfertigung in Libellform; Pergament; Quinternio mit zeitgenössischer Foliierung, Bl. 1r radierter, unleserlicher Vermerk, Bl. 1v-2r leer, auf Bl. 10v [alt 9v] von Hand des 15. Jahrhunderts: Bischoff Caspars zu Meyssen brief die geselschaft sanct Iheronimi betreffend datum Meyssenn anno domini $\mathrm{M}^{\circ} \mathrm{CCCC}^{\circ}$ im $\mathrm{L}$ jare, darunter von Hand des 16. Jabrbunderts Schrank secundus kästlein x n. 1 Bl. 76 b, darunter von späterer Hand in Rotstift 10.1. No. 680; vom Aussteller und Kurfürst Friedrich II. gemeinsam besiegelt; beide Siegel an blau-roter Seidenschnur anhängend, das des Bischofs nur noch in Resten erbalten).

$B_{1} \quad$ HStA Dresden, 10004 Kopiale, Nr. 1317, Bl. 329r-333v (korrigierter Entwurf zu A). Auf Bl. 333v der Vermerk uf sand Ieronimi gesehelschaft).

$B_{2} \quad H S t A$ Dresden, 10004 Kopiale, Nr. 1317, Bl. 323r-326v (Bl. 324 und 325 verheftet) (korrigierter Entwurf zur verlorenen Ausfertigung der in A inserierten Gründungsurkunde vom 30. September 1450. Darüber das Rubrum dis sal sein eyn erblich geselschaft).

C HStA Dresden, 10003 Diplomatarien und Abschriften, Kapsel 140, Nr. 34 (Abschrift aus $A$, 19. Jahrbundert).

D HStA Dresden, 10003 Diplomatarien und Abschriften, Bd. 39, Bl. 313 (Abschrift aus $B_{2}$, 19. Jabrhundert).

Druck: Kurzer Auszug nach A oder $B_{1}$ bei HORN, Nützliche Sammlungen (wie Anm. 31), S. $873 \mathrm{ff}$. Den Text Horns übernahmen BIEDENFELD, Geschichte 1 (wie Anm. 11), S. 74 f.; und STORN-JASCHKOWITZ, Gesellschaftsverträge (wie Anm. 3), S. $317 \mathrm{ff}$.

Die Wiedergabe folgt A. Die dort inserierte Fassung der Urkunde vom 30. September 1450, deren Ausfertigung verloren ist, weicht an einigen Stellen leicht von $B_{1}$ und $B_{2} a b$. Dies lässt vermuten, dass die Vorlage bei der Bestätigung von 1460 überarbeitet wurde. Der textkritische Apparat dokumentiert nur inbaltich relevante Varianten; grafische oder grammatikalische Diversitäten und sonstige kleinere Abweichungen blieben unberücksichtigt. Die Textwiedergabe orientiert sich an den „Empfehlungen der Arbeitsgemeinschaft außeruniversitärer bistorischer Forschungseinrichtungen", in: Archiv für Reformationsgeschichte 72 (1981), S. 299-315. Groß- und Klein-, Getrennt- und Zusammenschreibung der Vorlage wurden normalisiert. 
Caspar Dei et apostolice sedis gratia episcopus Missnensis ad perpetuam rei memoriam. Unicus et unus Princeps noster, Motor immobilis, Deus trinus et unus, trinus quidem in personis et unus in essencia, pax nostra, qui facit utraque unum in unico perhennitatis sue primordio unam sanctam katholicam et apostolicam

5 ecclesiam, extra quam non est possibile quemquam salvari, ex bonitatis sue unico ac fontali principio benigniter decrevit preordinare eamque tamquam sponsam unicam matris sue in vestitu deaurato varietatis amictam fulgoribus humanitatis nostre assumptus conversationibus dignatus est sui personali presencia sibi desponsare unam fidem, unum baptisma in uno spiritu, in ea uniformiter edocens

10 unumque esse necessarium ac optimam partem eligendam numquam tum auferendam unico predicavit contextu, ut sic omnes, qui unus panis et unum corpus multi sumus tamquam unius moris in domo eiusdem ecclesie militantes, in unam spem vocacionis eterne vite bravium unamque mercedem, unum videlicet denarium diurnum pro quo unanimiter conventi sumus recipere satageremus. Sane super 15 illustris princeps christianissimus dominus dominus a)-Fridericus sacri Romani imperii archimarstallus, ${ }^{1)}$ princeps elector, dux Saxonie, lantgravius Thuringie et marchio Misnennsis, ${ }^{-a}$ ) dominus et amicus noster preclarissimus, hec considerans atque quam bonum et quam iocundum sit multos in visceribus caritatis in sinceritate fidei et devotionis unire, multos quam in unam soliditatem et societatem con-

20 gregare, ut orthodoxe fidei ampliores constituerentur zelatores et eiusdem fidei strennui defensores, ut sic in eis unionis concordie et sinceritatis augeatur devotio ad Deum omnipotentem eiusque gloriosissimam genitricem virginem Mariam, celorum reginam et hominum imperatricem, unitatis ministram et magistram. Quamobrem societatem certam cum statutis et ordinacionibus edidit in ea forma, 25 que sequitur, et est talis:

In dem namen der heyligen unde ungescheiden Drÿvaldikeit amen. Dem almechtigen, ewigen und gutigen Gote unde siner hochwirdigen gebenedyten muter Marian unde allen heÿligen zcu eren, des heiligen unde achtbarn lerers unde be-

30 kenners Gots $\left.{ }^{b}\right)$ sente Ieronimi, des wirde unde achtbarkeit in der heiligen cristenheit obir alle lerer als eine obirluchtige bornde lampe2) in schinbarkeit aller heyligkeyt wol gecziret clerlichen erschinet, dorczu auch zcu sterkunge und hoer erhebunge des heiligen glouben, wir c)-Friderich von Gots gnaden, herczogk zcu Sachssenn, des heyligen Romischenn richs erczmarschalk, kurfurste, lantgraffe in

35 Doringenn unde marcgrave zcu Missen. ${ }^{-c)}$ Nachdem wir eigentlich betracht unde in heimlichkeit unsers herczen wol vermerckit habenn, welcherley verdinstniss unde wiegetaner herlichkeit in dem hoffe des obirsten richs unde der gotlichen maiestat erhaben unde geachtet ist der erliche unde d)-hëlige bekenner gots ${ }^{-\mathrm{d})}$ und grose lerer sante Ieronimus, der der hochste ußleger gewest ist der heiligen schrifft,

40 ein meister des cristengloubens, der ganczen werlde zcirheit, allermenniglich forme unde rechte wiese, aller der, die leben, eine rechte unnde unstreffliche regil uß sinen worten, werken, wesen unde exempel von richtums wegenn siner obirswendigen und verdÿnten heyligkeit offinbarlich durch alle cristenheit bewert und 
verkundigt wirt, als das man von ÿm singet, schribet unde saget, was sent Ieronimus nicht gewust hat, das hat nÿe eÿn lebende mensche gewust, ${ }^{3)}$ unde das er aller schriffte des alden unde des nüwen gesetzee) ${ }^{e}$ unde aller schriffte warheit, dorczu ouch aller heimlichkeit, dovon die aldenn in beydenn gesetzen ${ }^{f)}$ in krichischer, arabischer, hebreischer, kaldeischer, latinischer, windescher und aller ander zcungen zcu iren schrifften gesagt unde verkundigt haben, ein getruwer, festir unde gruntlicher ußleger unde allerbehendister von einer sprache in die ander wandeler an alle insprache ader beselbung. $\left.{ }^{4}\right)$ Wol bewert ist sins lebens herlichkeit auch bey sinem leben, bey sinem tode durch offinbare wunderwerg unde zceichen an blinden, lamen unde allerleye krancken unde das merer ist, auch an vyl todenn, die durch sin verdinen unde anrurunge seiner cleyder vom tode erwackt unde uffirstanden sin, unde mancherley warheit verkundigt unde irretum geoffinbart unde verdamptg) haben. Derselb liebe herreh) sant Ieronimus auch ein harter hammer unde swerer vertriber der keczer,5) irer falschen lere unde verkarten boßheit ein ufloser unnde gruntlicher verfolger gewest ist, so das er der keczereyn so offinbar gemacht unde uffgedackt hat, das vyl keczer durch ÿn gepfloget, nydergeslagen, verdampt unde auch etliche durch sine wunderczeichen getotet unde ewig verdampts) wurden sint, etliche auch i)-widerruffen unde durch sine lere unde mechtige wunderczeichen $n^{-i)} z c u$ rechten erkentnis unde zcu dem glouben widerkomen sin unde haben derk) cristenheit, die sie als keczer unnde mit der keczereÿ swerlichen verfolget habenn, fride gegeben mussen. Von sulcher unde ander unmessiger unde hocher sachen wegen haben wir gedacht, den gnanten achtbarn lerer sent Ieronimum, nachdem das billich, mugelich unde seliglich ist, uß allen unnsern krefften zcu eren, zcu wirdigen unde zcu loben unde ander lute, so vil uns mugelich ist, ÿn auch zcu eren, zcu wirdigen unde zcu loben anczuhalden unde czu furen, unde haben nicht ylende nach ÿtel, sundern nach zcitlichem rate der unsern, fursten, graven, herren, frÿen, rittern, knechten, auch unser rete, manne unde lieben getruwenn eÿn cleynot von silber ader von golde in wiese eins halsbands an unserm leybe unde halse zcu eren und wirdikeÿt des vilgnanten heiligen sent Ieronimi gedacht zcu tragen unde andern luten, hern, fursten, graven, frÿen, rittern unde knechten, doch die von gutenn geslechten unde von yr beyder eldern edel geborn unde wirdigl) sin, zcu geben. An des cleynots fordern teyle sal hangen ein cardinalhut zcu gedechtnis, das sent Ieronimus der heyligen Romischen kirchen cardinal gewest ist, und nyder dem hute sal hangen ein bilde ader zceichen eyns lauwen, zcu gedechtnis, das er ë̈nenn unvernumfftigen lauwen in menschen dinst obirnaturlich bracht hat sinem closter unde der geistlichkeit zcu nucze unde fromen, unde ${ }^{\mathrm{m}-}$ )obir dem lawen unde hute sullen sin griffel zcu ringe umbe den hals gehnde, und umbe igczlichen griffel gewunden eÿn $\mathrm{rÿm}^{-\mathrm{m})}$ sulchs luts: $O$ wie gro $\beta$ ist der gloube, den der heylige sent Ieronimus gelert hat unde gepredigt. $\left.{ }^{6}\right)$ Dasselbe also geschickte cleÿnot unde halsbant wir meÿnen zcu einem grossen zceichen zcu eren unde wirdikeit sant Ieronimi zcu tragen unde zcu geben zcu sundirlicher andacht, hoffinde an allen zcwivel den heyligen sant Ieronimum zcu haben in sunderlicher liebe unde gedechtnis zcu einen patronen, stewrer unnsern) gesellen unde 
nothelffer unde wullen auch dorumb, das sulch cleÿnot den namen der geselleschafft sent Ieronimi habin sal, unde hoffen in gutem glouben mit allen den, die sulche geselleschafft tragen werden, als durch yn uff eyn mal zcu vorfechtung und

90 schirmunge des cristengloubens drÿ tode erwagkt sin, das wir auch mit allen den, die in disse friheit komenn unde das cleynot tragen werden, des heÿligenn gloüben lieber unde fryer verfechter werden mit solchen flissen unde sorgen, als das unser eldern unde vorfarn, die sich o)-unde wir dornoch-o) als ein mawer vor den glouben unde huß gotes gesaczt habenn unde haben, doran sich nicht eincherleÿe arbeÿte,

95 mühe, zcerunge unde grosse koste hindern lassen unde wir nach ÿn als vlissige nachfolger biß alher mit hilff des almechtigen gots unde anwaldunge des grossen lerers sant Ieronimi. Auch haben mit den unsern unerschrocken unde vestigclichen bestanden unde furderlich tun wollen unde uff das sulche geselleschaft voreynunge als eyn heylig unde milde ding von der menschen gedechtnis nicht

100 kome, sundern grunt unde gut fundament habe, so nemen wir alle die, die sulch sante Ieronimi unde unser geselleschafft von yrer harten unde trefflichen teten unde ander toguntlicher wergk wegen, die sie in ritterlichen ubungenp) unde offinbar in gemeÿnen der cristenheitq) nucz tun werden, tragen unde zcu tragenn erkorn werden, in unser eynikeit unde bruderlicher geselleschafft in sulcher guttir

105 meÿnunge, das sie mit uns unde wir mit ÿn in sulcher eÿnickkeit mit eÿnem munde, mit eÿnem gemute, in eÿnem gloüben unde mit eÿner meÿnunge einen almechtigen Got in sinem wesen unnde einen lerer, den heyligen eÿnigen sant Ieronimum, gewirdigen mugen in eynickeit unde eÿniger bruderlichen liebe in einer ritterschafft, eine crone, ein lon unde einen tagepfenning, dorumbe wir alle

110 eyntrechtiglich gemytet sin, ewiclich mugen in einem lone, ${ }^{\mathrm{r}}$-das Got selber ist, ${ }^{-\mathrm{r}}$ ) erwerben. Unde uff das sulche des heyligen sant Ieronimi unde unser geselleschafft vesten grunt habe unde ewige forteyl unde privilegia, so seczenn unde wullen wir vor allen dingen, das nÿmande sulch cleynot unde geselleschafft gegeben werden noch tragen sal, er sey danne siner geburt von edelm stamme als eÿn

115 furste, grave ader friie ader sust von guter ritterschafft, eins guten erlichen geslechts, wol und eelich von sinen vier anen geborn unde herkomen. Er sal auch sin von lobelicher handelunge unde erlichen unde redelichen sitten ${ }^{s-}$ ) unde nicht eÿn wucherer ader strassenröuber,-s) also das er von eincherley untrawe nicht vermerckt seÿ unde sich an sinem naturlichen erbherren ader sinem eelichen bette-

120 gnossen keÿner wiese vergriffen habe. Er sal auch sulcher truwe und gloübens sin, das er vortmer wider uns unde unsser herschafft keynerleÿe arges ader widers tun ader, sovil an ÿm ist, zcu tun nicht gestaten ungeverlichen, es sey danne, das uns unser cleÿnot unde geselleschafft, die er getragen hat, ab her sie auch umb sin eigen gelt, o)-doch mit unser bewust ${ }^{-0}$ ) geczeugt hette, vier wochen dofur, ${ }^{-}$)ehr er unser

125 vyhant wurde,-s) wider geschickt ader gesant habe. Er sal auch in striten ader andern ritterlichen geschefften sich uffrichticlich halden unde, wo her hin geschickt wirt, ab her auch an eÿnen ferlichen ort geschickt wurde, in keynerley wiese wichen, zcuruck treten ader die flucht geben, sunderlich manlich unde ritterlich tun nach geburlichkeit, auch biß in den tot, ab das not tun wurde. Er sal ouch die 
geistlichkeit lieben, kirchen, witwen unde weisen schuczen unde schirmen nach aller mogelichkeit unde allen den, die disse geselschafft tragen, hilff, rat unde guten willen erczeigen. Furder, das danne ouch sulche des heyligen sent Ieronimi geselleschafft unde disse gute unser ordenunge guten bestant unde wehre habe, so haben wir in unser cappellen der heiligen drier könige czu Missen durch uns gebuwet, gestifft und uffgebracht einen altar uffgericht unde von nuwes gestifft, dorczu wir einen sunderlichen altristen unde capplan geschickt, der danne Got dem almechtigen in sinen messen und ampten vlissiglich bitten sal vor alle, die sulche gesellschafft tragen werden ${ }^{t-}$ ) ${ }^{2}$ de getragen habenn. ${ }^{t}$ ) Unde uff das sulch altar furder nicht geergert, sundern gebessert ${ }^{s-}$ unde doruff von dem selben caplan alle tage eine messe gehalden ader durch ÿn bestalt-s) werde, so sal ein iczlicher, der disse sent Ieronimi geselleschafft am leben wirt tragen, also bestellen, das nach sinem tode die geselleschafft gancz unde unversert gein Missen in die gnante unser cappelle, ${ }^{s-}$ )nemlich ist das eyn grave ader ein herre, so sal sulche geselleschafft beÿ zcweyn erbarn knechten, ist es aber ein ritter ader edelman, so sal die beÿ einem erbarn knechte dahin gein Missen geschickt unde sinen schilt mit sinen wapenn gezciret in die cappelle vorberurt gehangen werden ${ }^{-s}$ ) und dem vorgnanten altristen obirantworten, der denne ${ }^{s-}$ )in der gnanten unnser cappelle mit andern unsern vicarien sin dorynne singen und anders gotsdinst uben unde ${ }^{-s}$ ) sulch geselleschafft bey sich unnde mit wissen enthalden sal, solange das dorumbe mit rate zcinse unde rente gekouft werden mugen, dodurch danne vor alle, die in der geselleschafft versterben, der dinst Gotes mit vigilien unde messen nach guter ordenunge von dem altristen bestalt werden sal, so offt obir das jar, als sich das wirt heischen. Es sal auch iczlicher uß der geselleschafft zcu eren Gote dem herren, der jungfrau Marien unde dem lieben hern ${ }^{\text {u) }}$ sante Ieronimo zcu lobe beten alle Sonnabent funffczehn pater noster unde sovil ave Maria unde einenv) gloübenn, unde alle Sontage funff pater noster und funff ave Maria unde dryw) gloüben vor die selikeit der lebinden in der geselleschafft verbundenn sin. Wenne auch einer uß der geselleschafft nach dem willen gots verscheidet unde todeßhalbin abegeet, so sullen die $\mathrm{u} ß$ der geselschaft nahe wonende ader sin ungeverlichen komen unnd den lichnam des toden zcu der erden helffen bestaten. Do sollen auch allex) bruder der geselschafft, die in eynem virtel jars sterben, uff alle quatuor tempora begangen werden, wie sich das heischen wirt mit messen unde vigilien. Dorczu danne alle, die sulch des heÿligen sant Ieronimi unde unser geselleschafft tragen, gemeinlich komen sullen, ${ }^{s-}$ )ader ab die zcu wyet weren, einen gloubhaftigen dorczu schicken ${ }^{-s)}$ alle virtel yars, unde sal yderman vor die toden an stat der messen und vigilienn drissig pater noster unde drissig ave Maria zcu beten verbunden sin, so das die bruder alle virteÿl jar ir gedechtniss zcu Missen in der gnanten capellen haben sullen. Bey sulcher sampnung unde gedechtnis auch die geselleschafft der vorstorben bruder obirantwurt werden sullen unde furder geratslaget werden uff das beste, was in sulcher geselleschafft notturfft sin wirdet, dadurch der wirdige heÿligey) sant Ieronimus hinfurder geeret unde gewirdigt werde allen brudern der geselleschafft zcu selikeit des leybs und der selen. ${ }^{\text {z }}$ aa)-Welcher auch in der geselleschafft verarmet 
durch redelich ursach,ab) nemlichen durch gefengnus in houptstriten ader andernn erlichen sachen, den ader dem sal der furst sine lebtage ac)-bequeme notturfft zcu 175 siner enthaldunge gebenn $\left.{ }^{-a a}-a c\right)$ alles Gote dem almechtigen zcu lobe, der do herscht unde lebet von ewigkeit zcu ewigkeit. ad)-Zcu bevestunge unde ewiger bliblichkeit haben wir, Friderich, herczog zcu Sachssen vorgnant unser ingesigel hir an dissen brif tun hengen, der gegeben ist zcu Missen an sant Ieronimus des heÿligenn ußerwelten bekenners gots tage ${ }^{a e-}$ )nach Cristi unnsers herrenn

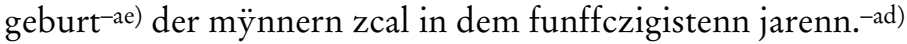

Prememoratus serenissimus princeps, ut prelibatam societatem ac fraternalem soliditatem in omnibus suis ordinacionibus, punctis et articulis licitis et salubribus ratificare, approbare et confirmare dignaremur, nobis affectuosius supplicare cura-

185 vit. Nos igitur, Caspar episcopus prenotatus, qui ex credito nobis pastorali officio de salute animarum plusquam de omni re tocius universi cogitare debemus, oculo directo inspicientes, quantum Deo acceptabile sit uno ore, una fide eodemque unitatis et caritatis vinculo deum glorificare sencientesque, quam pervigil exoratrix ipsa beatissima regina celorum coram unigenito suo, qui adveniente plenitudine

190 temporis in sua se clausit viscera, factus homo pro nobis miseris peccatoribus existat, pensantes denique gloriosissimi Ieronimi prefulgidi confessoris, lampadis ecclesie merita, quante venerabilitatis et dignitatis in celesti curia apud deum censeatur, intencionemque preclarissimi principis salubrem, piam et iustam recensentes huiusmodi peticionibus inclinati ipsam societatem cum ereccione novi altaris in

195 predicta cappella sanctorum trium regum duximus admittendam, roborandam et confirmandam ipsamque auctoritate nostra ordinaria et dyocesana admittimus, roboramus ratificamus, approbamus et in singulis punctis articulis et ordinacionibus predictis dei nomine per presentes confirmamus volentes inantea dictam societatem in suo vigore permansuram. Enimvero cupientes eciam, quo ad hec popu-

200 lum Deo reddere magis acceptabilem misticis de thesauris ecclesie militantis societatem sepedictam duximus fructuosius animandam, omnibus vere penitentibus et contritis seu in gracia existentibus, qui huiusmodi clinodium pro honore sancti Ieronimi portaverint et oraciones prenotatas singulis diebus sabatinis et dominicis in ea forma, ut preschribitur, devocius oraverint missisque et vigiliis pro fratribus cantandis vel legendis seu conduccionibus funerum, eciam aliis hominibus utriusque sexus non in fraternitate existentibus, qui huiusmodi vigiliis missis et conduccionibus interfuerint et orationes suas pro animabus fratrum defunctorum ad deum patrem omnipotentem fuderint, quociescumque et quicumque aliquot predictorum fecerint, de quolibet ipsorum quadraginta dies indulgenciarum de omni-

210 potentis dei misericordia et beatorum Petri et Pauli apostolorum eius auctoritate confisi in Domino misericorditer impartimur predictis omnibus et singulis auctoritatem nostram pariter et decretum interponentes. Nulli ergo omnino hominum liceat hanc paginam nostre approbationis, disposicionis, ordinacionis, ratihabicionis, acceptacionis, confirmacionis, af-)indulgenciarum elargicione-af) et decreti nos-

215 tri interpositionis ausu temerario infringere aut ei quovismodo contraire. Siquis 
autem hoc attemptare presumpserit, indignacionem Dei omnipotentis se noverit incursurum.ag) ah)-In cuius rei evidens robur et testimonium sigillum nostrum sigillo prefati domini nostri ducis pro omni premissorum et singulorum corroboracione duximus appendendum. Datum in castro nostro Stolpen ipso die circumcisionis domini nostri Ihesu Cristi anno eiusdem etcetera millesimo quadringentesimo sexagesimo.-ah)

a) - a) Fridericus sacri Romani imperii archimareschallus, Saxonie dux, lantgravius Thuringie et marchio Missnensis $\left.B_{1} \quad b\right)$ bekenners Gots] von anderer zeitgenössischer Hand über gestrichenem bichtigers $B_{1}$ bichtigers $\left.B_{2} \quad c\right)-c$ ) Fridrich von Gots gnaden des heiligen Romischen richs ertzmarschalk, kurfurste, herczog zcu Sachsen, lantgraff in Doringen und margraf zcu Missen $B_{1}$; Friderich von Gotes gnaden des heiligen Romischen richs erczmarschalg, herczug zcu Sachssen, lantgraff in Doringen unde marcgraff zcu Missen, kurfurste $\left.B_{2} \quad d\right)-d$ ) wirdige bekenner Gots (von anderer zeitgenössischer Hand verbessert aus wirdige bichtiger) $B_{1}$; wirdiege bichtiger $B_{2} \quad$ e) gesetze] von anderer zeitgenössischer Hand verbessert aus rechten $B_{1}$; rechten $B_{2}$ f) gesetzen] von anderer zeitgenössischer Hand verbessert aus rechten $B_{1}$; rechten $B_{2} \quad g$ ) verdampt] vortumet $B_{1} ; B_{2} \quad$ b) liebe herre] von anderer zeitgenössischer Hand über der Zeile ergänzt $B_{1}$; fehlt $B_{2}$ i) - i) hier verbessert nach $B_{1}$ und $B_{2}$; $A$ hat durch sine lere widerruffen unde mechtige wunderczeichen $k$ ) haben der] hier verbessert nach $B_{2}$; in $A$ stebt nur die; $B_{1}$ verbessert haben der zu die l) unde wirdig] von anderer zeitgenössischer Hand am Rand ergänzt $B_{1}$; fehlt $\left.B_{2}(m)-m\right)$ von anderer zeitgenössischer Hand über gestrichenem umb den leben sal gehin eyne schrifft zcu ringe gegraben eyns $B_{2} \quad n$ ) unsser] von anderer zeitgenössischer Hand über der Zeile ergänzt $B_{1}$; fehlt $B_{2} \quad o$ ) - o) von anderer zeitgenössischer Hand am Rand ergänzt $B_{1}$; fehlt $B_{2}$ p) ubungen] von anderer zeitgenössischer Hand verbessert aus sachen $B_{1}$; sachen $B_{2} \quad q$ ) der cristenheit] von anderer zeitgenössischer Hand am Rand ergänzt $B_{1}$; fehlt $\left.B_{2} \quad r\right)-r$ ) von anderer Hand am Rand ergänzt $B_{1}$; feblt $B_{2}$ s) - s) von anderer zeitgenössischer Hand am Rand ergänzt $\left.\left.B_{2} \quad t\right)-t\right)$ von der Hand des Korrektors in $B_{1}$ über der Zeile nachgetragen $B_{2}$ u) hern] heiligen $B_{2}$ v) einen] dry von anderer zeitgenössischer Hand über gestrichenem einen $B_{1}$; drey $\left.B_{2} \quad w\right)$ dry] eynen $B_{1} ; B_{2} \quad x$ ) alle] hier ergänzt nach $B_{1}$ und $B_{2} \quad$ y) folgt unde lerer $B_{2} \quad$ z) $B_{2}$ bricht hier $a b$. Es folgt von anderer zeitgenössischer Hand an den babist zcu schigken umbe aplas zcum altare sand Ieronimi zcu geben. Item zcu den cardinelen. Item zcu den bischofen; danach von Hand des 17. Jabrhunderts vide auff folgendem dritten blatt bischoff Johannsens zu Meißen confirmation und ratification alwo auch die jahrzahlen aa) - aa) welcher in der geselschaft verarmet durch redeliche zufelle, nemlichen durch gefengnisse, in houbstriten ader andern erlichen sachen, den ader dem sal der furst sine lebtage sine notdorft geben uf verlangen [?] etcetera am Rand des vorigen Blatts nachgetragen $B_{2} a b$ ) ursach] verbessert aus zufelle $B_{1}$ ac) - ac) von anderer zeitgenössischer Hand am Rand ergänzt $\left.\left.B_{1} \quad a d\right)-a d\right)$ von anderer Hand unter dem Text ergänzt $B_{1}$ ae) ae) feblt $B_{1}$ af) - af) von anderer Hand am Rand ergänzt $B_{1}$ ag) folgt gestrichen datum $\left.\left.B_{1} a b\right)-a b\right)$ von anderer Hand nachgetragen $B_{1}$

1) In dieser Form auch die Titulatur der Grabplatte Kurfürst Friedrichs II. in der Fürstenkapelle des Meißner Doms; MICHAEL KIRSTEN, Die Grabplatten in der Fürstenkapelle, in: Hütter/Kavacs/Kirsten, Portal (wie Anm. 105), S. 318-345, hier 
S. 321. 2) Vgl. Johann von Neumarkt, Eusebiusbrief, c. 12, ed. KLAPPER, Schriften 2 (wie Anm. 76), S. 35, Z. 5: o du lihte lamp suszes bildes, Z. 15: O du reines lamp an allen mayl 3) Vgl. Johann von Neumarkt, Augustinusbrief, c. 4, ed. KLAPPER, Schriften 2 (wie Anm. 76), S. 253, Z. 8 ff.: Vnd kurczleich czu sprechen: was der erwirdig Jeronimus nocht gekont hat, das ist in der naturn vnkunt vnd vnwissent allermenicleichen; vgl. auch CLEMENS BLUME/GUIDO MARIA DREVES (Hg.), Analecta Hymnica medii aevi, Bd. 26, Leipzig 1897, Nr. 35, S. 101 (Hieronymusoffizium, gedruckt im Breviarium Misnense Bischof Johanns von Weißenbach, Meißen [Markus Brandis], 16. Juli 1483 [GW 5390]); CLEMENS BLUME (Hg.), Analecta bymnica medii aevi, Bd. 55, Leipzig 1922, Nr. 169, S. 191: Quod nescivit Ieronymus, natura nulla nescivit (Hieronymussequenz des 15. Jabrbunderts, gedruckt in einem der um 1500 entstandenen undatierten Meißner Missalien (Speyer: Peter Drach d. M., um 1498, GW 24546; desgl., um 1499, GW 24547; Nürnberg: Georg Stuchs, nach 1. September 1500, GW 24545). 4) Johann von Neumarkt, Augustinusbrief, c. 4, ed. KLAPPER, Schriften 2 (wie Anm. 76), S. 252 f., Z. 24 ff.: Ebreische, krichische, arabische, von Caldea, von Persien, von Meiden und dorczu aller land vnd alles volks czungen, buchstaben vnd sprach kont er so gar volkumenleichen; vgl. auch S. $251 \mathrm{f}$., $Z$. $25 \mathrm{ff.:}$ wann er di alten vnd di newen schrift aws ebreischer czungen in krichesche vnd in lateinische czungen bracht hat; ferner Eusebiusbrief, c. 2, ed. KLAPPER, Schriften 2 (wie Anm. 76), S. 18, Z. 13 ff.: Er ist der selbe, der so vil bucher von ebreischer vnd krichischer czungen in lateynische czunge braht hat mit groszen erbeiten; $e b d$., c. 5, S. 21, Z. 1 ff.: Sein gesprechickeit seiner geplumten red, do mit er die heiligen schrift aws ebreischem vnd aws krichischem geczung in latein bracht hat. 5) $\mathrm{Vgl}$. BLUME, Analecta bymnica medii aevi, Bd. 55, a. a. O., Sachanm. 3, Nr. 169, S. 192: haereticorum iacula. 6) Ähnlich eine auf Hieronymus bezogene Umdichtung einer Angustinussequenz des 15. Jabrhunderts: Quam fidelis ille servus et prudens dispensator Ieronymus; BLUME, Analecta hymnica medii aevi, Bd. 53, Leipzig 1911, Nr. 126a, S. 126. Stilistisch ähnliche Formulierungen auch bei Johann von Neumarkt, z. B. Eusebiusbrief, ed. KLAPPER, Schriften 2 (wie Anm. 76), S. 223, Z. 17-19: O wi gar grosz ist vnser vater Jeronimus, wi vil vermag er wunders! Vgl. auch oben Anm. 94 mit dem Hinweis auf die Devise des Drachenordens.

Mitglieder der Hieronymusgesellschaft

[um 1460]

A Sächsisches Staatsarchiv - Hauptstaatsarchiv Dresden, 10004 Kopiale, Nr. 1317, Bl. 322r (korrigierte Direktschrift).

RICHARD VON MANSBERG, Erbarmannschaft wettinischer Lande. Urkundliche Beiträge zur obersächsischen Landes- und Ortsgeschichte in Regesten vom 12. bis Mitte des 16. Jahrbunderts, 4 Bde., Dresden 1903-1908, hier Bd. 1, S. 581, Bd. 2, S. 512 und Bd. 4, S. 161, datiert die Liste auf 1459. Vermutlich entstand sie in zeitlicher Nähe zur Bestätigung der Gesellschaft durch Bischof Caspar von Meißen (Anhang 1), was die Tatsache stützt, dass eine große Zahl der aufgeführten Mitglieder auch in verschiedenen Schriftsassenverzeichnissen des Jabres 1460 (wie oben Anm. 126) begegnet. Als Terminus ante quem ist das Todesjabr des Stifters (1464) anzuseben. 
Eine große Zabl der Quellenbelege, die zur Identifizierung der Hieronymusgesellen herangezogen wurden, hat Herr Prof. Dr. Joachim Schneider (Dresden) zur Verfügung gestellt. Für die großzügige Überlassung seiner Arbeitsmaterialien und viele weitere Hinweise sei ihm an dieser Stelle herzlich gedankt.

In den nachstehenden Anmerkungen werden folgende Vasallenverzeichnisse verkürzt zitiert: Thüringisches Hauptstaatsarchiv Weimar, Ernestinisches Gesamtarchiv, Reg. R, Bl. 55 b XIV Nr. 9, Bl. 10v-12r (Aufgebotsverzeichnis von $1454=$ Verz. 1); ebd., Nr. 11, Bl. 2r-5b (Aufgebotsverzeichnis von 1460 = Verz. 2); HStA Dresden, 10005 Hof- und Zentralverwaltung der Wettiner (Wittenberger Archiv), Loc. 4374/1, Bl. 6r-16r, hier Bl. 12v-16r (Steueranschlag von $1460=$ Verz. 3); ebd., Loc. 4376/18 (Tranksteuerausschreiben von $1470=$ Verz. 4); HStA Dresden, 10024 Gebeimer Rat (Gebeimes Archiv), Loc. 7997/3 (Aufgebotsverzeichnisse der Jahre 1473 bis 1482 = Verz. 5); ebd., Loc. 9603/3, Bl. 3r-7v (Verzeichnis des Gefolges der Hochzeit Herzog Albrechts in Eger im November $1459=$ Verz. 6).

Diese hirnachgeschriben sint in der geselschafft sente Ieronimi.

[1] Herzcog Friderich

Kurfürst Friedrich II. von Sachsen (*1412, reg. ab 1428, † 1464). Er gehörte seit 1455 auch dem hohenzollerischen Schwanenorden an; STILLFRIED/HAENLE, Buch vom Schwanenorden (wie Anm. 19), S. 199 f.

[2] Herczog Ernst zu Sachsen

Ernst, zweiter Sobn von Nr. 1 (*1441, reg. ab 1464, †1486).

[3] Herzcogk Albrecht

Albrecht, dritter Sohn von Nr. 1 (*1443, reg. ab 1464 gemeinsam mit seinem Bruder Ernst, nach 1485 im meißnischen Landesteil, †1500).

\section{[4] Grave Jurge von Anhalt}

Georg I. von Anbalt-Zerbst († 1474); vgl. HERMANN WÄSCHKE, Anhaltische Geschichte, Bd. 3, Köthen 1913, S. 559. Er war in den Naumburger Frieden von 1451 einbezogen; KOCH, Bruderkrieg (wie Anm. 27), S. 183; vgl. auch RICHARD VON MANSBERG, Erbarmannschaft wettinischer Lande. Urkundliche Beiträge zur obersächsischen Landes- und Ortsgeschichte in Regesten vom 12. bis Mitte des 16. Jabrbunderts, 4 Bde., Dresden 1903-1908, hier Bd. 3, S. 335 f. Am 28. April 1452 schlichtete er gemeinsam mit Adolf I. von Anhalt in einem Streit zwischen Kurfürst Friedrich II. von Sachsen und Kurfürst Friedrich II. von Brandenburg; HStA Dresden, 10001 Ältere Urkunden, Nr. 7243. Am 8. Juli 1453 erklärten Georg und Adolf von Anhalt die Fehde gegen Georg Podiebrad wegen dessen an den Wettinern verübten Unrechts; HStA Dresden, 10005 Hof- und Zentralverwaltung der Wettiner (Wittenberger Archiv), Loc. 4325/1, Bl. 176 (Kriegsverlust). 1459 begleitete Georg Albrecht von Sachsen zu dessen Egerer Hochzeit; Verz. 6; LANGENN, Albrecht (wie Anm. 128), S. 40. Georg I., Adolf I. und Albrecht V. von Anbalt waren Mitglieder des Schwanenordens; STILLFRIED/HAENLE, Buch vom Schwanenorden (wie Anm. 19), S. 113; KRUSE/PARAVICINI/RANFT, Ritterorden (wie Anm. 7), Nr. 69, S. 336. 
[5] Grave Berndt von Barbei

Graf Bernhard von Barby ( +1468 , Sohn Graf Günthers von Müblingen-Barby); vgl. FRANK BARON FREYTAG VON LORINGHOVEN, Europäische Stammtafeln. Stammtafeln zur Geschichte der europäischen Staaten, Bd. 4, Marburg 1957, Tafel 49. Im November 1459 begleitete er Herzog Albrecht zu dessen Egerer Hochzeit; Verz. 6. Ferner erscheint er in Schriftsassenverzeichnissen von 1473 und 1482; Verz. 5, Bl. 8v, 158 .

[6] Der alde Russe

Heinrich IX., der Ältere, Reuß von Plauen, Herr zu Greiz (erwähnt 1429 bis ca. 1475); vgl. SCHMIDT, Genealogie (wie Anm. 110), Tafel 6, Nr. 21; DETLEV SCHWENNICKE, Europäische Stammtafeln. Neue Folge, Bd. I/3, Frankfurt a. M. 2000, Tafel 355 (hier als Heinrich X., ab 1462 als d. Ä.); CURT VON RAAB, Regesten zur Ortsund Familiengeschichte des Vogtlandes (1350-1563), 2 Bde., Plauen 1893-1898, hier Bd. 1, Nr. 320, 461, 573, 591 f., 633, 660, 839; ROGGE, Herrschaftsweitergabe (wie Anm. 27), S. 241. Teilnebmer der im Kontext der Altenburger Teilung geschlossenen, mit dem Kurfürsten kooperierenden Ständeeinung vom 29. November 1445; wie oben Anm. 141. Im Januar 1446 ist er als Vertreter Kurfürst Friedrichs II. in den Verhandlungen mit Wilhelm III. in Zeitz belegt, 1447 im Bündnis mit Friedrich; KOCH, Bruderkrieg (wie Anm. 27), S. 49, 100. Zur Belebnung durch Friedrich II. vgl. FRIEDRICH SCHNEIDER, Die Belehnungsurkunde Kurfürst Friedrichs II. des Sanftmütigen für die Herren Reußen zu Greiz im Jabre 1449 und der Teilungsvertrag der Gebrüder Reußen im Jabre 1485, in: Festschrift Armin Tille zum 60. Geburtstag, Weimar 1930, S. 70-86. Im November 1459 begleitete er Herzog Albrecht zu dessen Egerer Hochzeit; Verz. 6; LANGENN, Albrecht (wie Anm. 128), S. 40; MANSBERG, Erbarmannschaft 2 (wie Nr. 4), S. 512. Genannt ist der Rwsse von Plawen auch in Schriftsassenverzeichnissen von 1473 und 1474; Verz. 5, Bl. 8v, 91r.

[7] Er Friedrich von Donyn

Friedrich II., Burggraf von Dohna, Herr zu Auerbach († vor 1469); vgl. zu ibm SIEGMAR FRIEDRICH VON DOHNA, Die Donins. Aufzeichnungen über die erloschenen Linien der Familie Dohna, Berlin 1876, S. 242 ff.; DoHNA, Die Dohnas 1 (wie Anm. 122), S. 141 f., 2, Stammtafel II. Teilnehmer der im Kontext der Altenburger Teilung geschlossenen, mit dem Kurfürsten kooperierenden Ständeeinung vom 29. November 1445; wie oben Anm. 141. 1447 kämpfte er im Bruderkrieg anf der Seite Friedrichs II.; KOCH, Bruderkrieg (wie Anm. 27), S. 100.1458 ist er bei der Hochzeit Annas von Sachsen mit Markgraf Albrecht Achilles, 1459 als kurfürstlicher Zeuge im Frieden von Eger belegt; MARIO MÜLLER, Die diplomatische Kärrnerarbeit des Vermittlers. Markgraf Albrecht Achilles von Brandenburg auf dem Egerer Fürstentreffen 1459, in: André Thieme/Uwe Tresp (Hg.), Eger 1459. Fürstentreffen zwischen Sachsen, Böbmen und ibren Nachbarn. Dynastische Politik, fürstliche Repräsentation und kulturelle Verflechtung (Saxonia. Schriften des Vereins für sächsische Landesgeschichte 13), Wettin-Löbejün 2011, S. 178-226, hier S. 215. Im November 1459 begleitete er Herzog Albrecht zu dessen Egerer Hochzeit; Verz. 6. Weiter begegnet er in einem Schriftsassenverzeichnis von 1460; Verz. 2, Bl. 2r. Die von Donyn zcu Uwerbach sind in einem Verzeichnis von 1473 genannt; Verz. 5, Bl. $8 v$. 
[8] Er Heinrich von Wyda

Wobl Heinrich XIX. von Weida zu Wildenfels; SCHMIDT, Genealogie (wie Anm. 110), Tafel 2, Nr. 31; SCHWENNICKE, Europäische Stammtafeln (wie Nr. 6), Tafel 352. 1447 und 1450 während des Bruderkriegs im Bündnis mit Kurfürst Friedrich II.; KoCH, Bruderkrieg (wie Anm. 27), S. 100; HStA Dresden, 10001 Ältere Urkunden, Nr. 7129. 1450 erklärt er gemeinsam mit Friedrich II. Apel Vitzthum die Febde; MANSBERG, Erbarmannschaft 3 (wie Nr. 4), S. 327.1459 nimmt er an der Egerer Hochzeit Herzog Albrechts teil; Verz. 6; LANGENN, Albrecht (wie Anm. 128), S. 40. Der von Wyda czu Wildenfels auch in Schriftsassenlisten von 1473 und 1482 unter den Herren genannt; Verz. 5, Bl. 8v, 158 .

[9] Er Matt(hes) Slicke

Matthias Schlick von Lazan, Herr zu Weißkirchen (Ungarn), Burggraf zu Cheb/ Eger und Loket/Elbogen, Bruder des Reichskanzlers Kaspar Schlick, 1439 bis 1447 im Besitz des Amts Voigtsberg, seit 1447 von den Wettinern mit der Herrschaft Stollberg belehnt und in Schriftsassenverzeichnissen ab 1454 zu den Grafen und Herren gerechnet, nach dem Verkauf Stollbergs 1473 wieder aus den Listen verschwunden; Verz. 1, Bl. 12r; Verz. 2, Bl. 2r; vgl. dazu SCHNEIDER, Dynastengeschlechter (wie Anm. 9), S. 7 f.; TRESP, Integration und Selbstverständnis (wie Anm. 125), S. 191, 194 f., zur Herkunft der Schlicks auch S. 184 ff. 1455 vermittelt er eine Übereinkunft zwischen Georg Podiebrad und Kurfürst Friedrich II.; HStA Dresden, 10001 Ältere Urkunden, Nr. 7443a = LUDWIG SCHLESINGER, Stadtbuch von Brüx bis zum Jabre 1526 (Beiträge zur Geschichte Böhmens 4/1), Prag u. a. 1876, S. 136.

\section{[10] Er Heinrich von Bunaw}

Heinrich von Bünau zu Weesenstein (†1467), kurfürstlicher Rat 1455 bis 1462, als Anbänger Kurfürst Friedrichs II. im Bruderkrieg belegt, 1441, 1455 und 1465 mit Weesenstein belehnt; RAAB, Regesten 2 (wie Nr. 6), S. 118, 149 f., Nr. 524, 659; SCHLESINGER, Stadtbuch (wie Nr. 9), S. 120, Nr. 267; MANSBERG, Erbarmannschaft 2 (wie Nr. 4), S. 508, 510; KOCH, Bruderkrieg (wie Anm. 27), S. 80, 128; STREICH, Hof (wie Anm. 11), S. 613; SCHNEIDER, Die Bünaus (wie Anm. 10), S. 171 f.; WILDE, Ritter- und Freigüter (wie Anm. 130), S. 385; HStA Dresden, 10004 Kopiale, Nr. 45, Bl. 340v (10. Mai 1461, erwähnt als Ritter und Rat). Teilnehmer der im Kontext der Altenburger Teilung geschlossenen, mit dem Kurfürsten kooperierenden Ständeeinung vom 29. November 1445; wie oben Anm. 141. 1447 als Herr im Vormundschaftsrat des letzten Willens Friedrichs II. erwähnt; HStA Dresden, 10001 Ältere Urkunden, Nr. 6991. 1459 mit Rudolf von Bünau (wie unten Nr. 34?) und dem alden Reussen (wie Nr. 6) bei der böhmisch-sächsischen Hochzeit in Eger; Verz. 6. In Verz. 1, Bl. 11v, und Verz. 2, Bl. 2v, unter den Rittern genannt; vgl. auch Verz. 3, Bl. $12 v$. MANSBERG, Erbarmannschaft 2 (wie Nr. 4), S. 512. Mebrere Träger des Namens sind 1455 und 1464/65 als Mitglieder des hohenzollerischen Schwanenordens belegt; STILLFRIED/HAENLE, Buch vom Schwanenorden (wie Anm. 19), S. 138), die sich jedoch gegen eine Identifizierung mit dem Weesensteiner aussprechen. Verz. 1, Bl. 10v, und 2, Bl. $4 v$, kennen auch einen Heinrich von Bunaw in Welchaw. Vgl. auch unten Nr. 34 . 


\section{[11] Er Diethrich von Miltitz}

Die Liste nennt insgesamt drei Personen mit Namen Dietrich (Titz) von Miltitz, die nicht eindeutig zu identifizieren sind; vgl. auch unten Nr. 27 und 28. Bei dem hier als Herr bezeichneten Dietrich v. M. dürfte es sich um den 1454 in Verz. 1, Bl. 12r, und 1460 in Verz. 2, Bl. 2v, unter den Rittern erwähnten Schriftsassen handeln, der bereits 1449/50, erneut 1462 als Rat begegnet und zu Scharfenberg bei Meißen saß; MANSBERG, Erbarmannschaft 2 (wie Nr. 4), S. 511, 3, S. 324; RAAB, Regesten 1 (wie Nr. 6), S. 149 f., Nr. 659; BRIGITTE STREICH, Das Amt Altenburg im 15. Jabrbundert. Zur Praxis der kursächsischen Lokalverwaltung im Mittelalter (Veröffentlichungen aus thüringischen Staatsarchiven 7), Weimar 2000, S. 169, 175; HStA Dresden, 10004 Kopiale, Nr. 45, Bl. 128r (29. Juni 1462). Vermutlich identisch mit dem Teilnehmer der im Kontext der Altenburger Teilung geschlossenen, mit dem Kurfürsten kooperierenden Ständeeinung vom 29. November 1445; wie oben Anm. 141, und dem 1446 als Unterbändler Friedrichs II. wäbrend des Bruderkriegs tätigen Dietrich v. M., 1447 als Mitglied des Vormundschaftsrats im letzten Willen des Kurfürsten belegt; KOCH, Bruderkrieg (wie Anm. 27), S. 117; CLEMENS FREIHERR VON HAUSEN, Vasallen-Geschlechter der Markgrafen zu Meissen, Landgrafen zu Thüringen und Herzöge von Sachsen bis zum Beginn des 17. Jahrbunderts. Auf Grund des im Königlichen Haupt-Staatsarchiv zu Dresden befindlichen Urkundenmaterials zusammengestellt, Berlin 1892, S. 300 (nach HStA Dresden, 10001 Ältere Urkunden, Nr. 6991). Verz. 3, Bl. 12v, und Verz. 4, Bl. 117r nennen einen nicht weiter bezeichneten Dietrich v. M. 1465 erscheint ein D. v. M. als Urkundenzenge Kurfürst Ernsts und Herzog Albrechts; ERMISCH, Urkundenbuch Stadt Freiberg 1 (wie Anm. 88), Nr. 334, 335, zwischen 1466 und 1470 als Hofmeister Ernsts und Albrechts; ebd., Nr. 351; GERSDORF, Urkundenbuch Hochstift Meißen 3 (wie Anm. 106), Nr. 1086, 1125, 1126, 1470 als Frauenhofmeister der „jungen Herren“; STREICH, Hof (wie Anm. 11), S. 243, 600, 1478 als Zenge in einer Urkunde der Kurfürsten Ernst und Albrecht; EDUARD BEYER, Das Cistercienser-Stift und Kloster Alt-Zelle im Bisthum Meißen, Dresden 1855, S. 696, Nr. 739. In einem Schriftsassenverzeichnis von 1473 wird Titcze (Thycz) von Milticz als Ebrbarmann neben Titze von Miltitz, hofemeister unter den kurfürstlichen Räten genannt, 1454, 1460 und 1474 erscheint Titz von Miltitz auf Batzdorf als Schriftsasse; Verz. 1, Bl. 11r; Verz. 2, Bl. 4r; Verz. 5, Bl. 4r, 5v, 9v, 21v, 79v, 83v, 88; vgl. auch ERMISCH, Urkundenbuch Stadt Freiberg 1 (wie Anm. 88), Nr. 312. Ein D. v. M ist 1455 und 1464/65 auch als Mitglied des hobenzollerischen Schwanenordens nachweisbar; STILLFRIED/HAENLE, Buch vom Schwanenorden (wie Anm. 19), S. 181. 1445 begegnet ein Dietrich v. M. als Amtsasse im Amt Dresden; HStA Dresden, 10024 Gebeimer Rat (Gebeimes Archiv), Loc. 7997/2, Bl. 19v; Ditz von Miltitz zum Sacke [Sacka ö. Großenhain] 1463 als Amtsasse in der Pflege Großenhain; 10005 Hof-und Zentralverwaltung der Wettiner (Wittenberger Archiv), Loc. 4338/2, Bl. 44v. Weitere Namensvertreter finden sich 1449 und 1452 als Zengen kurfürstlicher Urkunden; KARL FRIEDRICH VON POSERN-KLETT (Bearb.), Urkundenbuch der Städte Dresden und Pirna (Codex diplomaticus Saxoniae regiae II/5), Leipzig 1875, Nr. 234, 248; GERSDORF, Urkundenbuch Hochstift MeiBen 3 (wie Anm. 106), Nr. 1013. 1455 ist ein Dietrich v. M. Zeuge der Belehnung Heinrichs von Bünau mit Weesenstein; HStA Dresden, 10001 Ältere Urkunden, Nr. 7419c. 1457 fungiert ein Dietrich v. M. als Vogt von Liebenwerda; HESSE, Amtsträger (wie Anm. 136), S. 619, Nr. 2313. 1459 finden sich ein Namensträger im Gefolge Friedrichs II. als Zenge des Friedens von Eger; MÜLLER, Kärrnerarbeit (wie Nr. 7), 
S. 215, und mebrere als Teilnehmer der Egerer Hochzeit Herzog Albrechts; Verz. 6; LANGENN, Albrecht (wie Anm. 128), S. 41. Ein Dietrich v. M. stand 1460 gemeinsam mit Heinrich von Bünau im Heer Friedrichs II. gegen Linda; MANSBERG, Erbarmannschaft 2 (wie Nr. 4), S. 512.

\section{[12] Er Jhan von Slinitz}

Jan von Schleinitz ist 1451, 1454, 1460 und 1463 als Schriftsasse, Ritter und Rat belegt; HStA Dresden, 10004 Kopiale, Nr. 43, Bl. 295v (16. März 1451); Nr. 45, Bl. 147r (21. März 1463); Verz. 1, Bl. 12r; Verz. 2, Bl. 12r. 1449 bis 1464 zeitweilig Obermarschall, 1458 bis 1460 Marschall Kurfürst Friedrichs II.; vgl. STREICH, Hof (wie Anm. 11), S. 595. Am 27. April 1464 als verstorben erwähnt; MANSBERG, Erbarmannschaft 2 (wie Nr. 4), S. 355. 1446 als Unterbändler des Kurfürsten während des Bruderkriegs mit Herzog Wilhelm III. belegt; KOCH, Bruderkrieg (wie Anm. 27), S. 117. 1447 als Ritter im Vormundschaftsrat des letzten Willens Friedrichs II. erwähnt; HStA Dresden, 10001 Ältere Urkunden, Nr. 6991; HAUSEN, Vasallen-Geschlechter (wie Nr. 11), S. 439. 1455 als Schlichter zwischen dem Kurfürsten und Friedrich von Dobna zu Auerbach (wie Nr. 7); HStA Dresden, 10001 Ältere Urkunden, Nr. 7414, sowie als Zenge der Belehnung Heinrichs von Bünau (wie Nr. 10) mit Weesenstein belegt; HStA Dresden, 10001 Ältere Urkunden, Nr. 7419 c. 1457 mit Nickel von Schönberg und Hans von Metzsch (wie Nr. 17) als Bevollmächtigter Friedrichs II. in Böhmen tätig; MANSBERG, Erbarmannschaft 2 (wie Nr. 4), S. 351. Teilnehmer der Egerer Hochzeit Herzog Albrechts; Verz. 6.

\section{[13] Er Jurge von Bemburg}

Georg von Bebenburg († 1472), 1444-1454 Obermarschall Kurfürst Friedrichs II.; RAAB, Regesten 2 (wie Nr. 6), S. 125, Nr. 556; STREICH, Hof (wie Anm. 11), S. 126 f., 595 (bier als Günter von Bebenburg), Vogt von Zwickan 1454 bis 1459; HESSE, Amtsträger (wie Anm. 136), S. 627, Nr. 2436; STREICH, Amt Altenburg (wie Nr. 11), S. 75. Teilnebmer der im Kontext der Altenburger Teilung geschlossenen, mit dem Kurfürsten kooperierenden Ständeeinung vom 29. November 1445; wie oben Anm. 141. 1446 als Anbänger Kurfürst Friedrichs II. im Bruderkrieg; MANSBERG, Erbarmannschaft 2 (wie Nr. 4), S. 508. 1454 bis 1456 als kurfürstlicher Rat bezeichnet; 1 , S. 580. 1455 als Unterbändler Friedrichs II. bei Georg Podiebrad; HStA Dresden, 10001 Ältere Urkunden, Nr. 7443a = SCHLESINGER, Stadtbuch (wie Nr. 9), S. 136. Um 1460 auch als Rat des Markgrafen Albrecht Achilles tätig; SCHNEIDER, Fränkischer Adel (wie Anm. 30), S. $33 \mathrm{ff}$. Er war zugleich Mitglied des hobenzollerischen Schwanenordens; STILLFRIED/HAENLE, Buch vom Schwanenorden (wie Anm. 19), S. 119; FRANKL, Würzburger Vasallen (wie Anm. 19), S. $120 \mathrm{f}$.

\section{[14] Er Nickel von Wolffistorff}

Nickel von Wolffersdorff, 1454 und 1460 als Schriftsasse und Ritter zu Berga/Elster genannt; Verz. 1, Bl. 11v; Verz. 2, Bl. 11v. Vermutlich identisch mit dem 1445 als Vogt in Weida belegten N. v. W.; STREICH, Amt Altenburg (wie Nr. 11), S. 75, zwischen 1441 und 1448 auf Berga gesessen; RAAB, Regesten 1 (wie Nr. 6), S. 306, Register s. v., oder dessen Sohn. 1453 als Vogt zu Voigtsberg erwähnt; HESSE, Amtsträger (wie Anm. 136), S. 663, Nr. 2951. 1448 (obne Tagesdatum) verkaufen Herr (er) Nickel und Jörg v. W. (wohl Brüder) an Hans Metzsch als Altermann der St.-Adel- 
beid-Kapelle bei Greiz Zinsen in verschiedenen Dörfern; HStA Dresden, 10004 Kopiale, Nr. 43, Bl. 289v. Beide gehörten zu den Teilnehmern der mit dem Kurfürsten kooperierenden, im Kontext der Altenburger Teilung geschlossenen Ständevereinigung vom 29. November 1445; wie oben Anm. 141. Weitere Namensträger 1451 bis 1457 auf Dölau/Greiz, 1458 und 1464 auf Neumark bei Reichenbach/Vogtland als Amtsassen nachgewiesen; 10005 Hof-und Zentralverwaltung der Wettiner (Wittenberger Archiv), Loc. 4338/2, Bl. 32v; PAUL REINHARD BEIERLEIN, Geschichte der Stadt und Burg Elsterberg i. V., Bd. 1, Elsterberg i. V. 1928, S. 91, Nr. 169, S. 93, Nr. 176, S. 103, Nr. 216.

\section{[15] Hans Loser}

Vermutlich der 1454 als Schriftsasse obne Sitz und $1460 \mathrm{zu}$ Pretzsch genannte Hans Löser, Bruder von Nr. 23 (vgl. auch Nr. 25); Verz. 1, Bl. 11r; Verz. 2, Bl. 4r; vgl. auch Verz. 3, Bl. 12v (ohne Ortsangabe). Er ist bereits 1453 als Erbmarschall, 1454 als Rat und Untermarschall, 1456 als Erb-, 1460 als Untermarschall belegt; RAAB, Regesten (wie Nr. 6), S. 132, Nr. 584; STREICH, Hof (wie Anm. 11), S. 433, 596; HESSE, Amtsträger (wie Anm. 136), S. 654, Nr. 2839. Die Familie Löser hatte ibren Hauptsitz in Pretzsch, weitere Besitzungen in Axien und Jessen. Eine Belehnung mit Pretzsch und anderen Gütern in den Pflegen Torgau, Schweinitz und Trebnitz vom 24. August 1454 in HStA Dresden, 10004 Kopiale, Nr. 45, Bl. 196v-197r. Hans und Heinrich Loser erwarben 1445 die Pfandherrschaft über Stadt und Schloss Düben; SCHIRMER, Untersuchungen (wie Anm. 139), S. 361. Ein Hans Loser begegnet auch 1470 und 1473 in Schriftsassenverzeichnissen; Verz. 4, Bl. 117r (ebd. sein Bruder Heinrich); Verz. 5, Bl. 9v, $21 v$.

\section{[16] Hug von Tubenheim}

Hug von Taubenheim, 1460 als Schriftsasse erwähnt; Verz. 2, Bl. 4r. Zwischen 1457 und 1463 als Hofmeister der Söhne Kurfürst Friedrichs II. belegt; HAUSEN, VasallenGeschlechter (wie Nr. 11), S. 502; STREICH, Hof (wie Anm. 11), S. 290, 599; vgl. auch HStA Dresden, 10004 Kopiale, Nr. 45, Bl. 146v-147r (Stiftung für St. Afra in Meißen, 6. Januar 1462); ERMISCH, Urkundenbuch Stadt Freiberg 1 (wie Anm. 88), Nr. 317. Ein H. v. T. 1454 als Vogt zu Brüx, 1465 als Vogt von Frauenstein genannt; HESSE, Amtsträger (wie Anm. 136), S. 631, Nr. 2501, S. 641, Nr. 2644. 1459 begleitete ein nicht benannter Angehöriger der Familie Taubenheim Herzog Albrecht zu dessen Egerer Hochzeit; Verz. 6.

\section{[17] Hans Metzsch}

Hans Metzsch, 1454 (zusammen mit seinem Bruder Peter) und 1460 als Schriftsasse zu Mylau, 1470 obne Sitz erwähnt; Verz. 1, Bl. 10v; Verz. 2, Bl. 4r; Verz. 3, Bl. 12v; Verz. 4, Bl. 117r. Kurfürstlicher Untermarschall 1464 bis 1478, † 1483; STREICH, Hof (wie Anm. 11), S. 596. Als Amtmann zu Mylau (1451, 1453 bis 1454), Crimmitschau (1458, 1467 bis 1473) und Altenburg $(1474$ bis 1478, 1481) belegt; MANSBERG, Erbarmannschaft 1 (wie Nr. 4), S. 579 ff.; RAAB, Regesten 1 (wie Nr. 6), S. 279, Register s. v.; BEIERLEIN, Geschichte (wie Nr. 14), S. 92, Nr. 171; STREICH, Hof (wie Anm. 11), S. 243; HESSE, Amtsträger (wie Anm. 136), S. 656, Nr. 2852. Ein weiterer (?) Träger des Namens 1474 als Vogt von Eilenburg erwähnt; ebd., Nr. 2853. 1458, 1469, 1473 und 1481 als kurfürstlicher Rat bezeichnet; RAAB, Regesten 2 (wie Nr. 6), S. 348 f., 
Die Hieronymusgesellschaft Kurfürst Friedrichs II. von Sachsen

Nr. *49; BEIERLEIN, Geschichte (wie Nr. 14), S. 95, Nr. 182, S. 110 ff., Nr. 227; Verz. $5, B l .4 r, 5 v, 9 v, 21 v, 65 r, 79 v, 83 v$; so auch in einem Schriftsassenverzeichnis von 1482; ebd., Bl. 158v. 1446 beteiligte er sich auf Seiten Kurfürst Friedrichs II. am Bruderkrieg; KOCH, Bruderkrieg (wie Anm. 27), S. 77. 1474 auch ein Hans Metzsch zcur Plone (Plohn, Vogtlandkreis) als Schriftsasse erwähnt; Verz. 5, Bl. 88r. 1459 begleitete ein H. M. den jungen Herzog Albrecht zu dessen Egerer Hochzeit; Verz. 6. Am 20. April 1445 wurden die Brüder Hans und Peter sowie Hans, Konrad und Petzold v. M. mit dem Dorf Friesen (Vogtlandkreis, nw. Reichenbach) belehnt; HStA Dresden, 10004 Kopiale, Nr. 43, Bl. 172v. Hans, Landvogt zu Meißen, und Peter Metzsch bekommen vom Kurfürsten 1448 (o. T.) einen Zinsverkauf in Lengenfeld Vogtlandkreis, nö. Reichenbach) und Waldkirchen (ebd., nö. Lengenfeld) genehmigt; HStA Dresden, 10004 Kopiale, Nr. 43, Bl. 289r.

[18] Jurg von Slinitz

Jörg von Schleinitz, 1454 als Schriftsasse, 1460 als Schriftsasse zu Seerhausen (sw. Riesa) genannt; Verz. 1, Bl. 11r; Verz. 2, Bl. 2v; Verz. 3, Bl. 12v. 1473, 1474 und 1475 als Ritter und Rat erwähnt, 1481 und 1484 als Rat; Verz. 5, Bl. 3v, 5v, 8v, 34r, 65r, 79v, 86r; STREICH, Hof (wie Anm. 11), S. 424. 1459 begleitete ein Jörg v. S. Herzog Albrecht zu dessen Egerer Hochzeit; Verz. 6. 1461 Teilnebmer der Palästinafabrt Herzog Wilhelms III.; KOHL, Pilgerfahrt (wie Anm. 166), S. 71.1470 als Unterhändler Kurfürst Ernsts und Herzog Albrechts; FELIX PRIEBATSCH (Hg.), Politische Correspondenz des Kurfürsten Albrecht Achilles, Bd. 1 (Publicationen aus den Königlich Preußischen Staatsarchiven 59), Leipzig 1894, S. 114. 1474 Empfänger eines Hofgewands; STREICH, Hof (wie Anm. 11), S. 358.

\section{[19] Jhan von Kokeritz}

Wobl identisch mit dem 1460 als Schriftsassen genannten Jan von Köckritz zu Walda (bei Großenhain); Verz. 2, Bl. 5r; vermutlich der Bruder von Nr. 20; vgl. die Gesamtbelehnung mit Elsterwerda und anderen Besitzungen vom 8. März 1456; HStA Dresden, 10004 Kopiale, Nr. 45, Bl. 203r-204r. Ein Jan v. K. auch in einem Schriftsassenverzeichnis von 1473; Verz. 5, Bl. 4v; ebd., Bl. 10r; dort auch die Kokericz zcu Glubaczk (Glaubitz nö. Riesa), die Kokericz zu Elsterwerda und die Kokericz zu Mückenberg, heute Stadt Lauchhammer); ebd., Bl. 5r, 5v, Bl. 10v. 1474 und 1482 wird Jhan von Kokeritz zcu Strauch (zum Struch) (Strauch n. Großenhain) als Schriftsasse genannt; ebd., Bl. 84v, 89r, 158v. Der 1448 bis 1457 als Hofmeister, 1453 als Hofrichter Friedrichs II. belegte, in der oben erwähnten Belebnung von 1456 genannte Jan von Köckritz zu Elsterwerda ist ein Verwandter; RAAB, Regesten 1 (wie Nr. 6), S. 126, Nr. 561; STREICH, Hof (wie Anm. 11), S. 144, 600 f.; HESSE, Amtsträger (wie Anm. 136), S. 647, Nr. 2740; HStA Dresden, 10001 Ältere Urkunden, Nr. 7135 (8. April 1450). Hans von Köckritz zu Saathain (bei Elsterwerda) vermittelt 1444 und 1448 gemeinsam mit Heinrich von Bünau (vgl. Nr. 10) als Bevollmächtigter des Kurfürsten in dessen Streit mit Nickel von Polenz um Senftenberg. Auf Seiten des letzteren verhandelt Hans von Köckritz zu Drebkau, der im hobenzollerischen Schwanenorden begegnet; MANSBERG, Erbarmannschaft 2 (wie Nr. 4), S. 507, 509, 4, S. 377, 379, 386; STILLFRIED/HAENLE, Buch vom Schwanenorden (wie Anm. 19), S. 65, 166. Hans von Kokeritz zu Wildenaw (Wildenau, heute Stadt Schönewalde, Kreis Elbe-Elster) und Hans von Kokeritz zu Frawenhorst (Frauenhorst, heute Stadt Herzberg/Elster) begegnen 1458 als Amtsassen der Pflege Schweinitz; 10005 
Hof- und Zentralverwaltung der Wettiner (Wittenberger Archiv), Loc. 4338/2, Bl. 38v. Im Juni 1470 fungierten Hofmeister Titz von Miltitz und Bernhard von Schönberg, Untermarschall (wie Nr. 36) als Vormünder der Margarethe, Witwe des Hans von Köckritz; PRIEBATSCH, Korrespondenz 1 (wie Nr. 18), S. 128, Nr. 50. Vgl. auch JeNS KUNZE, Das Amt Leisnig im 15. Jabrhundert. Verfassung, Wirtschaft, Alltag (Schriften zur sächsischen Geschichte und Volkskunde 21), Leipzig 2007, S. 161.

\section{[20] Luppold von Kokeritz}

Vermutlich der Bruder von Nr. 19; HStA Dresden, 10004, Nr. 45, Bl. 203r-204r.

\section{[21] Titz vom Honsperg}

Vermutlich Dietrich von Honsberg, 1454 als Schriftsasse zu Schönfeld, 1460 zu Leuben (sw. Oschatz) und Schweta (beute Stadt Döbeln) genannt; Verz. 1, Bl. 11r; Verz. 2, Bl. 5r; zwischen 1473 und 1483 als Schriftsasse zu Leuben; Verz. 5, Bl. 1r, 4v, 10r, 22r, 65v, 80r, 88v; vgl. auch Verz. 4, Bl. 117v. Am 23. Dezember 1452 ist er zusammen mit seinen Söhnen Jörg und Hans belegt; HStA Dresden, 10004 Kopiale, Nr. 44, Bl. 268r; am 17. Dezember 1460 wurde er zusammen mit seinen Söhnen Jörg, Hans und Dietrich mit Schweta belehnt; HStA Dresden, 10004 Ko-piale, Nr. 45, Bl. $216 v$. 1445 ist er (Titz v. H. zu Leuben) noch als Amtsasse im Amt Oschatz genannt; HStA Dresden, 10024 Geheimer Rat (Gebeimes Archiv), Loc. 7997/2, Bl. 35 v. 1463 erscheint Titz v. H. zu Alt-Oschatz als Amtsasse; HStA Dresden, 10005 Hof- und Zentralverwaltung der Wettiner (Wittenberger Archiv), Loc. 4338/2, Bl. 47v. Am 28. Mai 1448 genehmigte Kurfürst Friedrich II. einem Titz v. H. den Verkauf des Dorf Lehetzschen (Lötzschen n. Radeburg); HStA Dresden, 10004 Kopiale, Nr. 43, Bl. 289r. Die Belebnung der Honsberg mit Schönfeld und anderen Besitzungen in den Ämtern Großenhain, Meißen und Oschatz vom 14. Mai 1448 nennt Dietrich v. H. und seinen Sohn Jörg sowie Dietrich und Heinrich v. H., Söhne des verstorbenen Sittig v. H. Am 14. Mai 1451/52 wird (der Hieronymusgeselle?) D. v. H. als Küchenmeister (?) Kurfürst Friedrichs II. belegt; KUNZE, Amt Leisnig (wie Nr. 19), S. 161. 1470 ist ein D. v. H. im Besitz von Wuschkewitz (Niederwutzschwitz bei Oschatz); GERSDORF, Urkundenbuch Hochstift Meißen 3 (wie Anm. 106), Nr. 1126. Ein Namensträger ist als Teilnehmer der Ständetage von 1488, 1489, 1499, 1502 nachweisbar; WOLDEMAR GOERLITZ, Staat und Stände unter den Herzögen Albrecht und Georg 1485-1539 (Sächsische Landtagsakten 1; Aus den Schriften der Sächsischen Kommission für Geschichte 32), Leipzig/Berlin 1928, S. 578.

\section{[22] Heinrich Spiegel}

Wobl identisch mit dem 1460 als Schriftsasse genannten Heinrich Spiegel zu Delitzsch; Verz. 2, Bl. 4v; Verz. 3, Bl. 13r; Sohn des Otto S., Bruder des Hans S.; HStA Dresden, 10004 Kopiale, Nr. 43, Bl. 205v-206r, 293r (28. März 1448, 24. Februar 1450). 1464 und 1474 wird ein Heinrich S. zu Zschortau (s. Delitzsch) erwähnt, der 1460, 1473 und 1474 auch als Inhaber des Burglehens zu Delitzsch begegnet; Verz. 5, Bl. 4r, 10r, 11r, 80r, 88v; WILDE, Ritter- und Freigüter (wie Anm. 130), S. 203, 208, 219, 229, 269, 355, 395, 411. Im November 1459 begleitete ein Heinrich S. Herzog Albrecht zu dessen Egerer Hochzeit; Verz. 6, 1455 ist ein Heinrich S. auch als Mitglied im hohenzollerischen Schwanenorden belegt; STILLFRIED/HAENLE, Buch vom Schwanenorden (wie Anm. 19), S. 216. Ein Heinrich S. zu †Paupitzsch (n. Delitzsch) 
wird 1445 und 1447 als Amtsasse im Amt Delitzsch genannt; HStA Dresden, 10024 Geheimer Rat (Gebeimes Archiv), Loc. 7997/2, Bl. 34r, 44r; vgl. WILDE, Ritter- und Freigüter (wie Anm. 130), S. 207, 319 ff.; HStA Dresden, 10004 Kopiale, Nr. 45, Bl. 202v-203r (Belehnung mit Paupitzsch von 1456).

\section{[23] Heinrich Loser in Pretzsch}

Heinrich Löser zu Pretzsch, Bruder von Nr. 15, 1454 und 1460 in verschiedenen Schriftsassenverzeichnissen erwähnt; Verz. 1, Bl. 11r; Verz. 2, Bl. 4r; Verz. 3, Bl. 13r. Listen von 1473 und 1474 fübren zwei Namensträger obne Angabe des Sitzes (vgl. auch Nr. 25) nebeneinander unter den kurfürstlichen Räten auf; Verz. 5, Bl. 4r, 5v, $9 v, 21 v, 79 v$. Weitere Träger des Namens - es ist unklar, ob Nr. 23 oder Nr. 25 gemeint sind - werden 1456 als Jungherr am kurfürstlichen Hof, 1464 bis 1470 und 1482 als Amtmann von Schlieben, 1465 bis 1474 als Landvogt zu Trebitz, 1465 bis 1472 und 1488 als Vogt von Schweinitz, 1465 bis 1466 und 1470 bis 1489 als Vogt der Lochau, 1467 bis 1474 und 1478 bis 1494 als Landvogt von Sachsen in Belzig und 1471 als Amtmann von Gräfenhainichen genannt; MANSBERG, Erbarmannschaft 3 (wie Nr. 4), S. 345; HESSE, Amtsträger (wie Anm. 136), S. 635, Nr. 2564; STREICH, Hof (wie Anm. 11), S. 423, 606. 1459 begleitete ein Heinrich L. Herzog Albrecht zu dessen Egerer Hochzeit; Verz. 6. 1477 erscheint der Ritter Heinrich Loser zu Pretzsch als Landvogt und Rat; Verz. 5, Bl. 130v. In Schrift-sassenlisten von 1481 und 1482 erscheinen nebeneinander er Heinrich Loser lantvoit und Gunter Loser sein gebruder sowie er Heinrich Loser zcu Pretzsch als Räte; das Verzeichnis von 1481 nennt als Rat den alde[n] Heinrich Loßer zcu Pretczsch; Verz. 5, Bl. 65r, 67r, 158v. Der Landvogt und sein Bruder Gunther sind offenbar die Söhne des in Nr. 15 genannten Erbmarschalls Hans Loser; RAAB, Regesten 1 (wie Nr. 6), S. 132, Nr. 584.

\section{[24] Cristoffel von Sliwenn}

Christoph von Schlieben zu Hohndorf (ö. Bad Schmiedeberg), 1460, 1470, 1473 und 1474 als Schriftsasse genannt; Verz. 2, Bl. 5r; Verz. 4, Bl. 117v; Verz. 5, Bl. 4v, 10r, 22r, 38r, 80r, 84r, 89r. Erwähnt am 3. September 1443; MANSBERG, Erbarmannschaft 4 (wie Nr. 4), S. 158, danach 1449, 1450, 1457 und 1458 als Vasall Friedrichs II.; ebd., S. 158 ff., 293. 1459 begleitete er Herzog Albrecht zur Hochzeit nach Eger; Verz. 6. † 1478; MANSBERG, Erbarmannschaft 4 (wie Nr. 4), Tafel 59. Sobn Hans von Schliebens, der am 9. Januar 1447 „mit 13 Anderen vom sächsischen Adel [...] um ibres Lehnsherrn, des Herzogs Friedrich, willen Febdebrief an Herzog Wilbelm von Sachsen" sendete; ebd., S. 159, 259.

\section{[25] Heinrich Loser}

Nachdem Heinrich Löser zu Pretzsch (Nr. 23) wobl der Bruder von Nr. 15 war, dürfte es sich hier um den in der Gesamtbelehnung der Löser mit Pretzsch vom 24. August 1454 genannten Heinrich Löser handeln, der zusammen mit seinem älteren Bruder Jörg auf Hausen (bislang nicht identifiziert) saß; HStA Dresden, 10004 Kopiale, Nr. 45, Bl. 196v-197r. 


\section{[26] Sigmunt von Miltitz}

Siegmund von Miltitz zu Miltitz, Batzdorf und Rabenau, Rat, Marschall und Landvogt zu Meißen, als Amtmann von Pirna 1487 bis 1491 belegt; GOERLITZ, Staat und Stände (wie Nr. 21), S. 586; SCHIRMER, Untersuchungen (wie Anm. 139), S. 363; HESSE, Amtsträger (wie Anm. 136), S. 682, Nr. 3234 (vgl. auch ebd., Nr. 3233: Siegmund v. M., Amtmann von Ostrau 1469 bis 1471). Erwähnt in Verz. 3, Bl. 13v; Verz. 4, Bl. 117r. Am 12. oder 13. März 1460 belehnte Kurfürst Friedrich II. die Brüder Siegmund, Titz und Hans von Miltitz mit Miltitz und anderen Gütern; HStA Dresden, 10004 Kopiale, Nr. 45, Bl. 265v (datiert auf feria quarta post Gregorii [wohl gemeint: pape]; der Gregoriustag 1460 [12. März] war jedoch selbst ein Donnerstag). Gemeinsam mit Bernhard von Schönberg (wie Nr. 36) zur Jabreswende 1461/62 als Unterbändler im Streit um die wettinischen Ansprüche an das Hochstift Würzburg belegt; MANSBERG, Erbarmannschaft 2 (wie Nr. 4), S. 303. 1471 als Rat Herzog Albrechts bezeichnet; STREICH, Hof (wie Anm. 11), S. 217, 312. 1473, 1474, 1480 und 1482 in verschiedenen Schriftsassenlisten erwähnt; Verz. 5, Bl. 4r, 9v, 21v, 71c, 83v, 88r, 158v. 1474 Teilnehmer der wettinischen Gesandtschaft zur Hochzeit Philipps von der Pfalz in Amberg; vgl. MAXIMILIAN BUCHNER, Zur Biographie des Stammvaters des sächsischen Königshauses, Herzog Albrechts des Beherzten, und seines Bruders, Kurfürsten Ernst von Sachsen, in: NASG 29 (1908), S. 155-162, hier S. 156, Anm. 6. Ein Sigmund von Miltitz zu Rudigsdorf (Röhrsdorf bei Wilsdruff) 1486 als Amtsasse im Amt Meißen erwähnt; HStA Dresden, 10024 Gebeimer Rat (Gebeimes Archiv), Loc. 7997/4, Bl. 5 .

[27] Titz sien Bruder

[28] Titz von Miltitz in Rabenaw

Vgl. Nr. 11 und 26. Einer der beiden hier genannten Personen kann vielleicht mit dem in Nr. 11 zu 1460 und 1474 nachgewiesenen Titz von Miltitz auf Batzdorf identifiziert werden.

\section{[29] Hans von Miltitz}

Ein Hans von Miltitz wird 1460 als Schriftsasse genannt; Verz. 2, Bl. Sr. Vermutlich handelt es sich um den jüngeren Bruder von Siegmund (Nr. 26) und Dietrich v. M. (Nr. 27 oder 28), der in HStA Dresden, 10004 Kopiale, Nr. 45, Bl. 265v, anlässlich der Belehnung mit Miltitz erwähnt wird, doch verwundert, dass ibn das Mitgliederverzeichnis nicht wie Nr. 27 ausdrücklich so bezeichnet. Die Brüder Siegmund und Hans von Miltitz zu Miltitz auch in GERSDORF, Urkundenbuch Hochstift Meißen 3 (wie Anm. 106), Nr. 1086 (22. September 1466) genannt. Verschiedene Hans v. M. sind 1453/54 als Zeugen in Urkunden Kurfürst Friedrichs II. genannt, ein Namensträger ist 1465 als Kanzler von Kurfürst Ernst und Herzog Albrecht belegt; HStA Dresden, 10001 Ältere Urkunden, Nr. 7319, 7349; OTTO POSSE, Die Lebre von den Privaturkunden, Leipzig 1887, S. 182. 1465 bis 1467 ist ein Hans v. M. als Vogt in Radeberg tätig; HESSE, Amtsträger (wie Anm. 136), S. 656, Nr. 2859. Auch Schriftsassenlisten von 1473 nennen einen H. v. M.; Verz. 5, Bl. 4r, 5r, 21v. H. v. M. auf Miltitz ist Teilnehmer der Ständetage von 1488, 1498, 1499 und 1502; GOERLITZ, Staat und Stände (wie Nr. 21), S. 586. 
[30] Ulrich vom Ende

Vermutlich der in einem Schriftsassenverzeichnis von 1454 genannte Ulrich vom Ende (Amtmann?) in Ronneburg, Bruder von Nr. 38; Verz. 1, Bl. 10v. Ein Konrad v. E. zu Ronneburg (der Vater?) war Teilnehmer der mit dem Kurfürsten kooperierenden Ständeeinung vom 29. November 1445; wie oben Anm. 141.1459 begleitete ein Ulrich v. E. Herzog Albrecht zu dessen Egerer Hochzeit; Verz. 6. In Schriftsassenverzeichnissen von 1473 und 1474 begegnen Ulrich v. E. zcu Erembergk/Erinberg (Ehrenberg bei Waldheim) und Lome (Lohma, Gemeinde Langenleuba-Niederhain sö. Altenburg); Verz. 5, Bl. 10r, 22r, 88v, 80r, dort auch ein weiterer Ulrich v. E., gemeinsam mit Heinz v. E. in Fuchshain bei Naunhof gesessen; ebd., Bl. 10v, 84r, 89r; vgl. auch unten $N r$. 38. Schriftsassenverzeichnisse von 1481 und 1482 nennen Ulrich vom Ende zu Blanckenhain, Ulrich vom Ende zcu Lome und Ulrich vom Ende zcu[m] Koÿn (Kayna, Burgenlandkreis); ebd., Bl. 65r, 158v. 1496 bis 1498 ist ein Ritter Ulrich v. E. als Amtmann der Wartburg und 1499 bis 1501 zu Dornburg belegt; HESSE, Amtsträger (wie Anm. 136), S. 683, Nr. 3255. Ulrich v. E. zu Blankenhain (Amt Zwickau) wird noch 1463 als Amtsasse genannt; 10005 Hof-und Zentralverwaltung der Wettiner (Wittenberger Archiv), Loc. 4338/2, Bl. 46r.

[31] Symon Marschalgk

Simon Marschalk, 1454, 14601473 und 1474 als Schriftsasse zu Skassa bei Großenhain genannt; Verz. 1, Bl. 11r; Verz. 2, Bl. 5r; Verz. 5, Bl. 38v, 79v, 83v, 88v. Als Vogt von Großenhain 1457 bis 1459 belegt; HESSE, Amtsträger (wie Anm. 136), S. 682, Nr. 3241.

\section{[32] Engelhart Thoof}

Der Name ist in der Vorlage gestrichen. Engelhart Toss wird erwähnt ab $1459 \mathrm{zu}$ Adorf, 1460 und 1473 bis 1475 ist er als Schriftsasse belegt; Verz. 2, Bl. 4r; Verz. 3, Bl. 13r; Verz. 5, Bl. 4r, 42r, 80r, 83v, 88v. † zwischen 1477 und 1479; RAAB, Regesten 1 (wie Nr. 6), S. 299, Register s. v.; ERICH WILD, Regesten zur Geschichte des Vogtlandes im 14.-17. Jahrbundert, Plauen 1929, Nr. 187, 200; CURT VON RAAB, Beiträge zur Geschichte des vogtländischen Adels. 1. Die von Reinsdorf, von Thoß und von Weischlitz, in: Mitteilungen des Altertumsvereins zu Plauen i. V. 3 (1882/83), S. 2846, hier S. 40. Am 21. Mai 1464 mit einem Salzwerk zu Erlbach (Vogtlandkreis) belehnt; HStA Dresden, 10004 Kopiale, Nr. 45, Bl. 349v.

\section{[33] Nickel Rabil}

Nickel Rabil (Rabiel), 1454 als Schriftsasse zu Tiefensee (w. Bad Düben) genannt; Verz. 1, Bl. 10v; so nochmals 1465; HAUSEN, Vasallen-Geschlechter (wie Nr. 11), S. 375. 1473 werden die Rabyle/Rabilen zcu Tyffensee/Tiffensehe als Schriftsassen erwähnt; Verz. 5, Bl. 5r, 10v, 22v; während sie 1447 dort noch als Amtsassen belegt sind; HStA Dresden, 10024 Geheimer Rat (Gebeimes Archiv), Loc. 7997/2, Bl. 44v. Die 1447 ebenfalls genannten Rabil zu Pouch waren jedoch schriftsässig (schribet myn herre). Nickel R. fungierte 1455 bis 1457 als Vogt von Schlieben; HESSE, Amtsträger (wie Anm. 136), S. 676, Nr. 3153; HELBIG, Ständestaat (wie Anm. 6), S. 333. 1459 begleitete er Herzog Albrecht zu dessen Egerer Hochzeit; Verz. 6. 


\section{[34] Rudulff von Bunaw}

Wobl der 1460 zu Meuselwitz (Kreis Altenburger Land) belegte Schriftsasse; Verz. 3, Bl. 14r; nach MANSBERG, Erbarmannschaft 2 (wie Nr. 4), S. 510 und Tafel 36, identisch mit Rudolf von Bünau zu Weesenstein ( $\dagger$ 1485), Sobn Heinrichs v. B. (oben Nr. 10). Ein R. v. B. 1459 im Gefolge Herzog Albrechts bei der böhmisch-sächsischen Hochzeit in Eger; Verz. 6. 1474 in einem Schriftsassenverzeichnis erwähnt; Verz. 5, Bl. 80 r.

\section{[35] Heinrich List}

Heinrich List, 1454 und 1460 gemeinsam mit Nickel L. als Schriftsasse zu Rockyt (Rackith sö. Wittenberg) genannt; Verz. 1, Bl.11r; Verz. 2, Bl. 5r. 1458 wurden Heinrich und Nickel L. mit Rackith belehnt; HStA Dresden, 10004 Kopiale, Nr. 45, Bl. 260v-261r. Am 19. September 1449 genehmigte der Kurfürst den Verkauf eines Zinses an die Kalandsbrüder zu Prettin durch Heinrich und Nickel L.; HStA Dresden, 10004 Kopiale, Nr. 43, Bl. 293r. Heinrich L. ist vielleicht identisch mit dem 1456/57 belehnten Vogt zu Bitterfeld; HESSE, Amtsträger (wie Anm. 136), S. 635, Nr. 2563. Heinrich L. zcu Wartembrucke (Wartenburg, heute Stadt Kemberg) wird in einem Schriftsassenverzeichnis von 1482 genannt; Verz. 5, Bl. 159 v.

\section{[36] Bernhart von Schonbergk}

Bernhard von Schönberg, Sohn Heinrichs von Schönberg zu Purschenstein, 1460 und 1473 als Schriftsasse genannt, 1473 auch als Rat; Verz. 2, Bl. 5r; Verz. 5, Bl. 5r-v, 21v; 1470 zusammen mit (seinem jüngeren Bruder?) Caspar v. S.; Verz. 4, Bl. 118r. Am 20. Januar 1451 erwähnt als Mitbelehnter seines Vaters; MANSBERG, Erbarmannschaft 2 (wie Nr. 4), S. 302, Dezember 1461/Januar 1462 gemeinsam mit Siegmund von Miltitz (oben Nr. 26) als Unterhändler bei den Verbandlungen über die Ansprüche der Wettiner an das Hochstift Würzburg; ebd., S. 303. 1464 bis 1470 kurfürstlicher Untermarschall; STREICH, Hof (wie Anm. 11), S. 160, Anm. 199, S. 171; PRIEBATSCH, Korrespondenz 1 (wie Nr. 18), S. 128, Nr. 50, 1465 bis 1476 Landvogt zu Sachsen; STREICH, Hof (wie Anm. 11, S. 606, 1466 als Rat bezeichnet; ebd. S. 160, Anm. 199. Im Juni 1470 fungierten Hofmeister Titz von Miltitz (wie oben Nr. 11) und Bernhard von Schönberg, Untermarschall, als Vormünder der Margarethe, Witwe des Hans von Köckritz; PRIEBATSCH, Korrespondenz 1 (wie Nr. 18), S. 128, Nr. 50. 1472 bis 1473 Vogt von Priebus, 1474 bis 1477 Landvogt von Sachsen auf Belzig; HESSE, Amtsträger (wie Anm. 136), S. 605, Nr. 2102. 1476 fübrte er gemeinsam mit Bischof Johann V. von Meißen die Verbandlungen mit dem Magdeburger Domkapitel um die Postulation Ernsts von Wettin; JÖRG ROGGE, Ernst von Sachsen, Erzbischof von Magdeburg und Administrator von Halberstadt (1476-1513), in: Werner Freitag (Hg.), Mitteldeutsche Lebensbilder. Menschen im späten Mittelalter, Köln 2002, S. 27-68, hier S. 30.1467 als Gesandter in Landshut, 1471 in Böhmen, 1473 in Rom und Österreich tätig. 1474 Angehöriger der wettinischen Delegation bei der Hochzeit Philipps von der Pfalz in Amberg; BUCHNER, Biografie (wie Nr. 26), S. 156, Anm. 2. Er starb 1486 als Teilnehmer der Pilgerfahrt Herzog Albrechts nach Rhodos; STREICH, Hof (wie Anm. 11), S. 596; DONATH, Rotgrüne Löwen (wie Anm. 116), S. 278. 
[37] Conrat Monich der jungere

Konrad Mönch d. J., am 3. Juli 1458 bei einer Lehnsaufteilung mit seinem gefettere Konrad d. Ä. zu Kayn fur Missen (Niederjabna, Kreis Meißen) genannt; HStA Dresden, 10004 Kopiale, Nr. 45, Bl. 236v. Letzterer vielleicht identisch mit Konrad Mönch, Vogt zu Müblberg 1425 bis 1426, 1431 bis 1435, Meißen 1426 bis 1428, 1436 bis 1438 und Torgau 1430 bis 1435; HESSE, Amtsträger (wie Anm. 136), S. 615, Nr. 2256. 1437 wurden Kurt Monch (d. A.) und seine Brüder mit Niederjahna, das zuvor Titz von Honsberg besessen hat, und Wingerten in Kötzschenbroda belehnt; HAUSEN, Vasallen-Geschlechter (wie Nr. 11), S. 314; HStA Dresden, 10004 Kopiale, Nr. 35, Bl. 114r. Ein K. M. nabm an der mit dem Kurfürsten kooperierenden Ständeeinung vom 29. November 1445 teil; wie oben Anm. 141. Ein Amts-assenverzeichnis von 1447 nennt Konrad Monche, Forwerck zcur Kane; HStA Dresden, 10024 Gebeimer Rat (Gebeimes Archiv), Loc. 7997/2, Bl. 51r. Zu 1461 wird Kunz Monich, zur Kaipen [?] gesessen, bei HAUSEN, Vasallen-Geschlechter (wie Nr. 11), S. 314, erwähnt. Cuntz Monch wird 1486 als Amtsasse zu Hermsdorf, Wurgwitz und Karsdorf (Amt Dresden) erwähnt; HStA Dresden, 10024 Geheimer Rat (Gebeimes Archiv), Loc. 7997/4, Bl. 4r. Ebd., Bl. 4v im Amt Meißen Nickel Monch mit seinen bruder zur Caynn.

[38] Heincz vom Ende

Vermutlich der in einem Schriftsassenverzeichnis von 1454 als Ritter genannte Heinz vom Ende, Bruder von Nr. 30, erwähnt auch 1482 als Schriftsasse; Verz. 1, Bl. $11 v$; Verz. 5, Bl. 158v; 1460 in Kutzschitz (Gautzsch, bente Stadt Markkleeberg) nachgewiesen; Verz. 3, Bl. 13v. 1459 begleitete ein Heinz v. E. Herzog Albrecht zu dessen Egerer Hochzeit; Verz. 6. Ein Heinz v. E. wirkt 1485 als sächsischer Gesandter auf dem Reichstag zu Frankfurt; STREICH, Hof (wie Anm. 11), S. 614. 1498 und 1500 ist dieser (?) als Hofmeister belegt; KUNZE, Amt Leisnig (wie Nr. 19), S. 280, 315, 333. Vgl. auch SCHNEIDER, Dynastengeschlechter (wie Anm. 9), S. 23 mit Anm. 95. Im Testament des Kurfürsten Ernst von 1486 wird Heinrich von Ende als Obermarschall genannt; BABENDERERDE, Sterben (wie Anm. 55), S. 52, Anm. 132. Schriftsassenverzeichnisse von 1473 und 1474 nennen Heincz vom Ende zcu Koyne (Kayna) unter den Rittern; Verz. 5, Bl. 8v, 21r, 79v, 91v. Ulrich und Heinz v. E. zu Fuchshain, Söhne des verstorbenen Konrad v. E., werden in einer Gesamtbelehnung von ca. 1450 erwähnt; HStA Dresden, 10004 Kopiale, Nr. 43, Bl. 222r-v; 1473/74 unter die Mannen gerechnet; Verz. 5, Bl. 1r, 4v, 10v., Heinz v. E. zu Fuchshain und Ulrich v. E. zu Blankenhain 1482 als Schriftsassen geführt. 1474 wird ein Heinz v. E. als Rat bezeichnet; Verz. 5, Bl. 5v. 1458 wird ein Heinz v. E. auch als Amtsasse im Amt Leipzig erwähnt; 10005 Hof- und Zentralverwaltung der Wettiner (Wittenberger Archiv), Loc. 4338/2, Bl. 31 .

[39] Jhan von Schonfelt in Lobenitz

Der 1454 und 1460 zu Löbnitz (nö. Delitzsch) genannte Schriftsasse Jan von Schönfeld; Verz. 1, Bl. 10v; Verz. 2, Bl. 4v. Bereits 1447 wird ein Jahen von Schönfelt, den schribet myn herre, in Amt Delitzsch erwähnt; HStA Dresden, 10024 Geheimer Rat (Geheimes Archiv), Loc. 7997/2, Bl. 44r; vgl. ebd., Bl. $35 r$ : Sifryd von Schonefeld mit sinen brudern habin Lobenicz. Am 14. November 1453 gestattete Kurfürst Friedrich II. Siegfried v. S. und seinem Bruder Jan sowie Jörg, ibrem Vetter, einen Zins- 
verkauf in Poßdorf nö. Delitzsch. Die Schonfelt zu Lobenicz auch 1473 bis 1482 als Schriftsassen belegt; Verz. 5, Bl. 5r, 10v, 38v, 80v, 84r, 89r, 158v. 1459 begleitete ein Jan v. S. Herzog Albrecht zu dessen Egerer Hochzeit; Verz. 6.

\section{[40] Herman von Wissenbach}

Hermann von Weißenbach, 1460 als Schriftsasse belegt, 1470 zusammen (mit seinem älteren Bruder?) Han[s] zu Schönfels (Kreis Zwickau), 1471, 1473, 1481 und 1484 auch als kurfürstlicher Rat; Verz. 2, Bl. 5r; Verz. 4, Bl. 118r; Verz. 5, Bl. 5r, 5v, 9v, 67r, 80v, 88r; Schirmer, Untersuchungen (wie Anm. 139), S. 315 mit Anm. 34. Am 8. Juli 1454 mit Weißbach (beute Stadt Schmölln) und anderen Besitzungen belehnt; HStA Dresden, 10004 Kopiale, Nr. 45, Bl. 244r. 1471 bis 1477 als Vogt zu Voigtsberg erwähnt; BEIERLEIN, Geschichte (wie Nr. 14), S. 133 ff., Nr. 251; HESSE, Amtsträger (wie Anm. 136), S. 640, Nr. 2633; STREICH, Hof (wie Anm. 11), S. 424, 447.

\section{[41] Ditherich von Friberg}

Dietrich von Freiberg, am 26. November 1450 als Verkäufer eines Zinses zu Zschernitz in der Pflege Delitzsch (w. Delitzsch) belegt; HStA Dresden, 10004 Kopiale, Nr. 43, Bl. 294v. 1459 begleitete er Herzog Albrecht zu dessen Egerer Hochzeit; Verz. 6. 1473 ist er als Vasall Kurfürst Ernsts und Herzog Albrechts belegt; HAUSEN, Vasallen-Geschlechter (wie Nr. 11), S. 88. 